LUCIENE ANGELINI

\title{
Avaliação da eficácia do automanejo no controle da asma
}

Dissertação apresentada à Faculdade de Medicina da Universidade de São Paulo para obtenção do título de Mestre em Ciências

Área de concentração: Fisiopatologia Experimental Orientador: Dr. Rafael Stelmach

SÃO PAULO 
Dados Internacionais de Catalogação na Publicação (CIP)

Preparada pela Biblioteca da

Faculdade de Medicina da Universidade de São Paulo

Creprodução autorizada pelo autor

\section{Angelini, Luciene}

Avaliação da eficácia do automanejo no controle da asma / Luciene Angelini.

-- São Paulo, 2010.

Dissertação(mestrado)--Faculdade de Medicina da Universidade de São Paulo para obtenção do título de Mestre em Ciências.

Área de concentração: Fisiopatologia Experimental.

Orientador: Rafael Stelmach.

Descritores: 1.Asma 2.Adulto 3.Educação de pacientes como assunto 4.Automanejo 5.Controle clínico 6.Qualidade de vida 7.Ansiedade 8.Depressão

USP/FM/SBD-107/10 


\section{Dedicatória}

Aos meus pais, Luiz e Vera, educadores admiráveis e grandes incentivadores de minha formação moral e acadêmica.

As minhas queridas irmãs, Regiane e Cristiane, pelo apoio e carinho.

Ao meu companheiro de todas as horas, Wellington França, por sua paciência e compreensão. 


\section{AGRADECIMENTOS}

A Deus, que sempre me acompanha e ilumina.

Ao Dr. Rafael Stelmach, pela orientação na confecção desta dissertação, pelo incentivo, dedicação, paciência e apoio ao longo de todas as etapas deste projeto. Agradeço a oportunidade de crescimento profissional através de seus ensinamentos: caminhar sempre juntos, mas confiando em nosso próprio passo, mesmo que pequeno.

Ao Prof. Dr. Alberto Cukier, grande mestre e incentivador da produção científica em nosso meio, pelo apoio não somente na confecção desta tese, como em diversas etapas de minha vida acadêmica.

À Dra. Regina M. Carvalho-Pinto, pela amizade e pelo grande apoio ao longo da coleta de dados e elaboração desta dissertação.

As amigas do ambulatório do HC-FMUSP, Daiane O. Santos e Priscila B. S. Amorim, pelo auxílio na coleta de dados, pelas sugestões e principalmente pela amizade ao longo da elaboração deste projeto.

Ao grupo da obstrução (NAPA), pela contribuição metodológica e científica.

Aos amigos iniciantes, mesmo que distantes, pelo incentivo e sugestões ao meu aperfeiçoamento profissional.

A toda equipe da pneumologia do InCor-HCFMUSP - pesquisa clínica, função pulmonar, ambulatório, administração e secretaria - pela assistência e colaboração nos momentos necessários. 
Aos pacientes, sem os quais seria impossível a realização desta dissertação.

A Coordenação de Aperfeiçoamento Pessoal de Nível Superior - CAPES pela concessão de bolsa de mestrado.

A todas as pessoas, que eu possa ter esquecido, que direta e indiretamente auxiliaram a desenvolver este projeto, meus agradecimentos. 
"A satisfação está no esforço e não apenas na realização final."

Mahatma Gandhi 
Esta tese está de acordo com as seguintes normas, em vigor no momento desta publicação:

Referências: adaptado de International Committee of Medical Journals Editors (Vancouver)

Universidade de São Paulo. Faculdade de Medicina. Serviço de Biblioteca e Documentação. Diretrizes para apresentação de dissertações e teses da USP: documento eletrônico e impresso. Elaborado por Vânia M.B. de Oliveira Funaro, Maria Cláudia Pestana, Eliana Maria Garcia, Maria Alice F. R. Rebello, Maria Aparecida B. Avello, Maria José de J, Carvalho, Maria Marta Nascimento, Rosana A. Paschoalino, Suely Campos Cardoso, Valéria Vilhena Lombardi. 2ed. São Paulo: Serviço de Biblioteca e Documentação; 2009.

Abreviaturas dos títulos dos Períodicos de acordo com List of Journal Indexed in Index Medicus. 


\section{Lista de abreviaturas, siglas e símbolos}

Lista de gráficos e ilustrações

Lista de tabelas

Resumo

Summary

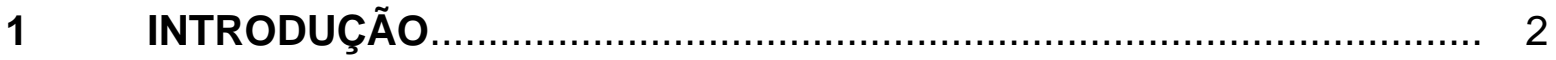

2 OBJETIVOS

3 REVISÃO DA LITERATURA ............................................................ 7

3.1 Definição de asma, prevalência e aspectos demográficos..................... 7

3.2 Gravidade, controle e tratamento................................................... 7

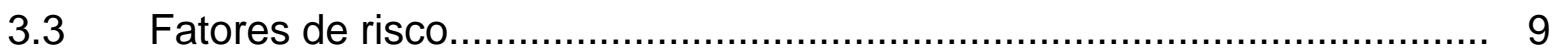

3.4 Aderência e papel da equipe multidisciplinar....................................... 10

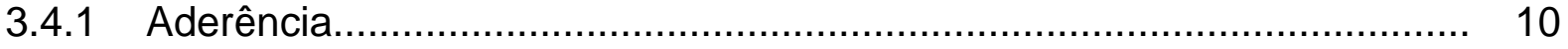

3.4.2 Equipe multidisciplinar................................................................... 11

3.5 Programas de Educação..................................................................... 11

3.5.1 Etapas da Educação..................................................................... 12

3.6 Programas de Automanejo........................................................... 12

$4 \quad$ CASUÍSTICA E MÉTODOS ...................................................... 15

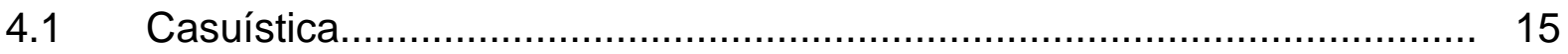

4.2 Critérios de inclusão......................................................................... 15

4.3 Critérios de exclusão.................................................................. 15

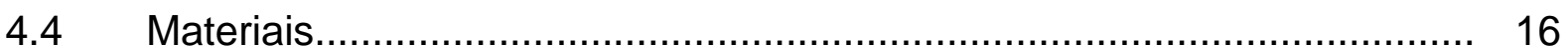

4.4.1 Ficha Clínica................................................................................. 16

4.4.2 Teste de Controle da Asma.......................................................... 16

4.4.3 Avaliação da Qualidade de Vida......................................................... 17 
4.4.4 Escala Hospitalar de Ansiedade e Depressão................................... 17

4.4.5 Teste de Alfabetização Funcional para Adultos na Área da Saúde.......... 18

4.4.6 Questionário de Avaliação de Conhecimento................................... 19

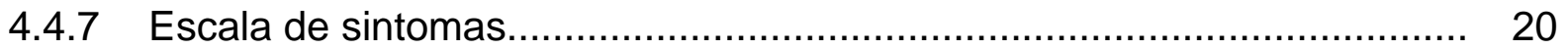

4.4.8 Plano de ação por escrito..................................................... 20

4.4.9 Programa de Educação........................................................................ 21

$4.5 \quad$ Delineamento do estudo......................................................... 21

4.6 Análise Estatística.................................................................... 22

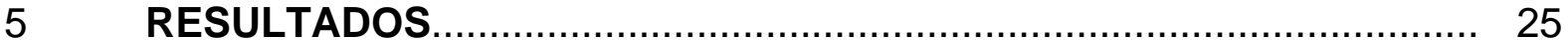

$5.1 \quad$ Dados demográficos e clínicos dos pacientes.................................. 26

5.1.1 Características demográficas basais dos pacientes............................. 26

5.1.2 Características clínicas basais dos pacientes.................................... 27

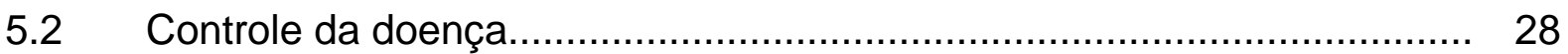

$5.3 \quad$ Conhecimento da doença e técnica inalatória................................... 31

5.3.1 Grupo Automanejo................................................................ 31

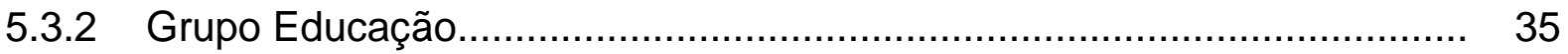

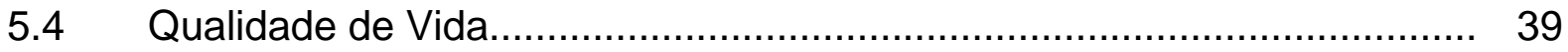

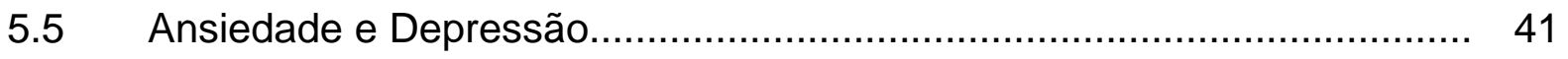

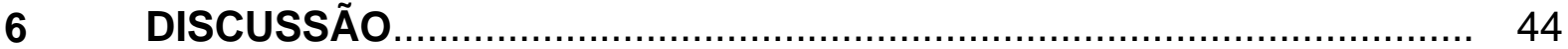

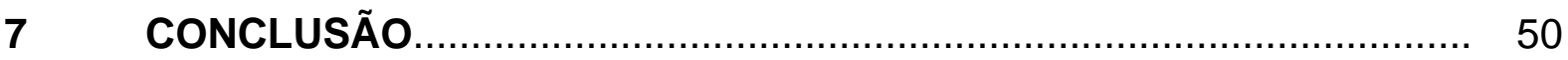

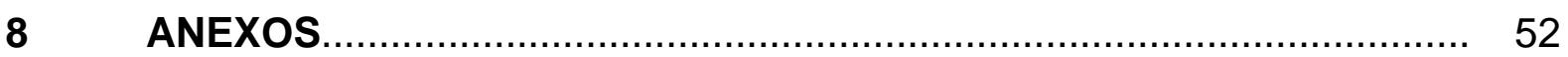

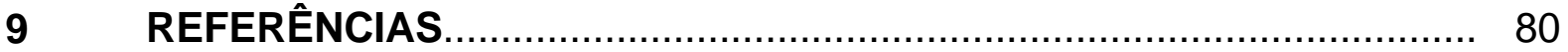
PUBLICAÇÃO 


\section{Lista de abreviaturas, siglas e símbolos}

HCFMUSP Hospital das Clínicas da Faculdade de Medicina da Universidade de São Paulo

$\beta 2$-agonistas broncodilatador

PFE pico de fluxo expiratório

ACT teste de controle da asma

AQLQ questionário de qualidade de vida em asma

HADS escala hospitalar de ansiedade e depressão

TOFLHA teste de alfabetização funcional para adultos na área da saúde

FPT fisiopatologia

QAC questionário de avaliação do conhecimento

CA controle ambiental

TTO tratamento

MDI inalador dosimetrado

PE programa de educação

V1 primeira visita (inicial)

V2 segunda visita

V3 terceira visita (final)

GA grupo automanejo

GE grupo educação

GC grupo controle

TCLE termo de consentimento livre e esclarecido

IMC índice de massa corpórea

CO monóxido de carbono

ppm partes por milhão

$\mathrm{VEF}_{1} \% \quad$ volume expiratório forçado no primeiro segundo

$\mathrm{VEF}_{1} / \mathrm{CVF} \quad$ relação entre volume expiratório forçado no primeiro segundo e capacidade vital forçada

DRGE doença do refluxo gastroesofágico

CAPPesq Comissão de Ética para Análise de Projetos de Pesquisa

et al. e outros 
Figura 1 Fluxograma do estudo................................................ 21

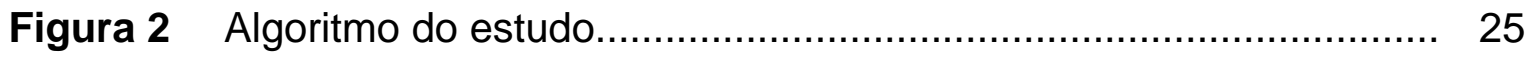

Figura 3 Questionário de Controle da Asma (ACT) entre os grupos ao longo do estudo.

Figura 4 Percentual de pacientes com asma controlada e não controlada no grupo automanejo ao longo do estudo.

Figura 5 Percentual de pacientes com asma controlada e não controlada no grupo educação ao longo do estudo.

Figura 6 Percentual de pacientes com asma controlada e não controlada no grupo controle ao longo do estudo.

Figura 7 Grau de conhecimento dos pacientes do grupo automanejo ao longo do estudo.

Figura 8 Técnica inalatória sem uso do espaçador no grupo automanejo ao longo do estudo.

Figura 9 Técnica inalatória com uso do espaçador no grupo automanejo ao longo do estudo.

Figura 10 Técnica inalatória do dispositivo em pó grupo automanejo ao longo do estudo.

Figura 11 Grau de conhecimento dos pacientes do grupo educação ao longo do estudo.

Figura 12 Técnica inalatória sem uso do espaçador no grupo educação ao longo do estudo.

Figura 13 Técnica inalatória com uso do espaçador no grupo educação ao longo do estudo.

Figura 14 Técnica inalatória do dispositivo em pó grupo educação ao longo do estudo.

Figura 15 Qualidade de vida relacionada à saúde (AQLQ) em todos os domínios no grupo automanejo ao longo do estudo. 
Figura 16 Qualidade de vida relacionada à saúde (AQLQ) em todos os domínios no grupo educação ao longo do estudo.

Figura 17 Traço de ansiedade na Escala hospitalar de ansiedade e depressão - HADS no grupo automanejo............................ 41

Figura 18 Traço de ansiedade na Escala hospitalar de ansiedade e

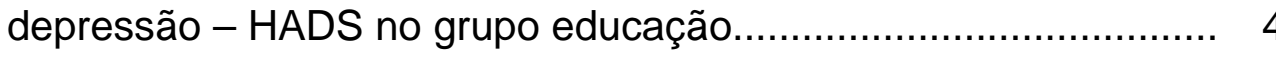




\section{LISTA DE TABELAS}

Tabela 1 Dados demográficos basais dos pacientes................................. 26

Tabela 2 Dados clínicos basais dos pacientes........................................... 28 


\section{RESUMO}

Angelini L. Avaliação da eficácia do automanejo no controle da asma [dissertação]. São Paulo: Universidade de São Paulo, Faculdade de Medicina, 2010. 87p.

Introdução: A educação em saúde é considerada essencial no controle da asma. A implantação de um programa de educação (PE) com automanejo tem impacto positivo na melhora da qualidade de assistência em asma. Entretanto, os benefícios de um PE ainda são controversos em função das barreiras estruturais. Objetivo: Avaliar o controle clínico de pacientes submetidos a um programa de automanejo associado automonitorização e auto-tratamento comparando-os com dois grupos em atendimento ambulatorial de rotina, com e sem aplicação de um PE. Ainda, mensurar o conhecimento da doença e técnica inalatória, os índices de qualidade de vida, sintomas de ansiedade e depressão e a alfabetização funcional em saúde. Métodos: Trata-se de um estudo aleatorizado, controlado, de grupos paralelos, alocados em três grupos: grupo controle (GC), educação (GE) e automanejo (GA) durante um período de doze meses. Foram incluídos 110 pacientes com asma persistente moderada e grave. O PE foi oferecido para pequenos grupos nos dias de consulta, e consistiu de aulas expositivas divididas em módulos: (1) fisiopatologia e controle ambiental; (2) sinais/sintomas da asma; (3) tratamento e treinamento da técnica inalatória. O GA ainda recebeu um diário de sintomas e um plano de ação individualizado por escrito. Para avaliar o controle da doença foi utilizado a média de pontos do teste de controle da asma (ACT) e o percentual de pacientes com escore $\geq 20$. Outros questionários incluídos foram: conhecimento sobre a doença (QCA), qualidade de vida relacionada à asma (AQLQ-s), escala hospitalar de ansiedade e depressão (HADS) e o teste de alfabetização funcional (s-TOFHLA). Resultados: $\mathrm{Em}$ dois anos, 84 pacientes completaram o estudo. Os grupos eram homogêneos em relação às características basais. A média do ACT aumentou de 14 para 18 pontos, sendo que $48 \%$ dos pacientes do GA atingiram o controle da asma. Os GA e GE aumentaram o conhecimento da doença e técnica inalatória para $100 \%$. E os sintomas de ansiedade diminuíram em $14 \%$ e $12 \%$, respectivamente. O escore do AQLQ-s foi clinicamente relevante com aumento significativo maior que 0,5 pontos nos dois grupos. O s-TOFLHA foi classificado como alfabetização em saúde adequada com escore médio de 76 pontos. Conclusões: PE associado automanejo durante a rotina de atendimento ambulatorial mostrou impacto relevante sobre a melhora clínica de pacientes portadores de asma moderada e grave. O PE aumentou o conhecimento sobre a doença e tratamento medicamentoso, com melhora da qualidade de vida relacionada à saúde e os sintomas de ansiedade. Nesta população os pacientes apresentaram adequada alfabetização funcional em saúde.

Descritores: Asma, Adulto, Educação de pacientes como assunto, automanejo, controle clínico, qualidade de vida, ansiedade, depressão. 
Angelini L. Evaluation of self-management efficacy of asthma control. [dissertation]. São Paulo: University of São Paulo, Medical School, 2010. 87p.

Background: Health education is considered essential in asthma control. The implementation of an education program (EP) with self-management has a positive impact on improving the quality of care in asthma. However, the benefits of an EP are still controversial according of structural barriers. Objective: Evaluate the clinical control of patients submitted a self-management program associated with selfmonitoring and self-treatment comparing with two groups during the routine outpatient visits with and without the EP application. Also, measure the disease knowledge and inhalation technique, the indices of quality of life, symptoms of anxiety and depression and functional health literacy. Methods: This was a randomized study, controlled, divided into three groups: control group (CG), education (EG) and self-management (AG) during twelve months. The study included 110 patients with moderate and severe persistent asthma. The EP was applied to small groups on outpatient visit days, consisted of lectures divided into three parts: (1) pathophysiology and environmental control; (2) asthma symptoms; (3) treatment and training in the inhalation technique. The $A G$ also received a symptoms diary card and written personal asthma action plan. Disease control was measured by the score of asthma control test (ACT) and the percentage of patients with scores $\geq 20$. Other questionnaires included: disease knowledge (UDQ), asthma quality of life (AQLQ-s), hospital anxiety and depression scale (HADS) and functional literacy health test (sTOFHLA). Results: In two years, 84 patients completed the study. Groups were similar in baseline characteristics. The mean ACT increased from 14 to 18 points, with $48 \%$ of patients in the AG achieved better control of asthma. The AG and EG increased disease knowledge and inhalation technique up to $100 \%$. And the anxiety symptoms decreased $14 \%$ and $12 \%$, respectively. The AQLQ-s score was clinically relevant with a significant increase of more than 0.5 points in both groups. The sTOFLHA was classified as adequate health literacy with a mean score of 76 points. Conclusions: EP associated with self-management during routine outpatient visit showed significant impact on the clinical improvement in patients with moderate to severe asthma. The EP increased knowledge about the disease and drug treatment, with improvement in quality of life and symptoms of anxiety. In this population patients had adequate functional health literacy.

Descriptors: Asthma; Adult; Patient education as topic, self-management, clinical control, quality of life, anxiety, depression. 
INTRODUÇÃO 


\section{INTRODUÇÃO}

A educação em saúde é considerada essencial no controle da asma ${ }^{1}$, por promover conhecimento, aumentar a habilidade na identificação de agravantes e desencadeantes da doença, e ainda melhorar a aderência ao tratamento ${ }^{2,3}$.

Embora as diretrizes para a terapêutica da asma incluam a implantação de programas de educação e automanejo para melhora da qualidade de assistência em asma $^{4-5}$, o impacto no controle clínico de longo prazo em pacientes adultos não está claramente determinado ${ }^{6}$. Essa conclusão é possível pois as metas para o controle nem sempre são atingidas e, a ausência de padronização dos requisitos mínimos nos programas educativos/automanejo, ocasiona desacordo entre autores na validação do melhor modelo a ser seguido ${ }^{3}$. Alguns fatores são apontados como responsáveis por resultados díspares em diferentes estudos ${ }^{7-8}$, como a estruturação dos programas, as medidas de aderência, desfechos encontrados e também características dos pacientes.

Os programas estruturados, que incluem educação, automonitorização, avaliações médicas regulares e planos de ação por escrito ${ }^{9-10}$, são realizados por longos períodos para pequenos grupos, administrados por educadores treinados, utilizando formas verbais, escritas, visuais e/ou auditivas para transmitir conhecimento $^{11}$. Esses programas denominados estruturados resultam em desfechos melhores, maior repercussão clínica e parecem proporcionar maior benefício quando direcionados a pacientes com asma moderada ou grave, especialmente para aqueles com alto índice de co-morbidades ${ }^{3-12}$.

$A$ efetividade dos programas de asma depende ainda, de aspectos sociais e ambientais. O maior número de barreiras estruturais como falta de tempo, de recursos financeiros, o fato de morar longe e a necessidade de retornos freqüentes ao serviço de saúde diminui a participação dos pacientes em programas de educação $^{13}$. 
Devido às controvérsias sobre os benefícios de um programa de automanejo adequado a realidade de cada serviço, este estudo baseia-se na hipótese de que implantar um trabalho de educação, realizado durante atendimento médico ambulatorial de rotina, associado à automonitorização, plano de ação por escrito e auto-ajuste da medicação, permite maior controle da doença em portadores de asma persistente moderada e grave. 


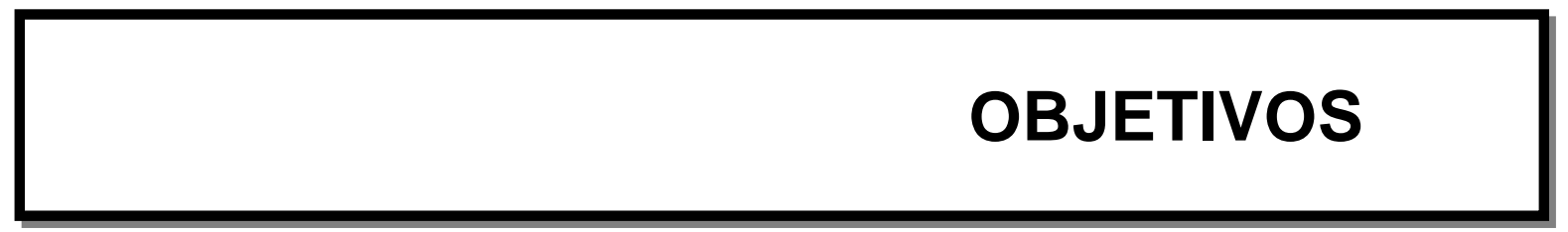




\section{OBJETIVOS}

\subsection{Primário}

Avaliar o controle clínico de pacientes com asma persistente moderada e grave, submetidos a um programa de automanejo associado automonitorização e auto-tratamento (grupo estudo) comparando-o com dois grupos em atendimento ambulatorial de rotina (grupo educação e controle), com e sem aplicação de um programa educacional.

\subsection{Secundário}

Avaliar o conhecimento da doença e medicações de tratamento, os fatores desencadeantes e irritantes, os sinais e sintomas da asma, a técnica inalatória, os índices de qualidade de vida, sintomas de ansiedade e depressão e alfabetização funcional em saúde no grupo automanejo e educação. 


\section{REVISÃO DA LITERATURA}

\subsection{Definição de Asma, Prevalência e Aspectos Demográficos}

A asma é uma doença inflamatória crônica das vias aéreas definida por características clínicas, fisiológicas e patológicas ${ }^{4}$. A inflamação está associada à hiperresponsividade brônquica caracterizada por episódios recorrentes de sibilos, dispnéia, aperto no peito e tosse ${ }^{14}$ particularmente à noite ou no início da manhã. Estes episódios são normalmente associados à obstrução reversível das vias aéreas ${ }^{4}$.

Nos últimos anos têm-se observado mudanças na prevalência da asma ${ }^{15}$, principalmente em crianças $^{16}$. Ocorrem anualmente 350.000 internações por asma no Brasil $^{5}$, doença que afeta aproximadamente $20 \%$ da população brasileira ${ }^{16}$ e cerca de 5 a $10 \%$ da população mundial ${ }^{4-17}$. Os fatores sociais e econômicos são determinantes para a compreensão da asma, seus cuidados e conseqüências como falta no trabalho e/ou na escola, visita ao serviço de emergência, morbidade e mortalidade $^{18}$. O resultado é uma significativa sobrecarga em termos de custos diretos e indiretos, tanto para os pacientes como para o sistema de saúde ${ }^{19}$. Propor tratamento para melhorar o controle da doença, representa um desafio para os pacientes, profissionais, organizações de saúde e para o governo ${ }^{4}$.

\subsection{Gravidade, controle e tratamento}

A classificação da asma usada na avaliação inicial do paciente envolve a gravidade da doença, a resposta dos sintomas ao tratamento, as limitações físicas e a variabilidade da função pulmonar. A gravidade é subdividida em quatro categorias: intermitente, persistente leve, persistente moderada e persistente grave ${ }^{4}$. Esta 
classificação não é estática, por isso não é recomendada para decisões do tratamento continuado, uma vez que a asma tem variações de gravidade ao longo do tempo.

Alcançar e manter o controle da asma ${ }^{20}$ refere-se às manifestações clínicas, ou seja, mínimos sintomas, mínimas ou infreqüentes exacerbações, nenhuma visita no serviço de emergência, uso mínimo de broncodilatador ( $\beta 2$-agonistas), nenhuma limitação às atividades diárias, pico de fluxo expiratório (PFE) normal ou próximo do normal com variação menor que $20 \%$, e poucos eventos adversos das medicações ${ }^{4}$.

Devido a variações da gravidade e controle da asma, os consensos ${ }^{4}$ propõem degraus (níveis) para o tratamento farmacológico com mínima terapia necessária para manter o controle da doença. Quando a asma está controlada, os pacientes podem prevenir as exacerbações, evitar sintomas diurnos e noturnos, e permanecer fisicamente ativos ${ }^{21}$.

A opção do tratamento está baseada na gravidade da doença, no controle do tratamento atual do paciente, propriedades farmacológicas e disponibilidade de medicamentos. A tática do degrau terapêutico recomenda aumentar o número e a freqüência da medicação ("subir") com a piora da asma, e diminuir ("descer") quando a asma está sob controle. Após alcançando e mantido o controle por no mínimo três meses, é recomendada a redução gradativa da terapia de manutenção ${ }^{4}$. 0 tratamento medicamentoso pode ser administrado de diferentes modos: inalatório, oral ou parenteral ${ }^{17}$.

Os medicamentos de manutenção para asma de maior eficácia atualmente são os corticóides inalatórios, que devem ser utilizados diariamente em longo prazo, para manter a asma sob controle clínico por meio dos seus efeitos antiinflamatórios ${ }^{4-}$ 22. A principal vantagem da terapia inalatória é que as drogas são depositadas diretamente nas vias aéreas, produzindo maior concentração local, com menor risco de efeitos colaterais sistêmicos ${ }^{23-24-25}$. Já os medicamentos de resgate, como os broncodilatores ( $\beta 2$-agonistas), agem rapidamente revertendo a broncoconstrição e aliviando sintomas, porém o aumento de sua utilização ou o uso diário é um alerta para a perda do controle da asma e indica a necessidade de reavaliação do tratamento ${ }^{4}$. 


\subsection{Fatores de risco}

Embora a intervenção farmacológica no tratamento da asma seja eficaz no controle de sintomas e na melhora da qualidade de vida dos pacientes, medidas para reduzir ou evitar a exposição aos fatores de risco devem ser tomadas sempre ${ }^{26}$. Existe uma série de fatores de risco que podem influenciar no desencadeamento da asma que não estão claramente identificados ${ }^{1}$, porém estão presentes no cotidiano das pessoas. Alguns deles são:

- Alérgenos domésticos: ácaros, pêlos de animais, baratas e fungos.

As diretrizes recomendam a redução à exposição à alérgenos domiciliares e propõem como medidas alternativas a remoção de animais de dentro da residência, banhos diários nos animais, acaricidas e filtros de $\mathrm{ar}^{27-28}$.

- Alérgenos externos: pólens, mofo e poluentes de ar (tabagismo, óxido nítrico, óxidos de azoto, monóxido de carbono, dióxido de carbono, enxofre, formaldeído e endotoxinas) $)^{29}$.

Os alérgenos externos não são possíveis de serem completamente evitados. Contudo, a exposição pode ser reduzida pelo fechamento de janelas e portas, mantendo-se os espaços internos com ar condicionado (se possível). O tabagismo produz efeitos prejudiciais mensuráveis, incluindo maior risco de desenvolver sintomas de asma, pois está associado ao declínio da função pulmonar, aumento da gravidade da doença, menor resposta ao tratamento com corticóides inalados ${ }^{30-31} \mathrm{e}$ sistêmicos $^{32}$, resultando em exacerbações freqüentes e hospitalizações, com aumento do risco de morte. A medida mais importante para o controle desse poluente do ar é evitar a exposição ativa e passiva. Entretanto, programas de 
cessação ao tabagismo deveriam ser oferecidos para todos os pacientes com asma $^{4}$.

- Medicação: aspirina e alguns fármacos antiinflamatórios.

Alguns medicamentos podem agravar a asma ${ }^{4}$. Aspirina e outros fármacos antiinflamatórios devem ser evitados em pacientes com histórico de reação alérgica a esse tipo de medicamento ${ }^{33}$. A vigilância médica é essencial principalmente para medicamentos administrados por via oral ou intraocular, como os beta-bloqueadores, já que podem exacerbar broncoespasmo quando utilizados por pacientes com asma $^{34}$.

\subsection{Aderência e papel da equipe multidisciplinar}

\subsubsection{Aderência}

A aderência dos pacientes asmáticos ao tratamento medicamentoso ${ }^{35}$ é considerada baixa, oscilando entre $38 \%$ e $50 \%{ }^{36}$. A não adesão, em geral, decorre da complexidade do regime do tratamento ${ }^{6-37-38}$, da ação das medicações ${ }^{39}$, da técnica inalatória ${ }^{36}$, da falta de compreensão da doença ${ }^{34}$, da não aceitação da doença crônica ${ }^{36}$, do esquecimento ${ }^{36}$, da dificuldade de percepção da gravidade da doença $^{18}$, disfunção $\operatorname{cognitiva}^{18}$, barreiras socioeconômicas ${ }^{40}$, e também devido à crenças $^{37}$ e atitudes dos pacientes ${ }^{41}$. 


\subsubsection{Equipe multidisciplinar}

A educação continuada e repetida de profissionais de saúde e pacientes é essencial para discutir e decidir metas do tratamento, e desenvolver um plano de ação por escrito, individualizado, encorajando os pacientes a serem responsáveis por seu tratamento ${ }^{42}$. A educação em saúde envolve uma equipe multidisciplinar com vários tipos de profissionais que podem ser educadores em asma, incluindo fisioterapeutas, enfermeiras, médicos e farmacêuticos ${ }^{42}$. O objetivo desta relação é permitir que os pacientes obtenham conhecimento, confiança e competência necessários para assumir seu papel no manejo da doença.

\subsection{Programas de Educação}

A educação em saúde é considerada um componente essencial no manejo da asma $^{1}$, com impacto positivo no controle da doença ${ }^{2}$. A efetividade das estratégias educativas tem sido incorporada no manejo da asma para melhorar o automanejo e a adesão ao tratamento ${ }^{35}$, especialmente em longo prazo ${ }^{18-43-44}$. A educação em asma pode ser escrita, verbal, visual ou auditiva, interativa ou não interativa e estruturada ou não estruturada ${ }^{4}$ e classificada em duas modalidades: a "educação mínima" (informativa) tem por meta primária aumentar conhecimento e entendimento da asma ${ }^{4}$, conduzida por material escrito ou programa não estruturado com interação verbal entre profissional de saúde e paciente; e a "educação máxima" é considerada estruturada, com uso do modelo interativo e não interativo para transferir informação; tem por objetivo aumentar conhecimento e entendimento da doença e da técnica inalatória, melhorar as condições clínicas, diminuir hospitalização, menor utilização de broncodilatador e melhorar a função pulmonar ${ }^{35}$. 


\subsubsection{Etapas da Educação}

$\mathrm{Na}$ consulta inicial, o paciente tem necessidade de informações simples sobre o diagnóstico e os tipos de tratamento disponíveis ${ }^{4}$. Diferentes dispositivos inalatórios podem ser demonstrados para avaliar as habilidades e custos, e para incentivar a participação do paciente na decisão do tratamento ${ }^{4}$. 0 uso de material audiovisual é uma alternativa para manter a uniformidade da informação ${ }^{45}$. Na primeira consulta, a informação verbal deve ser complementada por materiais escritos (folhetos) contendo informações sobre a asma e seu tratamento. Os pacientes e familiares devem ser incentivados anotar quaisquer dúvidas que possam surgir para serem respondidas na próxima consulta ${ }^{4}$.

Nas visitas médicas regulares, em datas previamente determinadas pela unidade de saúde, é feito o acompanhamento da evolução da doença e tratamento medicamentoso. É analisado o controle, a aderência, o acompanhamento do plano de ação determinado, a medicação utilizada, a técnica inalatória ${ }^{46}$ e, se necessário, as recomendações para reduzir a exposição a fatores de risco. Mensagens educativas devem ser revistas e repetidas ou adicionadas, sempre que necessário ${ }^{47}$.

\subsection{Programas de Automanejo}

A educação direcionada para o automanejo da asma enfatiza a participação do paciente na automonitorização da gravidade da doença (através de medidas e registro regulares do $\mathrm{PFE}$ e/ou sintomas diários ${ }^{48}$ ) e no ajuste da terapia medicamentosa, acompanhados por visitas médicas regulares ${ }^{42-49}$. O automanejo diminui visitas ao serviço de emergência ${ }^{18-50}$; admissões hospitalares ${ }^{50}$, sintomas $^{51}$, uso de medicação de resgate ${ }^{6-48}$, cursos de corticóide oral ${ }^{6-48}$, visita médica não agendada, falta no trabalho e/ou escola ${ }^{18-51}$ além de melhorar a função pulmonar ${ }^{6-48}$; 
o pico de fluxo ${ }^{48}$; a técnica inalatória ${ }^{51}$, a aderência da medicação ${ }^{42}$ e a qualidade de vida relacionada à saúde ${ }^{42-51}$.

Atualmente, o plano de ação, por escrito, individualizado com automonitorização e programa de educação é recomendado e incentivado no manejo internacional das doenças crônicas ${ }^{52}$. Os resultados são positivos quando associados à revisão médica periódica ${ }^{4}$. É uma estratégia simples e importante na educação da asma, e caracterizado por ajudar os pacientes a entenderem o tratamento e a gravidade da doença, especialmente para pacientes com asma persistente moderada e grave ${ }^{42-48}$. 


\section{CASUÍSTICA E MÉTODO}

\subsection{Casuística}

Trata-se de um estudo randomizado por sorteio, controlado, de grupos paralelos, realizado no ambulatório de asma do Hospital das Clínicas da Faculdade de Medicina da Universidade de São Paulo (HC-FMUSP), previamente aprovado pela Comissão de Ética sob no 1021/05 [Anexo A].

\subsection{Critérios de inclusão}

Foram incluídos pacientes de ambos os sexos, com idades entre 18 e 65 anos, portadores de asma persistente moderada e grave ${ }^{4}$, em acompanhamento ambulatorial por, no mínimo, dois anos e tratamento medicamentoso regular (corticóide inalatório e broncodilatador de ação prolongada) por, no mínimo, três meses.

\subsection{Critérios de exclusão}

Os critérios de exclusão foram: Infecção do trato respiratório nas últimas semanas, outra doença pulmonar associada, participação em outros programas de educação e outras comorbidades que impedissem a participação no programa. 


\subsection{Materiais}

Para coleta de dados utilizamos uma ficha clínica ambulatorial, um questionário para avaliar o controle da asma, uma escala hospitalar de ansiedade e depressão, um questionário específico de qualidade de vida em asma, o teste de alfabetização funcional em adultos, um questionário de conhecimento da asma, um diário de sintomas, a medida do pico de fluxo expiratório e um plano de ação individualizado por escrito.

\subsubsection{Ficha Clínica}

A ficha clinica foi elaborada pelos especialistas do ambulatório, para obter dados demográficos, doenças associadas, comorbidades, gravidade da doença (GINA ${ }^{4}$ ), função pulmonar (espirômetro de fluxo KOKO® Pulmonary Data Service Instrumentation, Inc., Louisville, CO, EUA) e monóxido de carbono (Micro CO Meter, Micro Medical Ltd., Rochester, RU) [Anexo B].

\subsubsection{Teste de Controle da Asma (Asthma Control test - ACT)}

O controle da asma foi avaliado pelo ACT traduzido para língua portuguesa ${ }^{20}$ [Anexo C], que é constituído por 5 questões relacionadas aos sintomas da doença, uso de medicação de resgate e impacto funcional da asma. Cada questão pode ser pontuada de 1 a 5 e a pontuação total varia de 5 a 25, permitindo classificar a asma em: não controlada, quando $\leq 19$ pontos; parcialmente controlada, entre 20 e 24 
pontos; e controlada quando igual a 25 pontos. Entretanto, o estudo de Schatz et al. ${ }^{53}$ determinaram como pontos de corte do ACT para asma controlada $\geq 20$ pontos (sensibilidade, $78,1 \%$ e a especificidade, $83,8 \%$ ), e não controlada $\leq 15$ pontos (sensibilidade, 90,4\%; especificidade, 80,9\%).

\subsubsection{Avaliação da Qualidade de Vida (Asthma Quality Life Questionnaire Short - AQLQ-s)}

Para avaliar a qualidade de vida utilizamos o AQLQ(s) ${ }^{54}$ [Anexo D]. É composto por 32 questões referentes às duas últimas semanas, divididas em 4 domínios: limitação das atividades, sintomas, função emocional e estímulo ambiental. Cinco perguntas são sobre atividades identificadas na primeira visita e mantidas para todas as visitas subsequentes de acompanhamento. A pontuação em cada resposta varia entre 1 ponto (valor mínimo: comprometimento grave) a 7 pontos (valor máximo: sem comprometimento); a pontuação obtida das respostas dividida por 32 representa a pontuação média total. A pontuação média dos domínios é analisada da mesma forma. Assim, quanto maior a pontuação melhor a qualidade de vida. Considerado-se clinicamente relevante um aumento de 0,5 pontos.

\subsubsection{Escala Hospitalar de Ansiedade e Depressão (Hospital Anxiety and Depression Scale - HADS)}

Para avaliar a ansiedade e depressão utilizamos a $\operatorname{HADS}^{55}$, traduzida e validada para língua portuguesa [Anexo E], composta por 14 itens, sendo sete voltados para a avaliação da ansiedade (HADS-A) e sete para a depressão (HADS- 
D). Cada um dos seus itens pode ser pontuado de 0 a 3 , compondo um escore máximo de 21 pontos para cada escala. E são adotados os seguintes pontos de corte para as sub-escalas:

- HAD-ansiedade: sem ansiedade de 0 a 8 , com ansiedade $\geq 9$.

- HAD-depressão: sem depressão de 0 a 8 , com depressão $\geq 9$.

\subsubsection{Teste de Alfabetização Funcional para Adultos na Área da Saúde (Test Function Literacy Health Adults Short Version - S-TOFLHA)}

Para avaliar a alfabetização funcional em saúde foi utilizado S-TOFLHA ${ }^{56}$, validado para língua portuguesa [Anexo F], composto por 40 itens, dividido em duas partes: compreensão de leitura e numérica. A escala de compreensão de leitura mede habilidade para ler e entender as instruções para (1) preparação de exame radiológico gastrointestinal, (2) direitos do paciente, (3) responsabilidade médica e (4) termo de consentimento hospitalar. É formada por 36 itens relacionados com o contexto da frase ou gramática, composto por quatro opções de respostas múltiplas; cada resposta correta equivale a dois pontos (36 questões $=72$ pontos). A sessão numérica é formada por quatro perguntas referentes a um (1) cartão de consulta médica (data de retorno), (2) um cartão com resultado de exame (glicemia) e (3) dois frascos de medicações com instruções de uso. Cada resposta correta equivale a 7 pontos ( 4 questões $=28$ pontos). $O$ resultado da soma da escala de compreensão de leitura e numérica varia de 0-100 pontos, classificada e interpretada em pontos de cortes, conforme definido abaixo:

- Alfabetização em saúde inadequada (escores 0-53): indivíduos com dificuldades de interpretar materiais simples, incluindo indicação contida nos frascos de medicações e cartões, e instruções para radiografia gastrointestinal. 
- Alfabetização em saúde limítrofe (escores 54-66): indivíduos com melhor entendimento para perguntas simples, mas com dificuldade de compreensão referente a direitos e responsabilidades médicas.

- Alfabetização em saúde adequada (escores 67-100): indivíduos que completaram com sucesso as tarefas necessárias nos cuidados em saúde, embora muitos tenham dificuldade de compreender as informações mais difíceis.

\subsubsection{Questionário de Avaliação de Conhecimento (QAC)}

O questionário de avaliação de conhecimento foi elaborado em conjunto por uma equipe multidisciplinar formada por médicos pneumologistas, alergistas, clínicos gerais e fisioterapeutas respiratórios, sendo estes os responsáveis por sua aplicação [Anexo G]. Este questionário é constituído de (1) quatro questões qualitativas sobre fisiopatologia - FPT (sim/não); (2) duas questões sobre controle ambiental - CA, contendo um checklist composto por 15 fatores desencadeantes/irritantes e um checklist composto por 11 cuidados com o domicílio e animais; (3) duas questões sobre sinais e sintomas de exacerbação, contendo um checklist composto por quatro sintomas de asma e uma questão quantitativa (sim/não) sobre o controle da crise em casa; (4) e sete questões sobre tratamento medicamentoso - TTO, contendo quatro questões quantitativas (sim/não) e três checklists da técnica inalatória, um para medicação em pó e dois para nebulímetro dosimetrado com e sem espaçador. Os questionários eram auto-aplicavéis, exceto para pacientes não alfabetizados.

A pontuação máxima a ser atingida pela aplicação deste questionário, com exceção da técnica inalatória, equivale 75 pontos (100\% de acerto). As questões qualitativas $(1,2,3,4,8,9,10,11,12)$ equivalem cinco pontos para cada resposta correta; a questão 5 (checklist) é composta por 15 alternativas sendo um ponto para cada resposta correta; a questão 6 (checklist) é composta por 11 alternativas sendo um ponto para cada resposta correta; a questão 7 (checklist) é composta por quatro alternativas sendo um ponto para cada resposta correta. 
A técnica inalatória foi pontuada utilizando checklist, atribuindo-se um ponto para cada passo correto. Para o inalador dosimetrado (MDI) com e sem espaçador a pontuação total equivale nove pontos, e para o inalador em pó seco (DPI) equivale a oito pontos. A soma da pontuação foi divida pelo total da técnica inalatória correta, multiplicada por 100 (número de passos corretos/pontuação total $X$ 100) e apresentada como percentual de passos corretos ${ }^{57-58}$. Para erros na técnica inalatória, como a incapacidade de remover a tampa e/ou usar o dispositivo de ponta cabeça, acionar o dispositivo ou expirar ao invés de inalar corretamente foi atribuído a pontuação zero ${ }^{57}$.

\subsubsection{Escala de sintomas}

A escala de sintomas é um instrumento adaptado pelo grupo, médicos pneumologistas e fisioterapeutas respiratórios, que descreve sob forma de desenhos a medida do PFE e os sintomas de gravidade da asma, como: tosse, sibilos, dispnéia, despertar noturno e uso de medicação de resgate [anexo $\mathrm{H}$ ].

Essa escala possui uma coluna de cor vermelha que deve ser assinalada na presença de sintomas e/ou uso da medicação de resgate, e uma coluna na cor verde que deve ser assinalada na ausência de sintomas.

\subsubsection{Plano de ação por escrito}

O plano de ação por escrito individualizado foi elaborado por uma equipe multidisciplinar formada por médicos pneumologistas e fisioterapeutas respiratórios [Anexo I]. É constituído por medidas do PFE e uma escala de sintomas com pontuação de 0 a 3 (zero igual nenhum sintoma e três muitos sintomas). A manutenção ou modificação da medicação pelo paciente durante o estudo baseouse no valor do escore. Pontuação até 5 indicava manutenção da medicação prescrita; escore de 6 a 10 pontos indicava uso de medicação de resgate; se fosse necessário acima de 4 doses da medicação de resgate ou escore acima 11 pontos os pacientes eram orientados a procurar o serviço de emergência [Anexo J]. Neste 
mesmo diário, os pacientes registraram visitas no pronto socorro, internações e hospitalizações.

\subsubsection{Programa de Educação}

O Programa de Educação (PE) consistiu de aulas expositivas (por meio de cartazes), ministradas a grupos de três a sete pacientes, com duração aproximada de duas horas cada aula. O programa foi ministrado em módulos sobre fisiopatologia e controle ambiental, fatores desencadeantes/irritantes, sinais/sintomas de asma, tratamento de manutenção e resgate e o treinamento da técnica inalatória.

\subsection{Delineamento do estudo}

Em dia de consulta, obedecendo à rotina do ambulatório de asma, foram selecionados pacientes que preencheram os critérios de inclusão para o estudo. Aleatoriamente, por sorteio, os pacientes foram alocados em 3 grupos de acordo com a Figura 1:

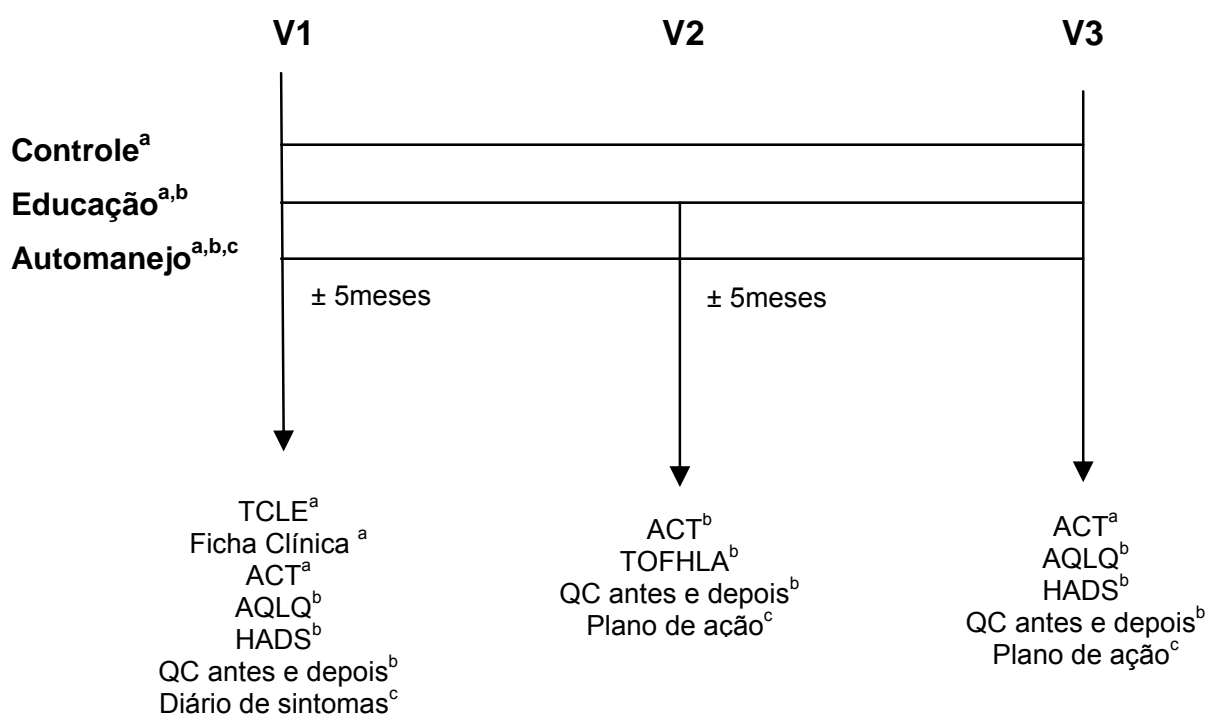

Figura 1 - Fluxograma do estudo. 
$\mathrm{Na}$ primeira visita (V1), os que aceitaram participar da pesquisa foram informados sobre o estudo e assinaram o termo de consentimento livre e esclarecido (TCLE) [Anexo L]. Todos os grupos preencheram a ficha clínica e o ACT. O grupo automanejo (GA) e grupo educação (GE) responderam o questionário de qualidade de vida, a escala de ansiedade e depressão, e o questionário de conhecimento antes e depois do Programa Educacional. O GA recebeu ainda o diário de sintomas e PFE, e foi orientado a retornar em 15 dias para avaliação do diário. Nesse retorno, os pacientes receberam o plano de ação por escrito individualizado.

Após cinco meses, os GA e GE retornaram para segunda visita (V2) do protocolo. Neste retorno, os pacientes responderam o ACT, o TOFLHA, o QAC antes e depois do Programa de Educação.

$\mathrm{Na}$ terceira visita (V3), no período de aproximadamente 5 meses, todos os grupos foram submetidos ao mesmo procedimento da $\mathrm{V} 1$ e avaliados pela última vez no Programa de Educação (GA e GE). Durante todo o período do estudo, os pacientes tiveram acompanhamento médico ambulatorial de rotina ou de acordo com instabilidade clínica (visitas extras). O grupo controle (GC) e GE tiveram o tratamento medicamentoso ajustado pelo médico assistente nas consultas, e o GA seguiu o plano de ação individualizado.

\subsection{Análise Estatística}

Inicialmente foi realizada uma análise descritiva e verificada a homogeneidade dos grupos. Os dados antropométricos, demográficos e clínicos obtidos em cada grupo foram comparados pelo test $t$ student e apresentado em percentual, média e desvio-padrão.

Os parâmetros de controle clínico, questionário de conhecimento, teste de alfabetização funcional e a avaliação da qualidade de vida foram submetidos à ANOVA para medidas repetidas, descritos em percentual médio de acertos, exceto para qualidade vida e teste de alfabetização, que foram apresentados em pontuação 
média. Para o questionário de ansiedade e depressão foi utilizado o teste quiquadrado e apresentado em percentual.

A análise estatística foi realizada pelo software SPSS (Statistical Package for the Social Sciences) versão 16.0 e SigmaStat (Systat Software Inc.) versão 2.0 (Jandel Corporation®).

Foi considerado significativo o valor de $p<0,05$. 
RESULTADOS 


\section{RESULTADOS}

110 pacientes foram selecionados para o estudo. Destes, sete pacientes tinham menos de dois anos em acompanhamento no ambulatório (conforme critérios de inclusão), seis não aceitaram participar do estudo, três apresentavam infecção do trato respiratório nas últimas semanas, dois já haviam participado de outros programas de educação e dois pacientes apresentavam outras comorbidades (paralisia cerebral), Figura 2.

Foram incluídos 90 pacientes. Durante o estudo um paciente do GE e outro do GA não retornaram para seguimento no serviço. Um paciente do GC, GE e GA não retornaram para seguimento do estudo e um paciente foi excluído do GE por apresentar outra doença pulmonar associada. Desta forma, 84 pacientes terminaram o estudo sendo 29 no GC, 27 no GE e 28 no GA.

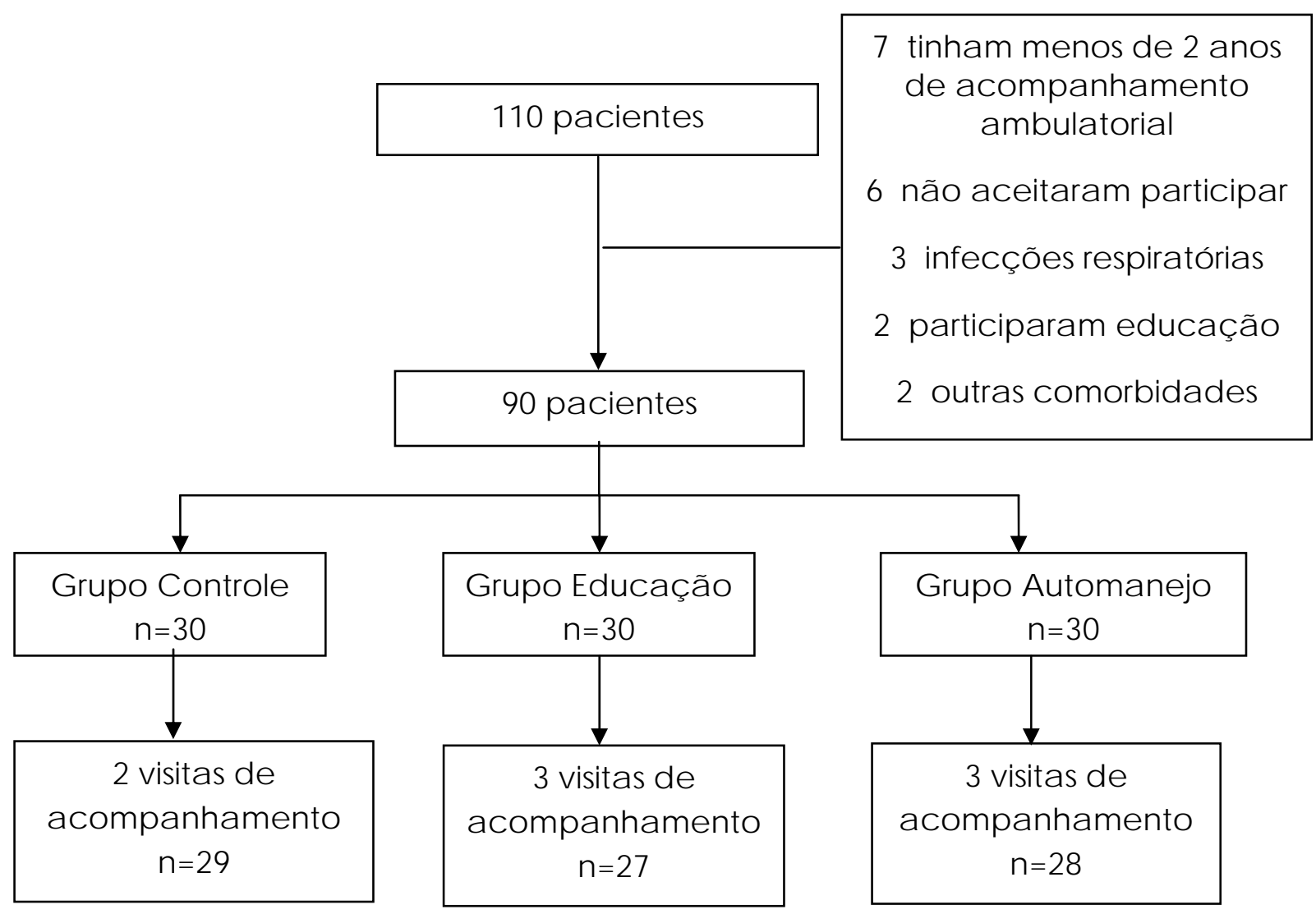

Figura 2 - Algoritmo do estudo. 


\subsection{Dados demográficos e clínicos dos pacientes}

\subsubsection{Características demográficas basais dos pacientes}

Os resultados descritos na Tabela 1 mostram os dados basais (V1) dos 90 pacientes. Os grupos são homogêneos, com predomínio do sexo feminino, sendo a idade média em torno de 44 anos no GC, 50 anos no GE e 47 anos no GA.

Tabela 1. Dados demográficos basais dos pacientes

\begin{tabular}{|c|c|c|c|c|}
\hline & $\begin{array}{c}\text { Grupo } \\
\text { Controle } \\
(n=30)\end{array}$ & $\begin{array}{c}\text { Grupo } \\
\text { Educação } \\
(n=30)\end{array}$ & $\begin{array}{c}\text { Grupo } \\
\text { Automanejo } \\
(n=30)\end{array}$ & valor $p$ \\
\hline Sexo (F/M) & $22 / 8$ & $19 / 11$ & $23 / 7$ & \\
\hline Idade, anos & $44 \pm 15$ & $50 \pm 14$ & $47 \pm 16$ & 0,310 \\
\hline IMC, kg. $\mathrm{m}^{2}$ & $25 \pm 7$ & $28 \pm 6$ & $27 \pm 8$ & 0,310 \\
\hline Escolaridade, anos & $9 \pm 4$ & $6 \pm 4$ & $7 \pm 3$ & 0,051 \\
\hline Renda Familiar, R\$ mensal & $401,00-700,00$ & $701,00-1000,00$ & $701,00-1000,00$ & 0,205 \\
\hline Tempo de asma, anos & $28 \pm 18$ & $29 \pm 20$ & $29 \pm 17$ & 0,998 \\
\hline \multicolumn{5}{|l|}{ Tabagismo (\%) } \\
\hline Ex- Fumantes & 23 & 47 & 20 & \\
\hline Fumantes & 3 & 3 & 0 & \\
\hline \multicolumn{5}{|l|}{ Monóxido de Carbono } \\
\hline CO ppm & -- & $4,7 \pm 2,4$ & $6,0 \pm 2,8$ & 0,086 \\
\hline $\mathrm{CO} \mathrm{Hb \%}$ & -- & $0,8 \pm 0,4$ & $1,0 \pm 0,4$ & 0,097 \\
\hline Alfabetização funcional, score & -- & $75 \pm 14$ & $77 \pm 14$ & 0,508 \\
\hline
\end{tabular}

Dados apresentados como média \pm Desvio Padrão ou \%.

IMC: índice de massa corpórea; CO: monóxido de carbono; ppm: partes por milhão; Alfabetização funcional: TOFLHA. 
A escolaridade média dos grupos foi 9 anos no GC, 6 anos no GE e 7 anos completos de estudo no GA. A renda familiar média no GC foi de $\mathrm{R} \$ 401,00$ 700,00 , no GE e no GA de $R \$ 701,00$ - 1 000,00. O tempo médio de história de asma foi de 29 anos. Não há diferença entre os grupos na situação basal. Em relação ao histórico de tabagismo, $3 \%$ dos pacientes dos grupos GC e GE declararam ser fumantes. $20 \%, 23 \%$ e $47 \%$ de ambos os grupos, respectivamente referiram ser ex-fumantes. Nos GE e GA ainda foram examinadas medidas de monóxido de carbono exalado, sendo que no GE a média de CO ppm (partes por

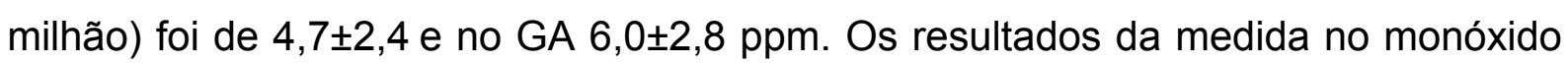
de carbono comprovam que os pacientes não haviam fumado no dia da visita ${ }^{59-60}$. O escore médio do TOFLHA foi $76 \pm 14$ pontos, que indica adequada alfabetização funcional em saúde, sem diferença significativa entre o GE e GA.

\subsubsection{Características clínicas basais dos pacientes}

Os resultados descritos na Tabela 2 mostram as características clínicas basais dos pacientes. O número de internações no último ano por asma foi semelhante nos três grupos. O valor médio percentual do Volume Expiratório Forçado no primeiro segundo $\left(\mathrm{VEF}_{1} \%\right)$ em relação ao previsto foi de $72 \pm 22$ para o GC, $69 \pm 21$ para o GE e $80 \pm 22$ para GA. Em relação às comorbidades, a média variou entre $77 \%$ e $93 \%$ para rinite, $37 \%$ e $53 \%$ para sinusite, $47 \%$ a $60 \%$ para refluxo gastroesofágico e para o relato de ansiedade e depressão, de $53 \%$ a $60 \%$. 
Tabela 2. Dados clínicos basais dos pacientes.

\begin{tabular}{|c|c|c|c|c|}
\hline & $\begin{array}{c}\text { Grupo } \\
\text { Controle } \\
(n=30)\end{array}$ & $\begin{array}{c}\text { Grupo } \\
\text { Educação } \\
(n=30)\end{array}$ & $\begin{array}{c}\text { Grupo } \\
\text { Automanejo } \\
(n=30)\end{array}$ & valor $p$ \\
\hline Internações no último ano & $0,2 \pm 1$ & $1 \pm 2$ & $1 \pm 1$ & 0,428 \\
\hline \multicolumn{5}{|l|}{ Função Pulmonar } \\
\hline VEF $_{1} \%$ & $72 \pm 22$ & $69 \pm 21$ & $80 \pm 22$ & 0,159 \\
\hline $\mathrm{VEF}_{1} / \mathrm{CVF}$ & $0,7 \pm 0,1$ & $0,6 \pm 0,1$ & $0,7 \pm 0,1$ & 0,089 \\
\hline \multicolumn{5}{|l|}{ Comorbidades (\%) } \\
\hline Rinite & 93 & 80 & 77 & \\
\hline Sinusite & 53 & 37 & 43 & \\
\hline DRGE & 50 & 60 & 47 & \\
\hline Ansiedade/Depressão & 53 & 53 & 60 & \\
\hline
\end{tabular}

\subsection{Controle da doença}

$\mathrm{Na}$ Figura 3 estão demonstrados os resultados referentes ao controle da asma. Analisando o GA observaram-se valores iniciais de $14 \pm 5$ pontos na $\mathrm{V} 1,18 \pm 5$ pontos na $\mathrm{V} 2$ e $17 \pm 5$ pontos na $\mathrm{V} 3$, mostrando um aumento significativo do controle da asma entre V1-V2 $(p<0,05)$ que se manteve até V3. No GE observaram-se valores iniciais ACT de $15 \pm 6$ pontos em $\mathrm{V} 1,15 \pm 6$ pontos na $\mathrm{V} 2$ e $17 \pm 6$ pontos na V3, mostrando um aumento não significativo no controle da asma. No GC, observaram-se valores iniciais de ACT de $14 \pm 5$ pontos na $V 1$, que não se alteraram até o final do estudo. A análise entre os grupos nas três visitas mostrou que os pacientes do GA tiveram melhor controle da asma quando comparados aos outros grupos $(p<0,05)$. 


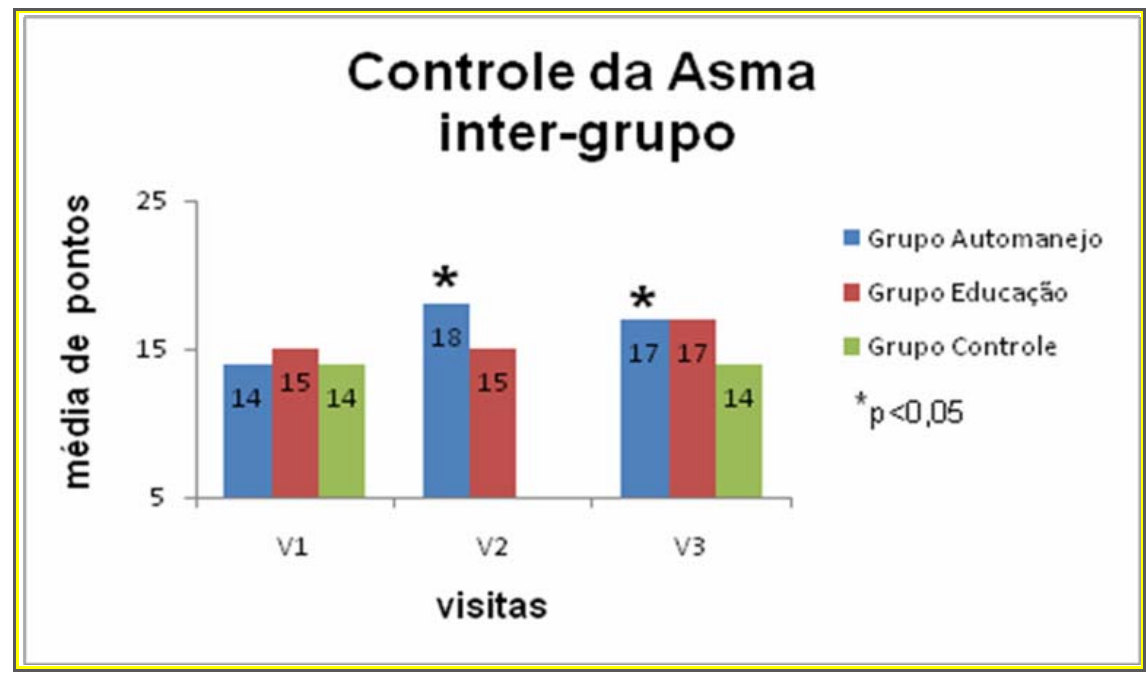

Figura 3 - Questionário de Controle da Asma (ACT) entre os grupos ao longo do estudo.

Na Figura 4 podemos observar o percentual de pacientes com asma não controlada e controlada no GA durante o estudo. Na V1 17\% dos pacientes apresentavam controle da doença. $\mathrm{Na} \mathrm{V} 2,48 \%$ dos pacientes apresentaram controle da asma $(p<0,001)$ e ao final do estudo (V3) 34\% ainda mantinham o mesmo. Uma variação de $31 \%$ entre $\mathrm{V} 1-\mathrm{V} 2$ e $17 \%$ entre $\mathrm{V} 1-\mathrm{V} 3$.

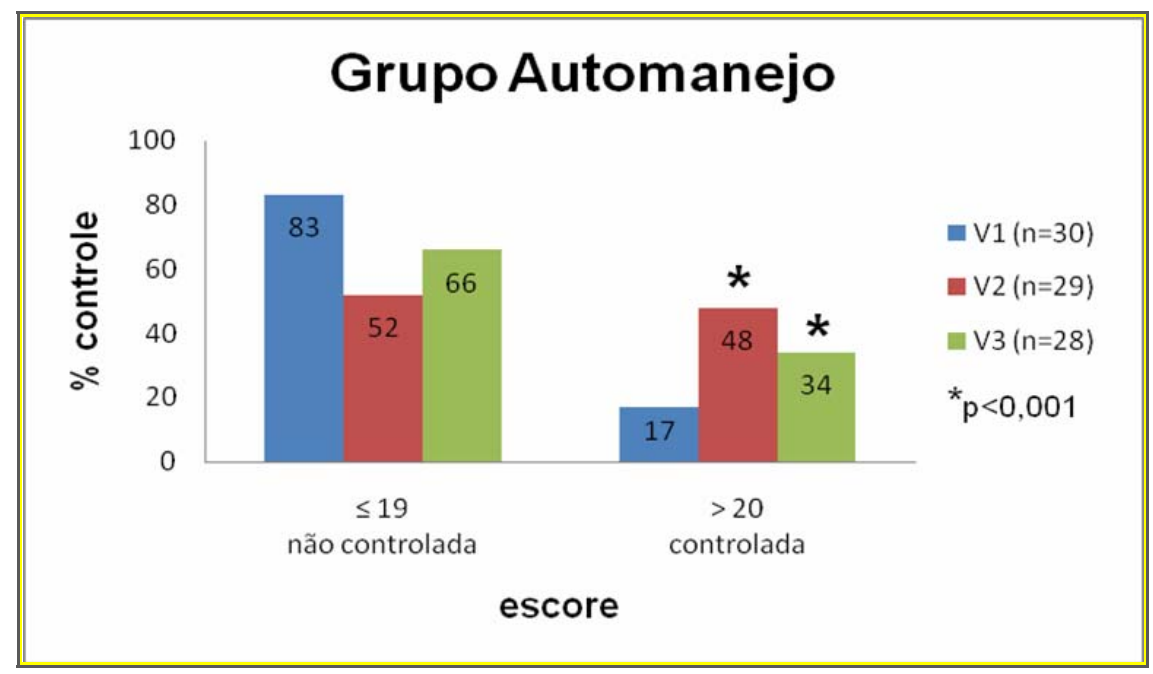

Figura 4 - Percentual (\%) de pacientes com asma controlada e não controlada no grupo automanejo ao longo do estudo. 
Na Figura 5 podemos observar o percentual de pacientes com asma não controlada e controlada no GE durante o estudo. Na primeira visita $37 \%$ dos pacientes apresentavam controle da doença e ao final do estudo $11 \%$ a mais dos pacientes $(48 \%)$ alcançaram controle da asma $(p<0,001)$.

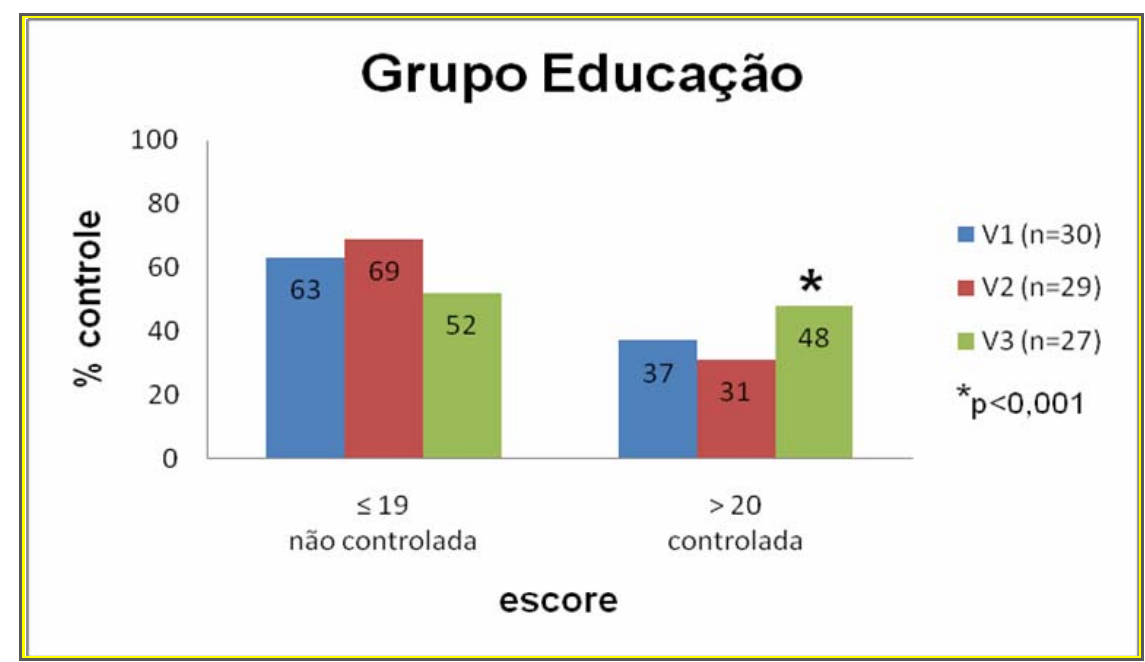

Figura 5 - Percentual (\%) de pacientes com asma controlada e não controlada no grupo educação ao longo do estudo.

Na Figura 6 podemos observar o percentual de pacientes com asma não controlada e controlada no GC. Na primeira visita 10\% dos pacientes apresentavam controle da doença e ao final do estudo (V3) apenas 7\% dos pacientes mantinham controle da asma, mostrando uma queda não significativa.

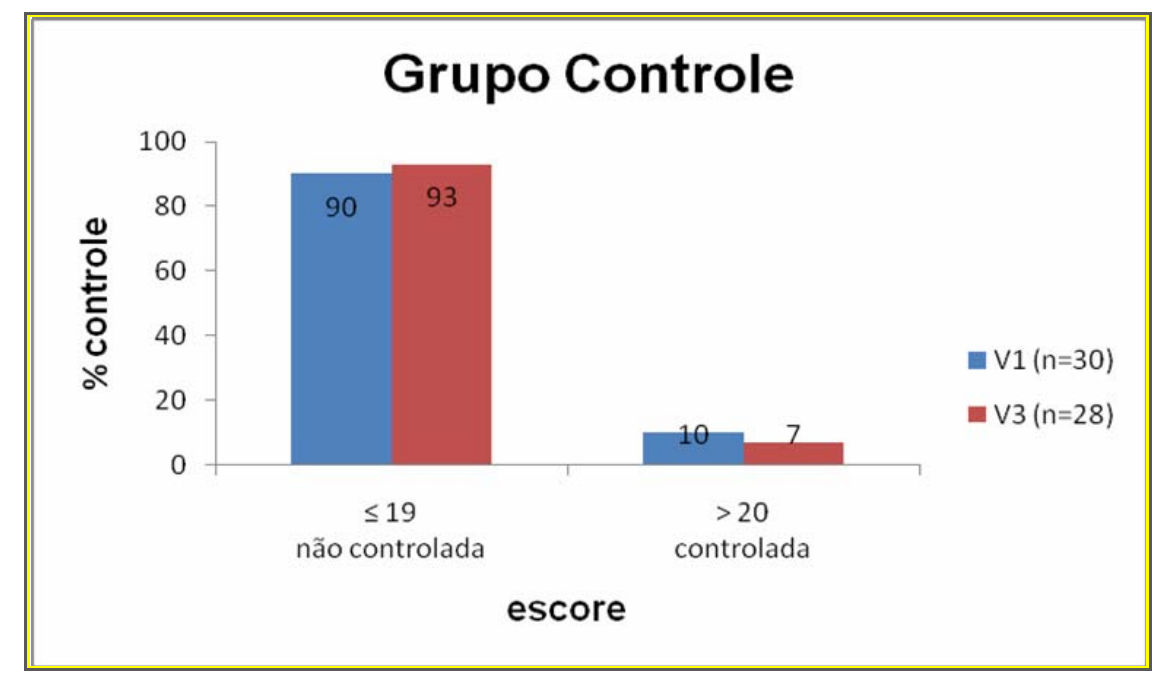

Figura 6 - Percentual (\%) de pacientes com asma controlada e não controlada no grupo controle ao longo do estudo. 


\subsection{Conhecimento da doença e técnica inalatória}

\subsubsection{Grupo Automanejo}

A Figura 7 demonstra os resultados do questionário de conhecimento aplicado no GA nas três visitas. Os resultados indicam que os pacientes apresentavam grande carência de informações sobre a asma antes da aplicação do PE. Depois de ministrado pela primeira vez, esses valores aumentaram significativamente de $63 \%$ para $93 \%(p<0,05)$.

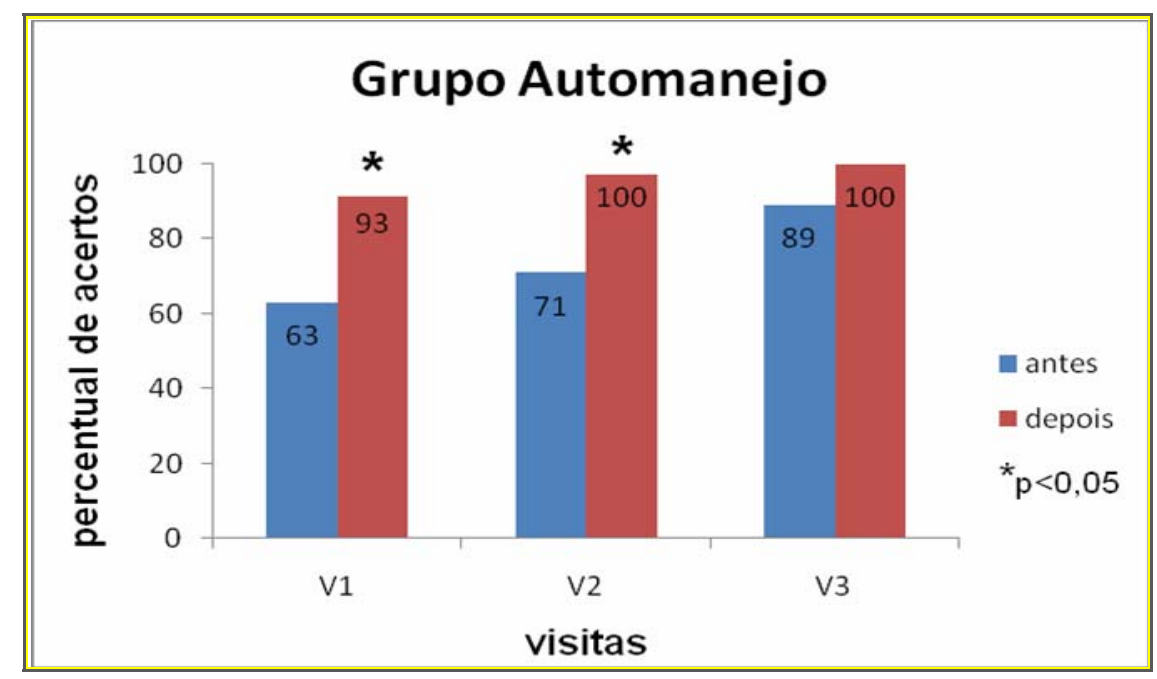

Figura 7 - Grau de conhecimento (\% acertos) dos pacientes do grupo automanejo ao longo do estudo.

Após 5 meses (V2), observou-se um redução significativa para $71 \%$ de acertos em relação aos valores atingidos ao final da V1. Entretanto, quando as informações do programa foram ministradas novamente na V2, observou-se um aumento dos valores para $100 \%$. Passados mais 5 meses (V3), o percentual de respostas certas voltou a diminuir para $89 \%$ em relação aos valores atingidos ao final da V2, sem significância estatística. Todavia, ao serem submetidos ao PE em V3, o percentual de acertos voltou a atingir valores semelhantes aos obtidos no final da V1 e V2. 
Na Figura 8 estão demonstrados os resultados do check list do aerossol dosimetrado sem o uso do espaçador aplicado no GA nas três visitas. Os resultados demonstram que os pacientes apresentavam baixo percentual de acertos da técnica em V1. Depois de orientar a técnica correta pela primeira vez, esses valores aumentaram significativamente de $67 \%$ para $100 \%(p<0,05)$.

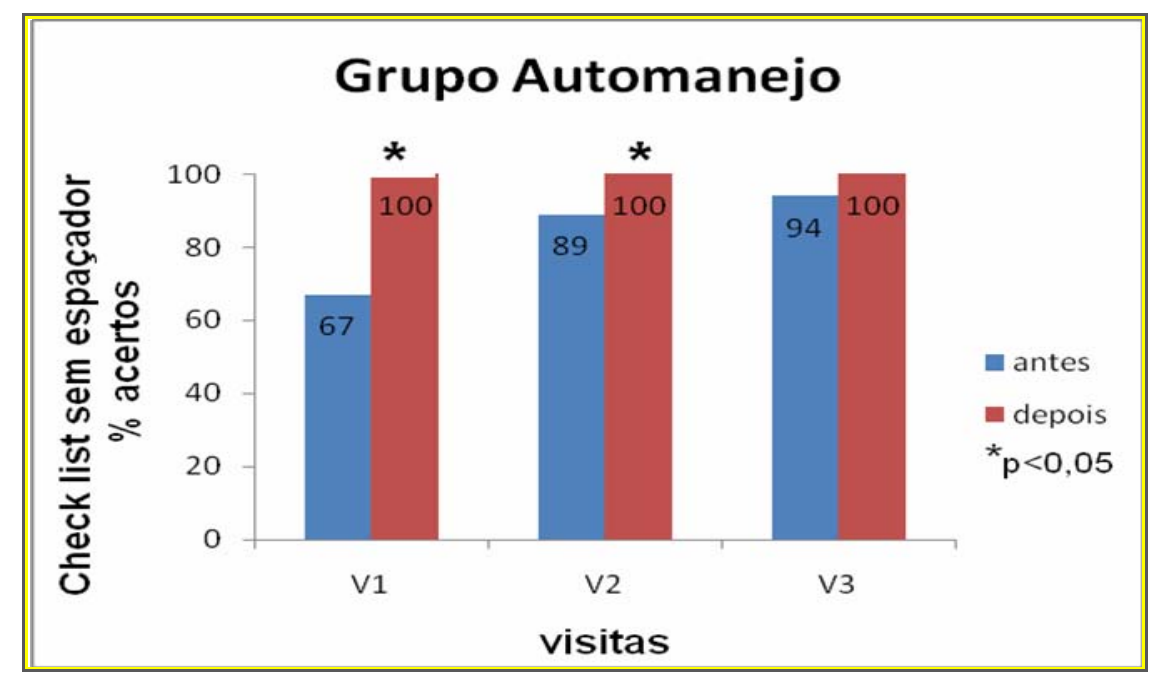

Figura 8 - Técnica inalatória sem uso do espaçador ( $\%$ acertos) no grupo automanejo ao longo do estudo. ${ }^{*} p<0,05$ em V1 e V2 antes e depois.

Após 5 meses (V2), observou-se um redução não significativa para $89 \%$ de acertos, antes da reavaliação da técnica, em relação aos valores atingidos ao final da V1. Entretanto, quando a técnica foi corrigida na V2, observou-se um aumento dos valores para $100 \%(p<0,05)$. Passados mais 5 meses (V3), o percentual de respostas certas voltou a diminuir para 94\%, sem significância estatística. Todavia, ao ser reavaliado e corrigido a técnica inalatória sem espaçador pela terceira vez, o percentual de passos corretos voltou a atingir valores semelhantes aos obtidos no final da V1 e V2. 
A Figura 9 mostra os resultados do check list do aerossol dosimetrado com uso do espaçador aplicado no GA nas três visitas. Os resultados demonstram que os pacientes apresentavam baixo percentual de acertos da técnica em V1. Depois de orientar a técnica correta pela primeira vez, esses valores aumentaram significativamente de $67 \%$ para $100 \%(p<0,05)$.

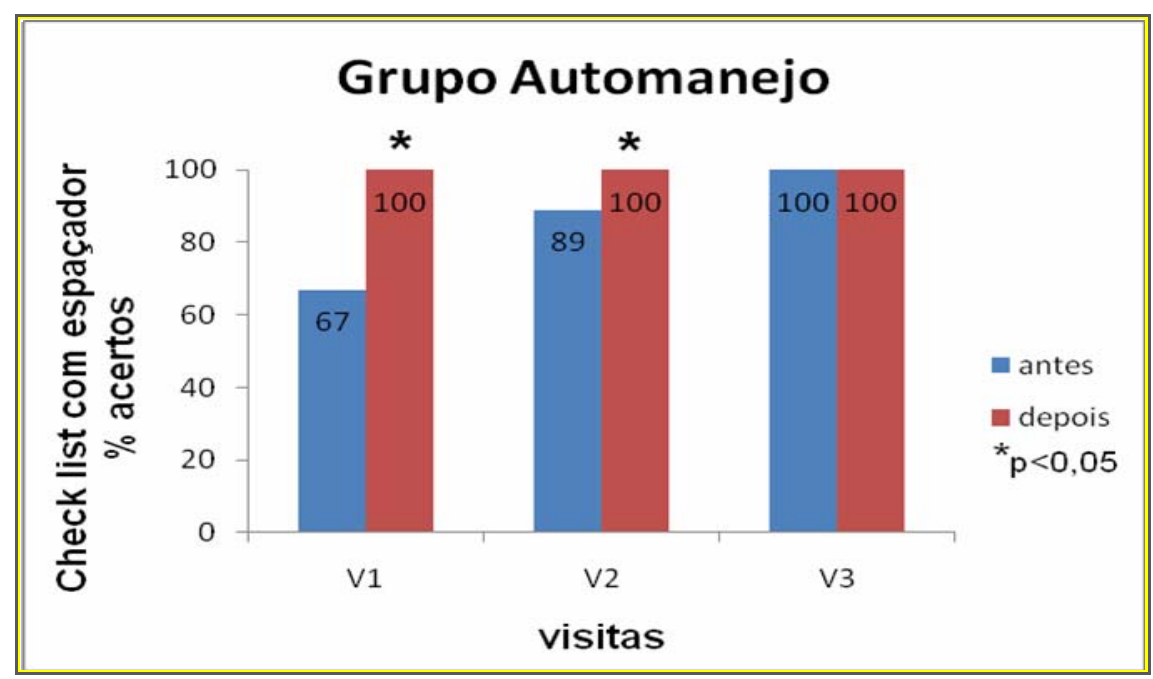

Figura 9 - Técnica inalatória com uso do espaçador (\% acertos) no grupo automanejo ao longo do estudo.

${ }^{*} p<0,05$ em V1 e V2 antes e depois.

Após 5 meses (V2), observou-se um redução não significativa para $89 \%$ da técnica em relação aos valores atingidos pelos pacientes no final da V1. Quando a técnica foi reforçada observou-se um aumento significativo dos valores para $100 \%$. Ao final do estudo (V3), o percentual de passos corretos manteve-se $100 \%$ em relação aos mesmos valores atingidos ao final da V1 e V2 sugerindo uma fixação do aprendizado. 
A Figura 10 mostra os resultados do check list do dispositivo em pó (turbohaler) aplicado no GA nas três visitas. Os resultados demonstram que os pacientes apresentavam baixo percentual de acertos também com esta técnica em V1. Depois de orientar a técnica correta pela primeira vez, esses valores aumentaram significativamente de $62 \%$ para $100 \%(p<0,05)$.

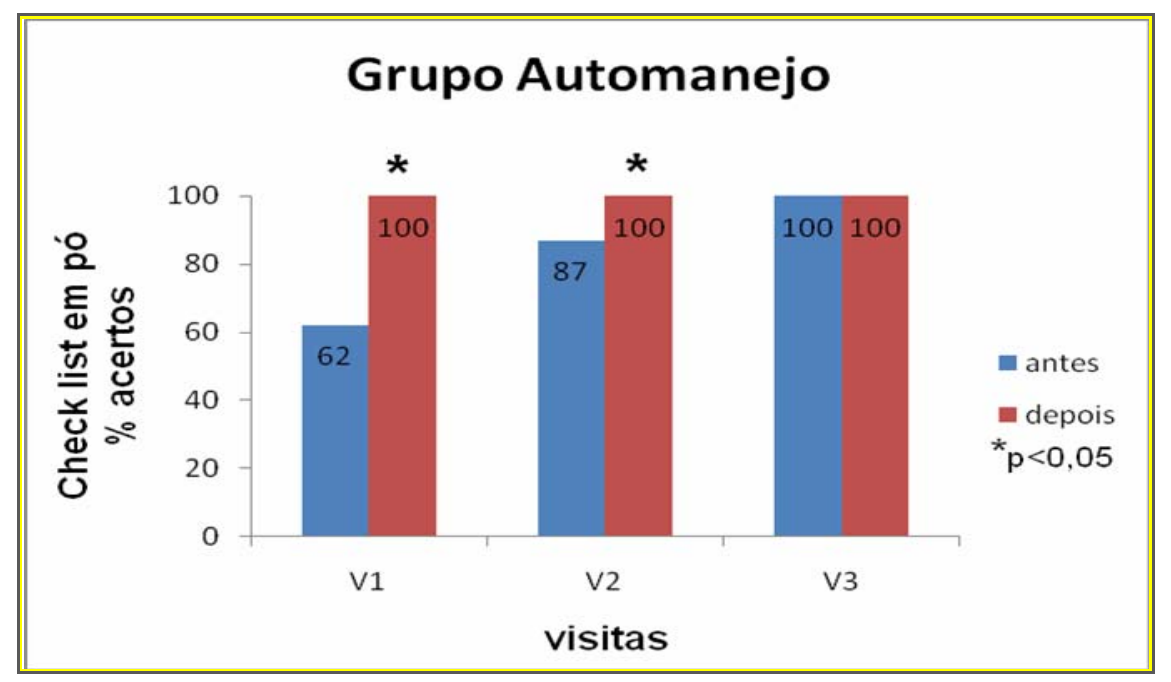

Figura 10 - Técnica inalatória do dispositivo em pó (\% acertos) no grupo automanejo ao longo do estudo. ${ }^{*} \mathrm{p}<0,05$ em $\mathrm{V} 1$ e $\mathrm{V} 2$ antes e depois.

Após 5 meses (V2), observou-se um redução não significativa para $87 \%$ da técnica em relação aos valores atingidos pelos pacientes no final da V1. Quando a técnica foi reforçada observou-se um aumento dos valores para $100 \%$. Ao final do estudo (V3), a percentagem das respostas manteve-se em 100\% em relação aos mesmos valores atingidos ao final da V1 e V2 sugerindo uma fixação do aprendizado. 


\subsubsection{Grupo Educação}

A Figura 11 mostra os resultados do questionário de conhecimento aplicado no GE nas três visitas. Os resultados indicam os pacientes apresentavam grande carência de informações sobre a asma antes da aplicação do PE. Depois de ministrado pela primeira vez, esses valores aumentaram significativamente de $64 \%$ para $80 \%(p<0,05)$.

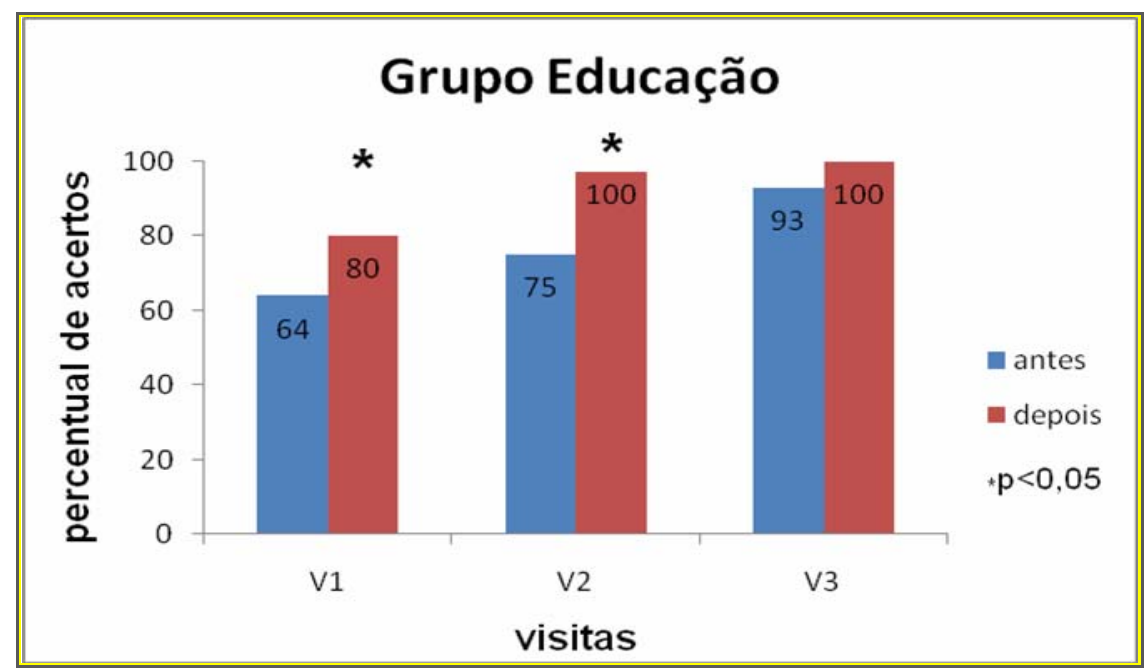

Figura 11 - Grau de conhecimento (\% acertos) dos pacientes do grupo educação ao longo do estudo.

$* \mathrm{p}<0,05$ em $\mathrm{V} 1$ e $\mathrm{V} 2$ antes e depois.

Após 5 meses (V2), observou-se um redução significativa para $75 \%$ no antes da aplicação do programa em relação aos valores atingidos pelos pacientes no final da V1. Entretanto, quando as informações do programa foram ministradas novamente na V2, observou-se um aumento significativo dos valores para $100 \%$. Passados mais 5 meses (V3), o porcentual de respostas certas voltou a diminuir para 93\% em relação aos valores atingidos ao final da V2, sem significância estatística. Quando reaplicado em V3, a percentagem de acertos voltou a atingir valores semelhantes (80\% e 100\%) aos obtidos no final da V1 e V2. 
A Figura 12 mostra os resultados do check list do aerossol dosimetrado sem o uso do espaçador aplicado no GE nas três visitas. Os resultados demonstram que os pacientes apresentavam baixo percentual de acertos nesta técnica em $\mathrm{V} 1$. Depois de orientar a técnica correta pela primeira vez, esses valores aumentaram significativamente de $49 \%$ para $100 \%(p<0,05)$.

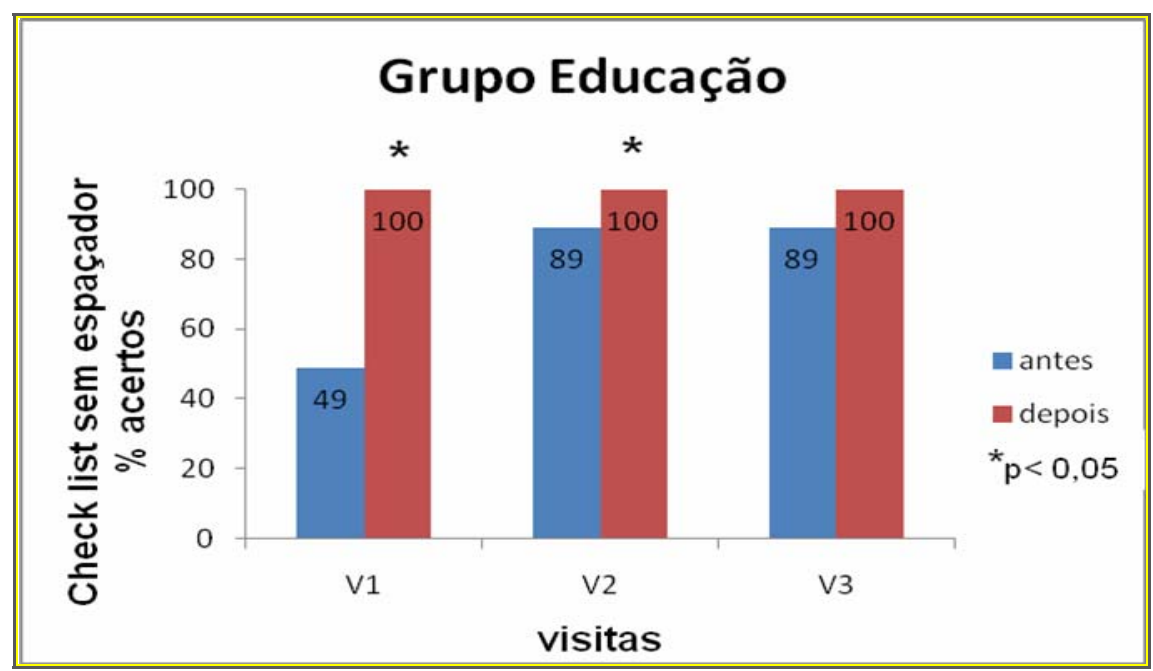

Figura 12 - Técnica inalatória sem uso do espaçador (\% acertos) no grupo educação ao longo do estudo. ${ }^{*} \mathrm{p}<0,05$ em V1 e V2 antes e depois.

Após 5 meses (V2), observou-se um redução não significativa para 89\% antes da reavaliação da técnica em relação aos valores atingidos pelos pacientes no final da V1. Entretanto, quando a técnica foi corrigida na segunda visita (V2), observou-se um aumento dos valores para 100\%. Passados mais 5 meses (V3), a porcentagem de respostas certas voltou a diminuir para $89 \%$ em relação aos valores atingidos ao final da V2, sem significância estatística. Todavia, ao ser reavaliado e corrigido a técnica inalatória sem o uso do espaçador pela terceira vez, o percentual de passos corretos voltou a atingir valores semelhantes (100\%) aos obtidos no final da V1 e V2. 
A Figura 13 mostra os resultados do check list do aerossol dosimetrado com espaçador aplicado no GE nas três visitas. Os resultados mostram que os pacientes apresentavam baixo percentual de acertos nesta técnica em V1. Depois de orientar a técnica correta pela primeira vez, esses valores aumentaram significativamente de $44 \%$ para $100 \%(p<0,05)$.

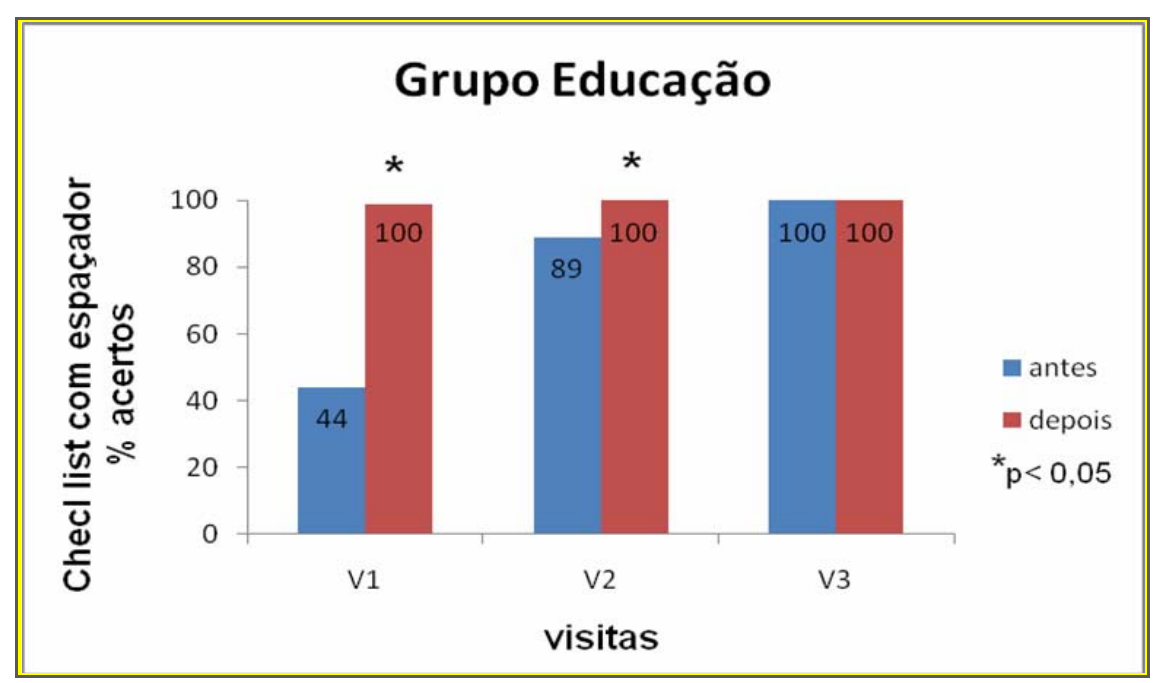

Figura 13 - Técnica inalatória com uso do espaçador (\% acertos) no grupo educação ao longo do estudo.

${ }^{*} \mathrm{p}<0,05$ em V1 e V2 antes e depois.

Após 5 meses (V2), observou-se um redução significativa para $89 \%$ antes da reavaliação da técnica em relação aos valores atingidos no final da V1. Entretanto, quando a técnica foi corrigida na segunda visita (V2), observou-se um aumento dos valores para $100 \%$. Passados mais 5 meses (V3), o percentual de respostas corretas manteve-se $100 \%$ em relação aos mesmos valores atingidos ao final da V1 e V2. 
A Figura 14 mostra os resultados do check list do dispositivo em pó (turbohaler) aplicado no Grupo Educação nas três visitas. Os resultados mostram que os pacientes apresentavam baixo percentual de acertos nesta técnica em V1. Depois de orientar a técnica correta pela primeira vez, esses valores aumentaram significativamente de $62 \%$ para $100 \%(p<0,05)$.

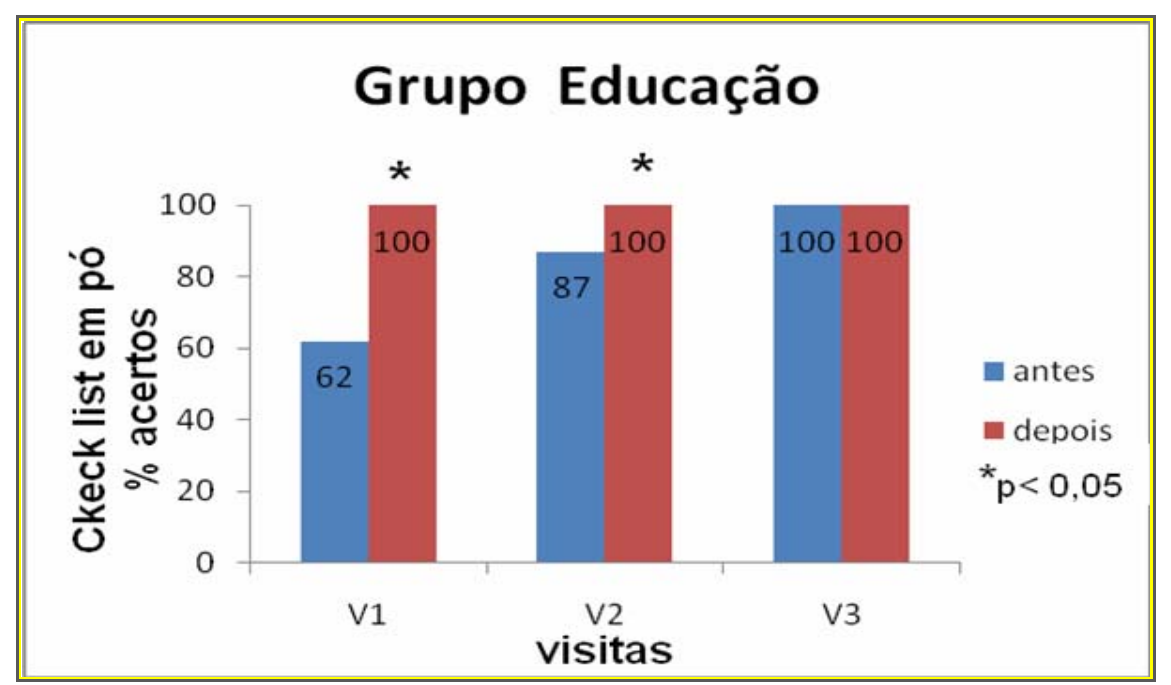

Figura 14 - Técnica inalatória do dispositivo em pó (\% acertos) no grupo educação ao longo do estudo.

${ }^{*} p<0,05$ em V1 e V2 antes e depois.

Após 5 meses (V2), observou-se um redução significativa para 87\% antes da reavaliação da técnica em relação aos valores atingidos pelos pacientes no final da V1. Entretanto, quando a técnica foi corrigida na segunda visita (V2), observou-se um aumento dos valores para 100\%. Passados mais 5 meses (V3), a percentagem de respostas corretas manteve-se $100 \%$ em relação aos mesmos valores atingidos ao final $\mathrm{V} 2$. 


\subsection{Qualidade de Vida}

Na Figura 15 são mostrados os resultados nos diferentes domínios (limitação da atividade física, sintomas, emoção, ambiente e escore total) do questionário de qualidade de vida em asma (AQLQ) no GA em V1 e V3.

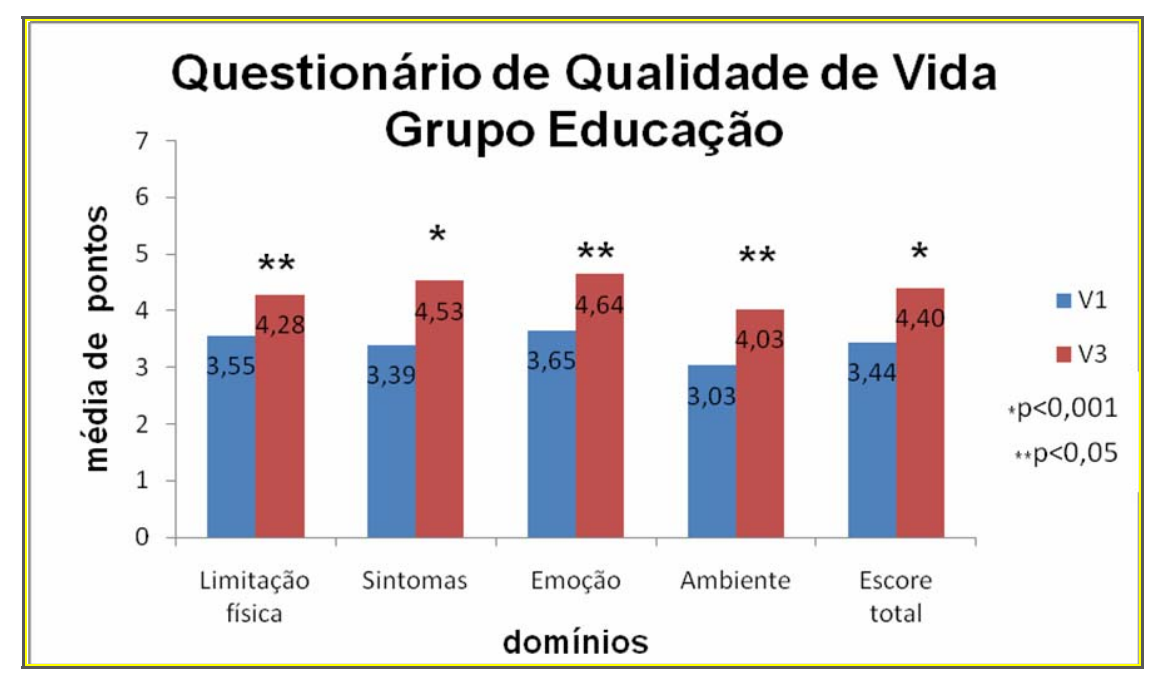

Figura 15 - Qualidade de vida relacionado à saúde (AQLQ) em todos os domínios no grupo automanejo ao longo do estudo.

Há um incremento significativo em todos os domínios, respectivamente: de $3,55 \pm 1,22$ para $4,28 \pm 1,17(p=0,030)$ no domínio limitação física, 3,39 $\pm 1,49$ para $4,53 \pm 1,66(p=0,001)$ no domínio sintomas, $3,65 \pm 1,58$ para 4,64 $\pm 1,76(p=0,002)$ no

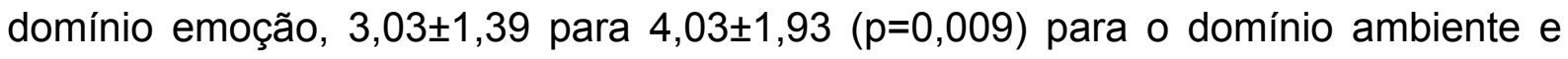
$3,44 \pm 1,20$ para $4,40 \pm 1,42$ ( $p<0,001)$ no domínio escore total. O aumento significativo de 0,5 pontos em cada domínio, e especialmente no escore total, indica melhor qualidade de vida com impacto clínico no grupo. 
Na Figura 16 são mostrados os resultados nos diferentes domínios (limitação da atividade física, sintomas, emoção, ambiente e escore total) do questionário de qualidade de vida em asma (AQLQ) no GE em V1 e V3.

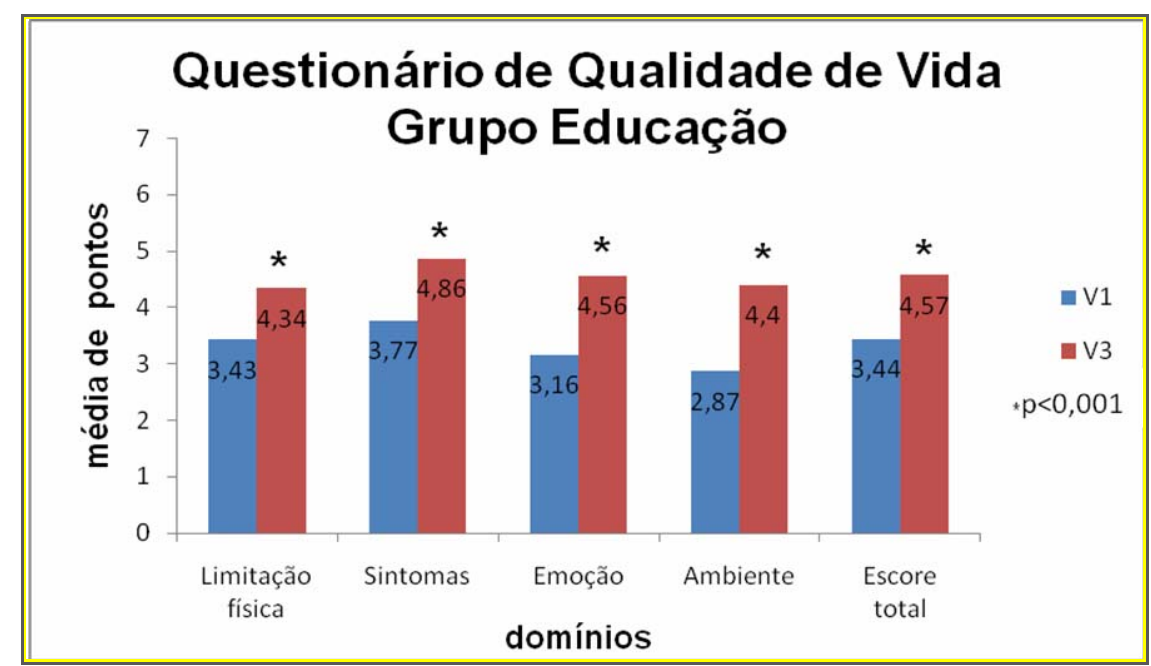

Figura 16 - Qualidade de vida relacionado à saúde (AQLQ) em todos os domínios no grupo educação ao longo do estudo.

Há um incremento significativo em todos os domínios, respectivamente de

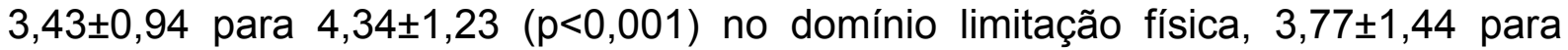

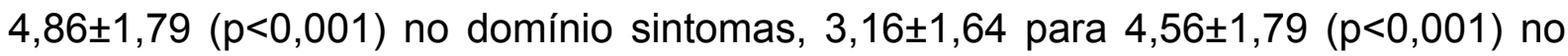

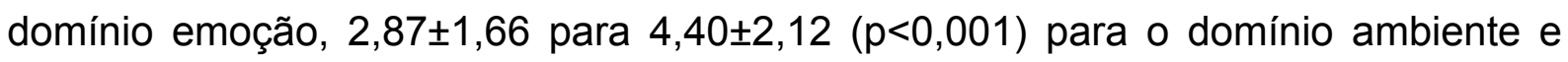
$3,44 \pm 1,16$ para $4,57 \pm 1,44$ ( $p<0,001$ ) no domínio escore total. O aumento significativo de 0,5 pontos em cada domínio, e especialmente no escore total, indica melhor qualidade de vida com impacto clínico no grupo.

Análise comparativa entre os grupos (GA e GE) não foram diferentes. 


\subsection{Ansiedade e Depressão}

A Figura 17 mostra o percentual de pacientes com traço de ansiedade referente à escala hospitalar de ansiedade e depressão (HADS) do GA durante o estudo (V1 e V3).

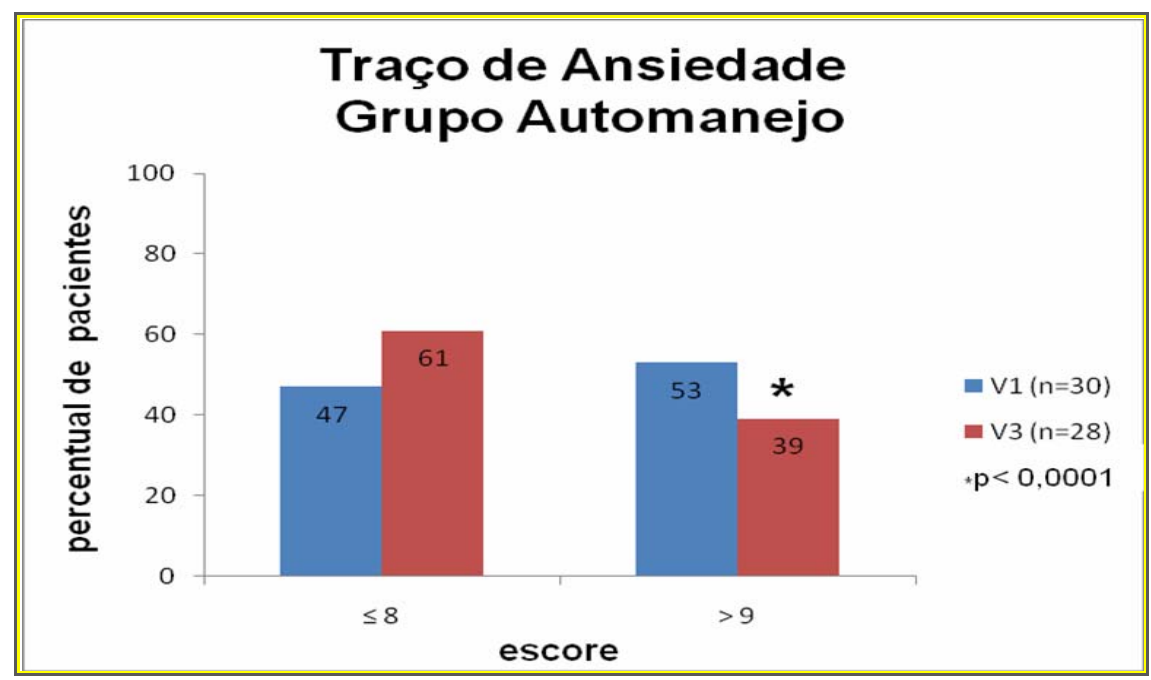

Figura 17 - Traço de Ansiedade (\% acertos) na Escala hospitalar de ansiedade e depressão - HADS no grupo automanejo.

Na primeira visita 53\% (16) dos pacientes apresentavam traço de ansiedade (escore maior que nove). Na terceira visita houve uma redução significativa para $39 \%$ (11) no traço ansiedade, o que indica melhora do sintoma neste grupo. 
A Figura 18 mostra o percentual de pacientes com traço de ansiedade referente à escala hospitalar de ansiedade e depressão (HADS) do GE durante o estudo (V1 e V3).

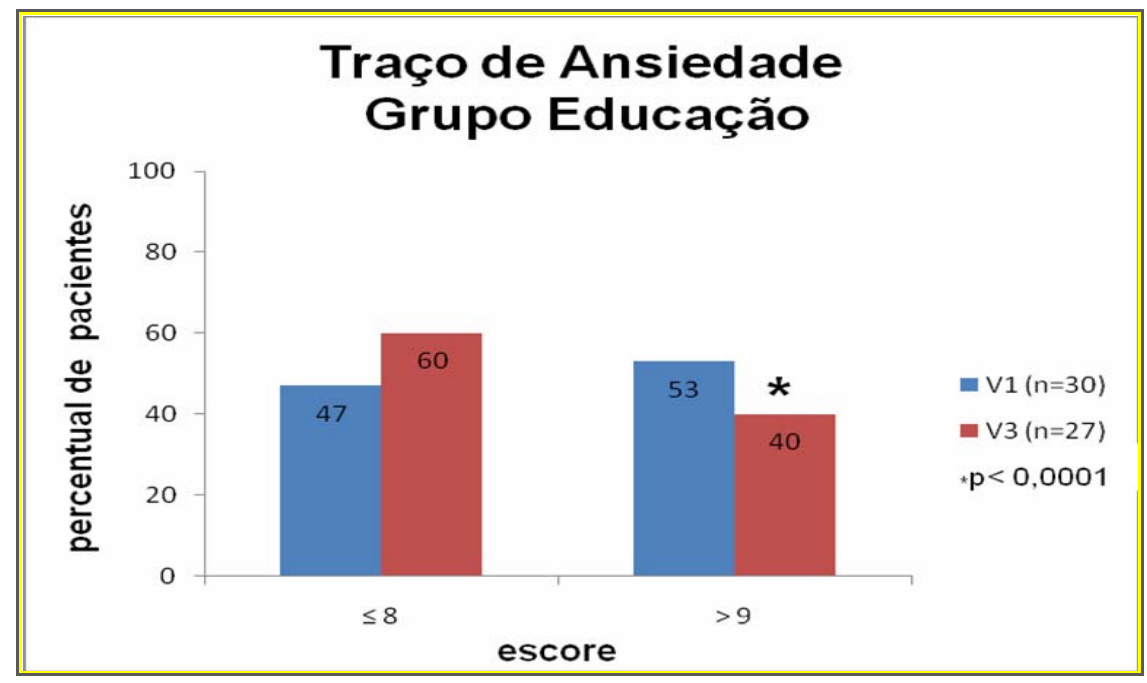

Figura 18 - Traço de Ansiedade (\% acertos) na Escala hospitalar de ansiedade e depressão - HADS no grupo educação.

Na primeira visita 53\% (16) dos pacientes apresentavam traço de ansiedade (escore maior que nove). Na terceira visita houve uma redução significativa para $40 \%$ (11) no traço ansiedade, o que indica melhora do sintoma neste grupo.

Análise comparativa entre os grupos (GA e GE) não foram diferentes. 
DISCUSSÃO 


\section{DISCUSSAO}

O presente estudo demonstrou que um programa educação com automanejo, orientado por um plano de ação por escrito, automonitorização e ao auto-ajuste da medicação, proporcionou melhor controle clínico de asmáticos moderados e graves quando comparado ao atendimento de rotina. Permitiu ainda, a fixação de conhecimento sobre a doença, incluindo o uso adequado de dispositivos inalatórios e, como conseqüência, melhorou a qualidade de vida relacionada à asma e diminuiu os sintomas de ansiedade. Uma vez que o programa de educação deste estudo foi aplicado no mesmo dia das consultas médicas, estes resultados indicam em melhor qualidade de assistência ao paciente asmático. E sugerem que, mesmo em hospital terciário de referência, os programas educacionais são necessários para alcançar o controle da asma ${ }^{32}$ na maior parte dos asmáticos.

O uso do ACT como instrumento para mensurar o controle clínico permite quantificar e comparar objetivamente o impacto do programa de educação. Mehuys e cols. ${ }^{57}$ aplicaram o ACT em 166 asmáticos assistidos em farmácias comunitárias concluindo que $82,3 \%$ deles acreditavam ter asma totalmente ou bem controlada quando de fato apenas 50,9\% apresentavam controle. Ao analisarmos o controle clínico em pontos de corte do $\mathrm{ACT}^{53}$, denominados neste estudo como asma controlada e não controlada, os pacientes submetidos ao PE - em especial GAapresentaram maior controle da doença. A maior parte dos estudos sobre o impacto de programas educacionais demonstra melhora de sintomas em questionários específicos próprios que não permitem uma avaliação objetiva em outras populações. Por exemplo, Urek et. al ${ }^{61}$ estudando asmáticos moderados com três tipos de intervenção distintas (informações verbais, individuais, por escrito e aulas sobre asma), encontraram melhora de sintomas em todos os grupos. Já, em um programa estruturado aplicado a 127 pacientes asmáticos adultos, controlados em relação a 111 pacientes que não o receberam, mostrou uma melhora significativa no número de dias livres de sintomas e na redução do uso de corticóide oral no grupo 
estudo $^{62}$. Até o momento, o presente estudo parece ser o primeiro a utilizar o ACT na análise horizontal de um programa de educação em longo prazo para asmáticos .

Constatamos que os pacientes do nosso estudo guardavam as informações adquiridas no dia da intervenção, mas não as fixavam para a consulta seguinte. Apresentavam aparente resistência em assimilar as informações em um curto espaço de tempo. A repetição das intervenções, em pequenos grupos de pacientes, com informações verbais, visuais e auditivas, e com aulas de reforço no período de 12 meses proporcionou $100 \%$ de acerto no questionário de conhecimento e $100 \%$ de acerto na técnica de uso dos dispositivos inalatórios. Confirmando resultado anterior com a utilização dos mesmos instrumentos ${ }^{43}$. Dois autores ${ }^{58-63}$ relataram que o programa de educação de longo prazo, realizado em ambulatório, tem impacto positivo sobre a morbidade da asma. Esse impacto pode ser ocasionado por uma variedade de fatores, como a aquisição de conhecimento, a compreensão da terapia medicamentosa e uma maior atenção da equipe médica aos pacientes ${ }^{7-64}$.

Nas duas maiores revisões sistemáticas sobre intervenções educacionais para o automanejo da asma, realizadas nos últimos anos, em crianças/ adolescentes e adultos ${ }^{48-65}$, fica claro que quanto mais completo e individualizado for o programa de educação, maior será sua efetividade sobre as medidas de morbidade. Segundo alguns autores ${ }^{66}$, programas de educação associados a planos de ação (estruturados) encorajam o paciente a assumir uma maior responsabilidade no manejo da doença, resultando em aumento de aderência ao tratamento e em redução na morbidade da asma. Note-se que a ausência do plano de ação por escrito não impediu que ocorresse um incremento no conhecimento e melhora clínica da asma no grupo denominado educação deste estudo. Achados esses encontrados também em uma revisão sistemática, realizada por Powell e Gibson em $2003^{49}$. Os autores demonstraram que a adequação do tratamento pelo auto-ajuste da medicação conduzida por um plano de ação por escrito ou visita médica sequencial foi igualmente eficaz. O domínio para identificar sinais e sintomas de deterioração da asma, advindo do programa de educação, beneficiou os pacientes, reduziu as visitas aos serviços de emergência, hospitalizações, a utilização de corticóides orais e diminuiu a perda de dias de trabalho/escola e lazer. 
Os aspectos relacionados à qualidade de vida específica em asma medida pelo $A Q L Q-s^{54}$ de ambos os grupos de pacientes (GA e GE) mostraram melhora em todos os domínios. Resultados similares foram encontrados por Klein et al. ${ }^{67}$ após avaliação de dois anos de um programa de educação com automanejo em adultos com asma. Estudos clínicos baseados na educação do paciente e automanejo da asma apresentam resultados positivos na melhora da qualidade de vida ${ }^{42}$.

Apesar da asma não ser primariamente um distúrbio psicossomático ${ }^{4-39}$ o fato de conviver com a doença pode resultar em alterações de humor (depressão e ansiedade) nos pacientes e/ou familiares, e estas podem comprometer o tratamento medicamentoso, o controle da doença e a qualidade de vida relacionada à asma ${ }^{68-}$ 69. Estudo transversal ${ }^{70}$, utilizando metodologia diferente do presente, mostrou alto grau de sintomas de ansiedade em asmáticos, e certo grau de depressão nos pacientes não controlados. Os achados do nosso estudo reafirmam estes resultados e mostram uma queda na proporção de pacientes com sintomas de ansiedade ao participarem de um programa de educação. Yorke $2005^{39}$, descreve que embora as alterações emocionais que acompanham a asma tenham uma variedade de causas, o entendimento sobre a terapia prescrita melhora os sintomas de ansiedade e manejo da doença.

As principais limitações deste estudo são de ordem metodológica. Primeiro, utilizamos um questionário de avaliação de controle de asma elaborado a partir da reposta ao tratamento medicamentoso. Não se pode ter certeza da sua sensibilidade para medir o impacto das intervenções deste estudo. A percepção dos sintomas de asma pelos critérios do GINA não se correlaciona com o nível de controle da doença ${ }^{71}$ o que dificulta a mensuração dos sintomas de asma entre os estudos. Por este motivo o controle da asma não foi critério de exclusão, independente da gravidade dos sintomas no início do protocolo. Uma segunda limitação foi utilização de um questionário de conhecimento desenvolvido para avaliar a intervenção educativa. Esse questionário foi elaborado com objetivo de adequar os módulos a realidade da população após ampla discussão da equipe multidisciplinar que atende os pacientes. $O$ fato que de os resultados obtidos neste estudo concordarem com os obtidos anteriormente ${ }^{43}$ não implica que ele possa ser usado sem uma adaptação em outras populações. O mesmo raciocínio pode ser aplicado ao plano de ação 
utilizado no GA. Ele foi desenvolvido a partir de exemplos internacionais ${ }^{72-73-74}$, associados à experiência dos autores com diários de sintomas. Sua utilização em outros estudos pode ajudar a certificação de sua eficácia. Finalmente utilizamos quase que experimentalmente o teste de alfabetização funcional. A alfabetização funcional $^{75}$, idade ${ }^{42}$ e sexo ${ }^{76}$ são fatores que devem ser levados em consideração nos programas de educação em saúde. Wolf $2005^{77}$ descreve que nos EUA, $81 \%$ dos pacientes com mais de 60 anos, provenientes de dois hospitais públicos, não conseguiram ler e entender materiais de situações cotidianas, como as prescrições dos rótulos das medicações, cartão de consulta e orientações para serem seguidas em casa. Outros estudos indicam que pacientes portadores de doença crônica com menos habilidades em alfabetização em saúde, tem menos conhecimento da doença e tratamento, pouca habilidade para automanejo, baixo uso de serviços de prevenção e maior freqüência de hospitalização ${ }^{78}$. Mais do que o grau de escolaridade, fatores relacionados à compreensão das informações recebidas e dúvidas quanto ao benefício do programa de educação são importantes no comportamento do paciente ${ }^{13}$. Pelo teste de alfabetização funcional em saúde utilizado neste estudo, os GA e GE apresentaram uma pontuação adequada que indica, no momento, que os indivíduos tinham capacidade de realizarem com sucesso as tarefas necessárias nos cuidados em saúde. Foi nossa primeira experiência com este tipo de instrumento em pneumologia, apesar de sua validação em outras áreas medicas ${ }^{56-79-80}$.

Aparentemente, não há consenso sobre o melhor instrumento de avaliação dos programas de educação, uma vez que esses são delineados por princípios metodológicos específicos, e seus resultados não apresentam parâmetros pelos quais podemos afirmar que conseguiram atingir os objetivos conceituais ${ }^{8}$. Diferentes modelos de intervenção são descritos pelos pesquisadores, baseados na população estudada e na sua caracterização, respeitando diferenças socioeconômicas e culturais $^{3}$. O programa de educação é um componente essencial para o manejo da asma e deveria ser aplicado a todos os pacientes, mas parece ter maior benefício no controle clínico para aqueles com asma grave ou para portadores de comorbidades associadas à asma ${ }^{1}$. Faz-se necessário simplificar e aperfeiçoar os tipos de programa e seus objetivos, assim como avaliar adequadamente seus desfechos ${ }^{7}$. 0 
real impacto do programa de educação na evolução dos pacientes ainda não está definido, mas esse deve, além de incrementar o conhecimento, também modificar o comportamento frente à doença. Mesmo utilizando instrumentos novos de medida da intervenção. O programa de educação aplicado na rotina de atendimento de adultos asmáticos moderados e graves proporcionou um crescente e progressivo aprendizado dos conceitos sobre a fisiopatologia da asma, o controle ambiental, e tratamento de curto e longo prazo. Paralelamente, a intervenção educacional reduziu o grau de ansiedade e melhorou qualidade de vida destes pacientes. Os resultados obtidos influenciaram o controle da asma, mais acentuado no GA, e podem contribuir para o conhecimento do assunto devido à importância da adequação dos programas de educação e automanejo de asmáticos às realidades locais, visando melhorar a assistência de atendimento em asma. 


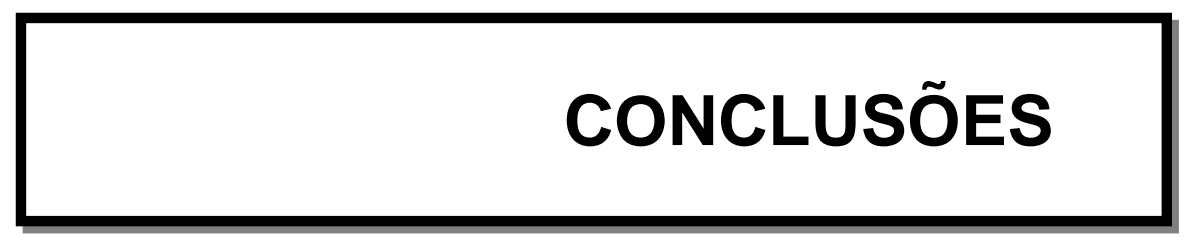




\section{CONCLUSÕES}

1. O programa de educação realizado em longo prazo e com visitas médicas regulares em nível ambulatorial mostrou impacto relevante sobre a melhora clínica de pacientes portadores de asma moderada e grave. Os pacientes do grupo automanejo apresentaram melhor controle clínico quando comparados com o grupo educação e grupo controle.

2. O programa educacional, aumentou o conhecimento sobre a doença e tratamento medicamentoso em longo prazo nesta população, com melhora da qualidade de vida relacionada à saúde, e redução dos sintomas de ansiedade.

3. Pacientes com asma persistente moderada e grave apresentaram adequada alfabetização funcional em saúde, independente do grau de conhecimento da doença. 


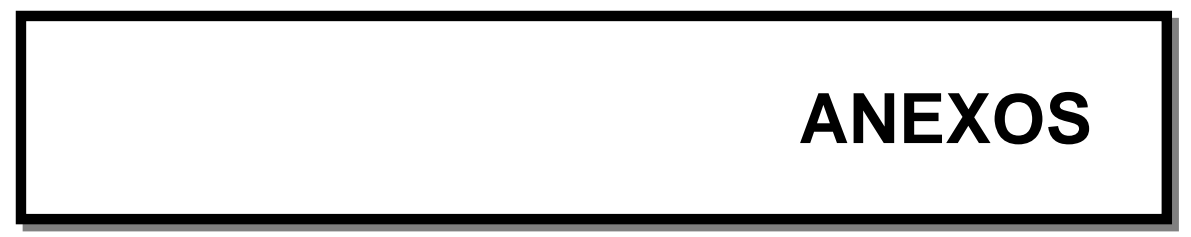




\section{ANEXO A - Parecer do Comitê de Ética}

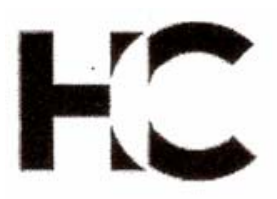

\section{APROVAÇÃO}

A Comissão de Ética para Análise de Projetos de Pesquisa - CAPPesq da Diretoria Clínica do Hospital das Clínicas e da Faculdade de Medicina da Universidade de São Paulo, em sessão de 14.06.06, APROVOU Protocolo de Pesquisa $n^{\circ}$ 1021/05 intitulado: "Avaliação da eficácia do automanejo no controle da asma" apresentado pelo Departamento Cardio-Pneumologia, inclusive Termo de Consentimento Livre e Esclarecido.

Cabe ao pesquisador elaborar e apresentar à CAPPesq, os relatórios parciais e final sobre a pesquisa (Resolução do Conselho Nacional de Saúde n 196, de 10.10.1996, inciso IX. 2, letra "c")

Pesquisador(a) Responsável: Prof.Dr. Rafael Stelmach

Pesquisador(a) Executante : Luciene Angelini

CAPPesq, 14 de Junho de 2006.

$$
\text { Whids Cahilho }
$$

PROF. DR. EUCLIDES AYRES DE CASTILHO

Presidente da Comissão de Ética para Análise de Projetos de Pesquisa 


\section{ANEXO B - FICHA CLÍNICA}

- Paciente leu, entendeu, concordou e assinou o TCLE : Sim （） Não （）

\section{- DADOS DEMOGRÁFICOS}

Sexo: $F(\quad)$ M ( ) Data de Nascimento: Idade:

Número de anos de estudo: (ex: estudou até $2^{\circ}$ ano colegial $=10$ )

Renda Familiar (R\$ mensal):

$\begin{array}{ll}\text { 1. }<180,00 & \text { 2. } 180,00-400,00\end{array}$

3. $401,00-700,00$

4. $701,00-1000,00$

5. $>1000,00 \quad(\quad)$

- ASMA há (_ ) anos

- Internações por asma : 1. Sim 2. Não $N^{\circ}$ vezes

Internações último ano:

Internações últimos 2 anos

UTI: 1. Sim 2. Não

EOT: 1. Sim $N^{\circ}$ vezes (

2. Não

PCR: 1. Sim $\mathrm{N}^{\circ}$ vezes

2. Não

\section{- DOENÇAS ASSOCIADAS E HÁBITOS}

Rinite ( ) Sinusite ( ) Dermatite ( ) Refluxo GE ( ) Disf de CV ( ) Transtorno ansiedade/depressão ( ) Vasculite ( ) DM ( ) HAS ( ) ICO ( ) SdCushing ( ) Bronquiolite ( ) Doença reumática ( )

História de TBC ( ) Bronquectasias ( ) Osteoporose ( ) Ronco alto ( ) Hipersonia diurna ( ) Obesidade ( ) Piora da asma no período menstrual: $\operatorname{Sim}(\quad)$ Não ( ) NA（ )

Piora da asma com ácido acetil salicílico ou AINH: Sim（） Não（）

Pêso :

Altura:

IMC : 
Tabagismo: 1. Nunca fumou 2. Passivo 3. Ex-fumante 4. Fumante ( )

Caso fumante/ex-fumante:

Início em (ano) Parou em (ano)

Cig / dia : Maços-ano:

Outros diagnósticos:

Exposição ocupacional:

Afastado

\begin{tabular}{|l|l|l|}
\hline Função & Sim Não & \\
\hline & & \\
\hline & & \\
\hline & & \\
\hline
\end{tabular}

- Espirometria (data :________ _ $)$ PEF (pred) :

\begin{tabular}{|l|l|l|l|l|l|l|}
\hline & Predito & Obtido & $\%$ Pred & Pós-BD & $\%$ Pós BD & $\% \Delta$ \\
\hline CVF & & & & & & \\
\hline$V_{\text {EF }}$ & & & & & & \\
\hline$V_{\text {VEF }} / \mathrm{CVF}$ & & & & & & \\
\hline
\end{tabular}

- Medicação utilizada:

- Beta Adrenérgico curta ação : inalatório ( ) oral ( )

Qual? Dose e freqüência:

- Corticosteróide inalado ( ) - contínuo ( ) intermitente ( )

Qual?

Dose Tempo: (anos) (meses)

- Corticosteróide enteral ( ) - contínuo ( ) intermitente ( ) 
Qual?

Dose _ Tempo:___ (anos) (meses)

- Corticosteróide parenteral ( )- contínuo ( ) intermitente ( )

Qual?

Dose __ Tempo:___ (anos) (meses)

- Beta Adrenérgico de longa duração ( )

Qual?

Dose Tempo: (anos) (meses)

- Associação $\beta 2$ + corticosteróide inalatório ( )
Qual?
Dose Tempo: (anos) (meses) Tempo: (anos) (meses)

- Xantina oral ( ) Dose

Nível sérico

- Antagonista de leucotrieno ( ) regular ( ) intermitente ( )
Qual?
Dose
Tempo: (anos) (meses)

- Outros medicamentos:

\section{Classificação da Gravidade da Asma:}

1. Freqüência dos sintomas:

1) $\leq 1 \mathrm{vez} /$ semana 2) $>1 \mathrm{vez} /$ semana

3) Diária 4) Contínua

\section{Exacerbações:}

1) ocasionais 2) podem afetar atividades ou sono

3) sempre afetam atividades 4) frequentes

3. Despertar noturno devido à asma:
1) $\leq 2$ vezes/mês
2) > duas vezes /mês
3) $1 \mathrm{vez} /$ semana
4) freqüentes 


\section{ANEXO C - Teste de Controle da Asma (ACT)}

1) Durante as últimas 4 semanas, com que freqüência sua asma impediu você de fazer coisas no trabalho, na escola ou em casa?
- O tempo todo
( ) 1 Ponto
- A maior parte do tempo
( ) 2 Pontos
- Algumas vezes
( ) 3 Pontos
- $\quad$ De vez em quando
( ) 4 Pontos
- Nunca
( ) 5 Pontos

2) Durante as últimas 4 semanas, com que freqüência você teve falta de ar?
- Mais de uma vez por dia
( ) 1 Ponto
- Uma vez por dia
( ) 2 Pontos
- $\quad 3$ a 6 vezes por semana
( ) 3 Pontos
- Uma ou duas vezes por semana
( ) 4 Pontos
- Nunca
( ) 5 Pontos

3) Durante as últimas 4 semanas, com que freqüência seus sintomas de asma (chiado no peito, tosse, falta de ar, aperto no peito, ou dor) acordaram você durante a noite ou de manhã mais cedo do que de costume?
- 4 ou mais noites por semana
( ) 1 Ponto
- 2 ou 3 noites por semana
( ) 2 Pontos
- Uma vez por semana
( ) 3 Pontos
- Uma ou duas vezes
( ) 4 Pontos
- Nunca
( ) 5 Pontos

4) Durante as últimas 4 semanas, com que freqüência você usou sua medicação de alívio como o inalador ou seu nebulizador (como por exemplo: Salbutamol ou Fenoterol)?
- 3 ou mais vezes por dia
( ) 1 Ponto
- 1 ou 2 vezes por dia
( ) 2 Pontos
- 2 ou 3 vezes por semana
( ) 3 Pontos
- Uma vez por semana ou menos
( ) 4 Pontos
- Nunca
( ) 5 Pontos

5) Como você avaliaria o controle da sua asma durante as últimas 4 semanas?
- Não controlada
( ) 1 Ponto
- Mal controlada
( ) 2 Pontos
- Um pouco controlada
( ) 3 Pontos
- Bem controlada
( ) 4 Pontos
- Completamente controlada
( ) 5 Pontos 


\section{ANEXO D - Qualidade de Vida relacionada Asma - (AQLQ)}

\section{$\underline{\text { Atividades }}$}

Pense em todas as atividades que desempenhou durante as 2 últimas semanas e em que se sentiu limitado/a pela sua asma.

Segue uma lista de atividades em que alguns asmáticos se sentem limitados e que talvez o/a ajude a identificar as 5 atividades mais importantes em que, nas 2 últimas semanas, se sentiu limitado/a por ter asma.

1. Andar de bicicleta

2. Ir as comprar e transportá-las

3. Dançar

4. Fazer consertos ou reparações em casa

5. Fazer o trabalho doméstico

6. Cuidar do jardim ou quintal

7. Ter de se apressar

8. Fazer ginástica ou correr

9. Rir as gargalhadas

10. Limpar ou esfregar o chão

11. Passar a ferro

12. Brincar com animais

13. Brincar com crianças ou pegá-las ao colo

14. Praticar esportes

15. Andar nos transportes públicos
16. Cantar

17. Manter a vida social normal

18. Ter relações sexuais

20. Falar

21. Subir escada ou a rua correndo

22. Usar o aspirador

23. Visitar amigos ou Família

24. Andar em terreno plano

25. Passear a pé

26. Subir uma escada ou uma rua

27. Fazer trabalhos de carpintaria ou marcenaria

28. Desempenhar atividades ligadas à sua profissão

29. Viajar para regiões com climas diferentes 
Por favor, escreva nas linhas seguintes, as 5 atividades mais importantes para você e, conforme as limitações que sentiu durante as 2 últimas semanas, em cada atividade, por ser asmático/a, assinale " $X$ " no quadrado que corresponde à sua opinião.

Até que ponto se sentiu limitado/a. durante as 2 últimas semanas nestas atividades?

\begin{tabular}{|c|c|c|c|c|c|c|c|}
\hline $\begin{array}{l}\text { Completamente } \\
\text { limitado/a }\end{array}$ & $\begin{array}{c}\text { Extremamente } \\
\text { limitado/a }\end{array}$ & $\begin{array}{c}\text { Muito } \\
\text { limitado/a }\end{array}$ & $\begin{array}{c}\text { Moderadamente } \\
\text { limitado/a }\end{array}$ & $\begin{array}{c}\text { Pouco } \\
\text { limitado/a }\end{array}$ & $\begin{array}{l}\text { Muito pouco } \\
\text { limitado/a }\end{array}$ & $\begin{array}{c}\text { Nada } \\
\text { limitado/a }\end{array}$ & $\begin{array}{c}\text { Não } \\
\text { desempenha } \\
\text { atividade }\end{array}$ \\
\hline 1 & 2 & 3 & 4 & 5 & 6 & 7 & 8 \\
\hline
\end{tabular}

1.
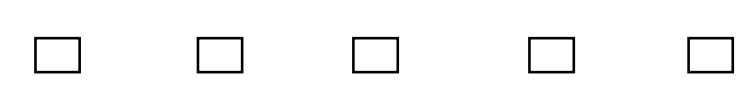

2.

3.

4.
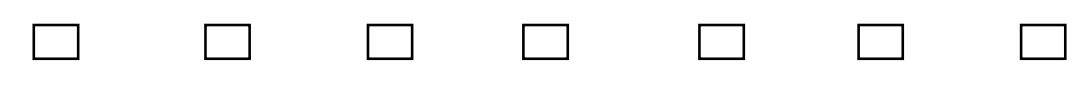

5.

.
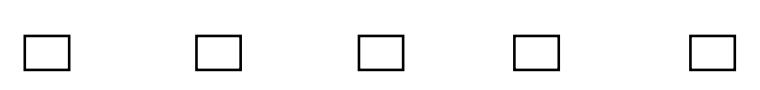

Que grau de Mal-estar ou Aflição sentiu durante as 2 últimas semanas?

$\begin{array}{ccccccc}\text { Muitissimo } & \text { Muito } & \text { Bastante } & \text { Moderado } & \text { Algum } & \begin{array}{c}\text { Muito } \\ \text { pouco }\end{array} & \text { Nenhum } \\ 1 & 2 & 3 & 4 & 5 & 6 & 7\end{array}$

6. Que grau de mal estar ou aflição sentiu durante as 2 últimas semanas, por causa de APERTO NO PEITO 
Em geral, quanto tempo durante as 2 últimas semanas:

$\begin{array}{ccccccc}\text { Sempre } & \begin{array}{c}\text { Quase } \\ \text { sempre }\end{array} & \begin{array}{c}\text { Bastante } \\ \text { tempo }\end{array} & \begin{array}{c}\text { Algum } \\ \text { tempo }\end{array} & \begin{array}{c}\text { Pouco } \\ \text { tempo }\end{array} & \begin{array}{c}\text { Quase } \\ \text { nunca }\end{array} & \text { Nunca } \\ 1 & 2 & 3 & 4 & 5 & 6 & 7\end{array}$

7. Sentiu-se preocupado/a por ter Asma?

8. Sentiu falta de ar por causa da Asma?

9, Teve sintomas de asma por estar exposto/a a fumaça de cigarro?

10. Sentiu chiado ("gatinhos") no peito?

11. Sentiu que tinha de evitar uma situação ou um ambiente por causa da fumaça de cigarro?

Que grau de mal estar ou aflição sentiu durante as 2 últimas semanas?

$\begin{array}{ccccccc}\text { Muitíssimo } & \text { Muito } & \text { Bastante } & \text { Moderado } & \text { Algum } & \begin{array}{l}\text { Muito } \\ \text { pouco }\end{array} & \text { Nenhum } \\ 1 & 2 & 3 & 4 & 5 & 6 & 7\end{array}$

12. Que grau de mal-estar ou aflição sentiu durante as 2 últimas semanas, por causa da tosse? 
Em geral, quanto tempo durante as 2 últimas semanas:

$\begin{array}{ccccccc}\text { Sempre } & \begin{array}{c}\text { Quase } \\ \text { sempre }\end{array} & \begin{array}{c}\text { Bastante } \\ \text { tempo }\end{array} & \begin{array}{c}\text { Algum } \\ \text { tempo }\end{array} & \begin{array}{c}\text { Pouco } \\ \text { tempo }\end{array} & \begin{array}{c}\text { Quase } \\ \text { nunca }\end{array} & \text { Nunca } \\ 1 & 2 & 3 & 4 & 5 & 6 & 7\end{array}$

13. Teve um sentimento de frustração, tristeza ou revolta por causa da asma?

14. Teve uma sensação de peso no peito?

15. Sentiu-se preocupado/a por ter de usar medicamentos ou "bombinhas" para a asma?

16. Sentiu necessidade de pigarrear (limpar a garganta)?

17. Teve sintomas de asma por estar exposto/a ao pó?

18. Teve dificuldade de expirar ou inspirar o ar por causa da asma?

19. Sentiu que tinha de evitar uma situação ou um ambiente por causa do pó?

20. Acordou de manhã com sintomas de asma?

21. Teve medo ou receio de não ter a mão a medicação para a asma?

22.Sentiu-se incomodado/ a por ter dificuldade em respirar? 
23. Teve sintomas de asma por causa do tempo do clima ou da poluição do ar?

24. Acordou durante a noite por causa da asma?

25. Evitou sair, ou saiu menos vezes, por causa do tempo do clima ou da poluição do ar?

26. Teve sintomas de asma por estar exposto/a a cheiros fortes ou perfumes?

27. Teve medo ou receio de ficar com falta de ar?

28. Sentiu que tinha de evitar uma situação ou um ambiente por causa de cheiros fortes ou perfumes?

29. Sua asma o/a impediu de dormir bem de noite?

30. Teve de fazer um grande esforço para conseguir respirar? 
Até que ponto que se sentiu limitado/a durante as 2 ultimas semanas?

\begin{tabular}{|c|c|c|c|c|c|c|}
\hline A maioria não & & Várias & & Muito poucas & & \\
\hline foi & & não & & não & & Nenhuma \\
\hline desempenhada & & desempenhadas & & desempenhadas & & limitação \\
\hline 1 & 2 & 3 & 4 & 5 & 6 & 7 \\
\hline
\end{tabular}

31. Pense em todas as coisas que gostaria de ter feito durante as 2 últimas semanas. Até que ponto o número das suas atividades foi limitado pela asma?

32. De um modo geral, em relaçãı todas as coisas que fez durante a últimas semanas, até que ponto sentiu limitado/a por ter asma?

$\begin{array}{ccccccc}\begin{array}{c}\text { Completamente } \\ \text { limitado/a }\end{array} & \begin{array}{c}\text { Extremamente } \\ \text { limitado/a }\end{array} & \begin{array}{c}\text { Muito } \\ \text { limitado/a }\end{array} & \begin{array}{c}\text { Moderadamente } \\ \text { limitado/a }\end{array} & \begin{array}{c}\text { Pouco } \\ \text { limitado/a }\end{array} & \begin{array}{c}\text { Muito } \\ \text { pouco }\end{array} & \begin{array}{c}\text { Nada } \\ \text { limitado/a }\end{array} \\ \text { limitado/a }\end{array}$




\section{ANEXO E - Escala de Ansiedade e Depressão Hospitalar - HADS}

\author{
A 1) Eu me sinto tenso ou contraído: \\ 3 ( ) a maior parte do tempo \\ 2 ( ) boa parte do tempo \\ 1 ( ) de vez em quando \\ 0 ( ) nunca
}

D 2) Eu ainda sinto gosto pelas mesmas coisas de antes:

0 ( ) sim, do mesmo jeito de antes

1 ( ) não tanto quanto antes

2 ( ) só um pouco

3 ( ) já não sinto mais prazer em nada

A 3) Eu sinto uma espécie de medo, como se alguma coisa ruim fosse acontecer:

3 ( ) sim, e de um jeito muito forte

2 ( ) sim, mas não tão forte

1 ( ) um pouco, mais isso não me preocupa

0 ( ) não sinto nada disso

D 4) Dou risada e me divirto quando vejo coisas engraçadas:

0 ( ) do mesmo jeito que antes

1 ( ) atualmente um pouco menos

2 ( ) atualmente bem menos

3 ( ) não consigo mais

\section{A 5) Estou com a cabeça cheia de} preocupações:

3 ( ) a maior parte do tempo

2 ( ) boa parte do tempo

1 ( ) de vez em quando

0 ( ) nunca

D 6) Eu me sinto alegre:
3 ( ) nunca
2 ( ) poucas vezes
1 ( ) de vez em quando
0 ( ) a maior parte do tempo

A 7) Consigo ficar sentado à vontade e me sentir relaxado:

0 ( ) sim, quase sempre

1 ( ) muitas vezes

2 ( ) poucas vezes

3 ( ) nunca

D 8) Estou lento para pensar e fazer as coisas:

\author{
3 ( ) quase sempre \\ 2 ( ) muitas vezes \\ 1 ( ) de vez em quando \\ 0 ( ) nunca
}

\section{A 9) Eu tenho uma sensação ruim de} medo, como um frio na barriga ou um aperto no estômago:

0 ( ) nunca

1 ( ) de vez em quando

2 ( ) muitas vezes

3 ( ) quase sempre

D 10) Eu perdi o interesse em cuidar da minha aparência:

3 ( ) completamente

2 ( ) não estou mais me cuidando como deveria

1 ( ) talvez não tanto quanto antes

0 ( ) me cuido do mesmo jeito que antes

A 11) Eu me sinto inquieto, como se eu não pudesse ficar parado em lugar nenhum:

3 ( ) sim, demais

2( ) bastante

1 ( ) um pouco

0 ( ) não me sinto assim

D 12) Fico esperando animado as coisas boas que estão por vir:

0 ( ) do mesmo jeito que antes

1 ( ) um pouco menos do que antes

2 ( ) bem menos do que antes

3 ( ) quase nunca

A 13) De repente, tenho a sensação de entrar em pânico:

3 ( ) a quase todo momento

2( ) várias vezes

1 ( ) de vez em quando

0 ( ) não sinto isso

D 14) Consigo sentir prazer quando assisto a um bom programa de televisão, de rádio ou quando leio alguma coisa:

0 ( ) quase sempre

1 ( ) várias vezes

2 ( ) poucas vezes

3 ( ) quase nunca 
ANEXO F - TOFHLA - short version

1) Seu médico encaminhou você para tirar um Raio $X$ de
a) estômago
b) diabetes
c) pontos
d) germes.

2) Quando vier para o

(3) você deve estar com o estômago
a) livro
b) fiel
c) raio $X$
d) dormir
a) asma
b) vazio
c) incesto
d) anemia

4) exame de Raio $X$ vai (5) de 1 a 3
a) durar
b) ver
c) falar
d) olhar
a) camas
b) cabeças
c) horas
d) dietas

A VÉSPERA DO DIA DO RAIO X:

6) No jantar, coma somente um pedaço de fruta,
a) pequeno
b) caldo
c) ataque
d) náusea

7) torradas e geléia, com ou chá.
a) lentes
b) café
c) cantar
d) pensamento

8) Após

(9) você não deve

(10) nem beber
a) o minuto
b) a meia-noite
c) durante
d) antes
a) conhecer
b) vir
c) pedir
d) comer
a) tudo
b) nada
c) cada
d) algum 
11) até o Raio X.
a) ter
b) ser
c) fazer
d) estar

NO DIA DO RAIO X:

12) Não tome
a) consulta
b) caminho
c) café da manhã
d) clínica

13) Não , (14) nem mesmo
a) dirija
b) beba
c) vista
d) dose
a) coração
b) respiração
c) água
d) câncer

15) Se você tiver alguma (16) ligue para de Raio X no n. 222- 2821.
a) resposta
b) tarefa
c) região
d) pergunta
a) o Departamento
b) Disque
c) a Farmácia
d) o Dental

17) Eu concordo em dar informações corretas para receber atendimento adequado neste hospital.
a) cabelo
b) salgar
c) poder
d) doer

18) $\mathrm{Eu}$ (19) que as informações que eu ao médico
a) compreendo
b) sondo
c) envio
d) ganho
a) provar
b) arriscar
c) cumprir
d) transmitir

(20) serão muito (21) para permitir o correto
a) proteínas
b) importantes
c) superficiais
d) numéricas
a) agudo
b) hospital
c) mioma
d) diagnóstico

22) $\mathrm{Eu}$ (23) que devo relatar para o médico qualquer nas
a) investigo
b) entretenho
c) entendo
d) estabeleço
a) alteração
b) hormônio
c) antiácido
d) custo 
24) minhas condições dentro de dias, a partir do momento
a) três
b) um
c) cinco
d) dez

25) em que me tornar da alteração.
a) honrado
b) ciente
c) longe
d) devedor

26) Eu entendo (27) se EU NÃO me ao tratamento
a) alimentar
b) isto
c) que
d) do que
a) assim
b) ocupar
c) dispensar
d) adaptar

28) tenho

(29) de

(30) uma nova consulta para o hospital.
a) brilho
b) esquerdo
c) errado
d) direito
a) solicitar
b) reciclar
c) falhar
d) reparar
a) contando
b) lendo
c) telefonando
d) observando

31) Se você (32) de ajuda para entender estas
a) lavar
b) precisar
c) cobrir
d) medir
a) instruções
b) taxas
c) hipoglicemias
d) datas

33) você deverá (34) uma enfermeira ou funcionária do Social.
a) relaxar
b) quebrar
c) aspirar
d) procurar
a) Tumor
b) Abdômem
c) Serviço
d) Adulto

35) para (36) todas as suas
a) encobrir
b) esclarecer
c) desconhecer
d) esperar
a) pélvis
b) dúvidas
c) tomografias
d) consoantes 
Cartão 1: Se você tomasse a primeira cápsula às 7:00 hs da manhã, a que horas você deveria tomar a próxima?

Cartão 2: Se essa fosse sua taxa de glicemia hoje, estaria normal?

$$
\text { Glicemia normal: } 70-99
$$

Sua glicemia hoje é de 120

Cartão 3: Se este fosse seu cartão, quando seria sua próxima consulta?

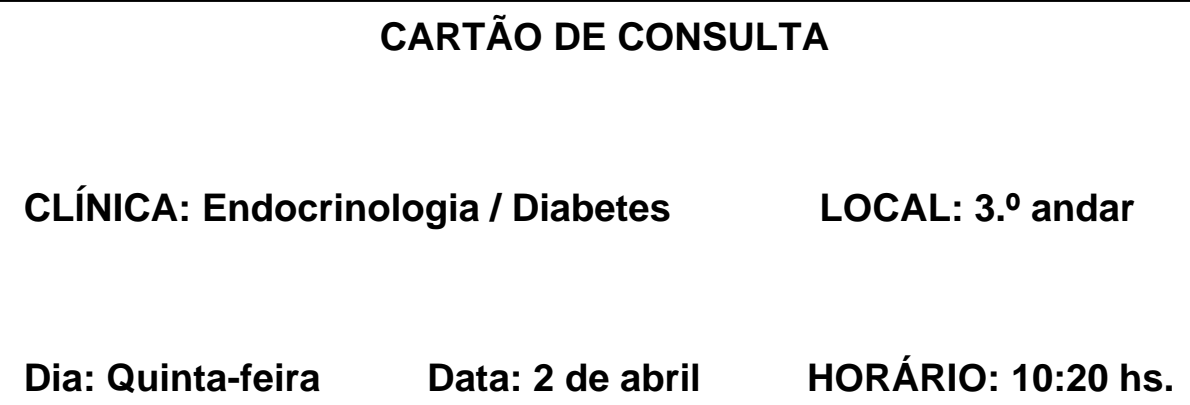

Cartão 4: Se você fosse almoçar às 12 horas, e quisesse tomar a medicação antes do almoço, a que horas você deveria tomá-la? 


\section{ANEXO G - QUESTIONÁRIO DE CONHECIMENTO}

\section{Módulo Fisiopatologia da Asma e Controle Ambiental}

1) O que você acha que tem no pulmão?

Asma ( ) Bronquite ( ) os dois ( )

2) O que é Asma para você?

( ) não sei

( ) é uma doença contagiosa

( ) é uma doença que pode pegar com o contato com o gato

( ) é uma inflamação dos brônquios

( ) é uma infecção nos pulmões

3) O que é broncoespasmo, chiado ou aperto no peito?

( ) não sei

( ) fechamento do caminho do ar nos brônquios

( ) entupimento do pulmão

( ) sujeira nos pulmões

( ) infecção nos pulmões

4) Você acha que alguém pode morrer por causa da Asma?

$\operatorname{sim}(\quad$ não ( )

5) Marque o que pode levar qualquer pessoa a ter uma crise de Asma?

\begin{tabular}{|c|c|c|c|c|c|c|}
\hline fumaça de cigarro & () & produto de limpeza & () & pêlos de animais & () & perfume \\
\hline poeira & () & mudança no tempo & () & mofo - bolo & () & poluição \\
\hline gravidez & () & emoção/raiva/tristeza & () & menstruação & () & risada \\
\hline gripe, resfriado & () & exercício & () & remédios & () & \\
\hline
\end{tabular}

6) Marque os cuidados que você deve ter com animais e com sua casa para evitar crise de Asma?

Manter a casa arejada ( ) Retirar objetos que acumulem pó （） usar acido fênico para limpar o mofo ( ) manter alimentos bem fechados ( ) usar mascara durante a limpeza ( ) banho em animais 1 vez/semana ( ) evitar de varrer a casa ( ) retirar animais de dentro casa ( ) preferência usar pano úmido ( ) não acumular lixo （ ） usar vinagre para limpar o chão ao invés de produtos com cheiro forte （ ） 


\section{Módulo Sinais e Sintomas}

7) Marque quais são os sintomas de crise de asma?

$\begin{array}{llll}\text { Tosse } & (\text { ) } & \text { falta de ar } & (\text { ) } \\ \text { Chiado } & (\quad) & \text { despertar noturno } & (\text { ) }\end{array}$

8) O que você deve fazer quando não consegue controlar uma crise de asma em casa?

$\begin{array}{lll}\text { Ir ao Pronto Socorro } & (\quad) \text { usar antibiótico } & (\quad) \\ \text { Tomar xarope } & (\quad) \text { fazer atividade física } & (\quad)\end{array}$

\section{Módulo Medicamentos e Utilização}
9) Para que servem os broncodilatadores na Asma?
( ) não sei
( ) é uma medicação para abrir os brônquios
( ) é uma medicação para melhorar a inflamação
( ) é uma medicação que acelera o coração
10) Durante uma crise de asma você deve usar?
( ) Broncodilatador
( ) Corticóide
( ) Antibiótico
( ) xarope
11) Para que servem os corticóides na Asma?
( ) não sei
( ) é uma medicação para passar a crise
( ) é uma medicação para tratar a inflamação
( ) é uma medicação que deixa a pessoa inchada

12) Você acha que o corticóide na Asma....

( ) pode fazer você ficar dependente

( ) pode fazer mal ao coração

( ) deve ser usado quando começa a crise de asma

( ) deve ser usado para prevenir as crises de asma 


\section{CHECK LIST}

Dispositivo dosimetrado Com Espaçador

Tirar a tampa do dispositivo

( )

Encaixar o espaçador

( )

Agitar o dispositivo vigorosamente

( )

Expirar até a CRF; colocar o espaçador na boca

( )

Disparar um jato

Inalar o remédio lentamente com a boca aberta

Segurar a respiração após inalar o remédio

Contar até 10 e depois expirar

Esperar até minuto para disparar outro jato

Dispositivo dosimetrado Sem espaçador

Tirar a tampa do dispositivo

( )

Agitar o spray

( )

Deixar espaço entre o dispositivo e a boca

( )

Expirar até $\mathrm{CRF}$

( )

Disparar um jato do spray

( )

Inalar o remédio lentamente com a boca aberta

( )

Segurar a respiração após inalar o remédio

( )

Contar até 10 e depois expirar

( )

Esperar até um minuto para disparar outro jato

\section{Dispositivo em pó}

Tirar a tampa do dispositivo

Colocar o dispositivo na boca

( )

Inalar o remédio com fluxo rápido e forte

( )

Segurar a respiração após inalar o remédio

( )

Contar até 10 e depois expirar

( )

Esperar até um minuto para outra dose/cápsula 
ANEXO H - Escala de Sintomas

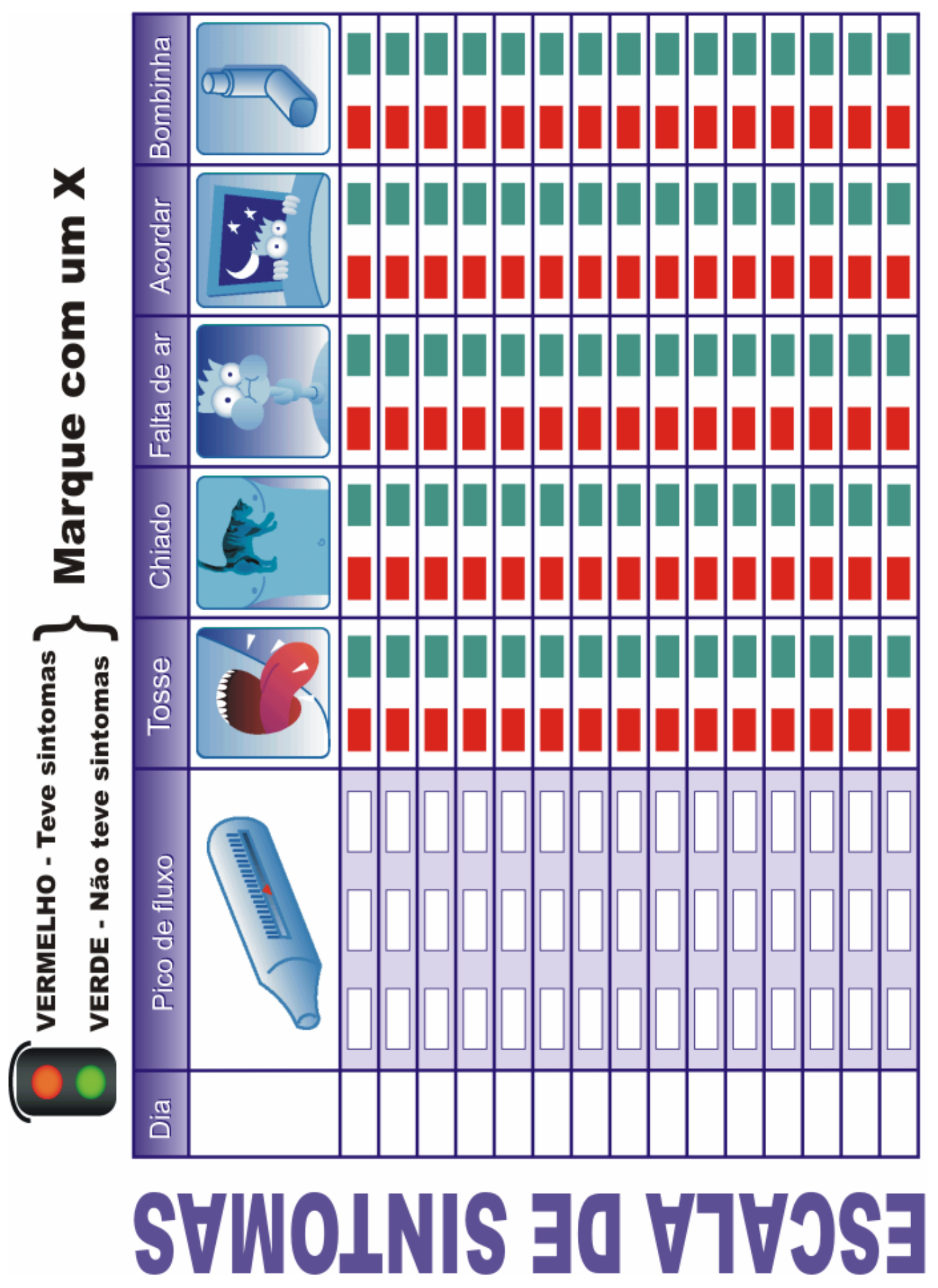


ANEXO I - Plano de Ação

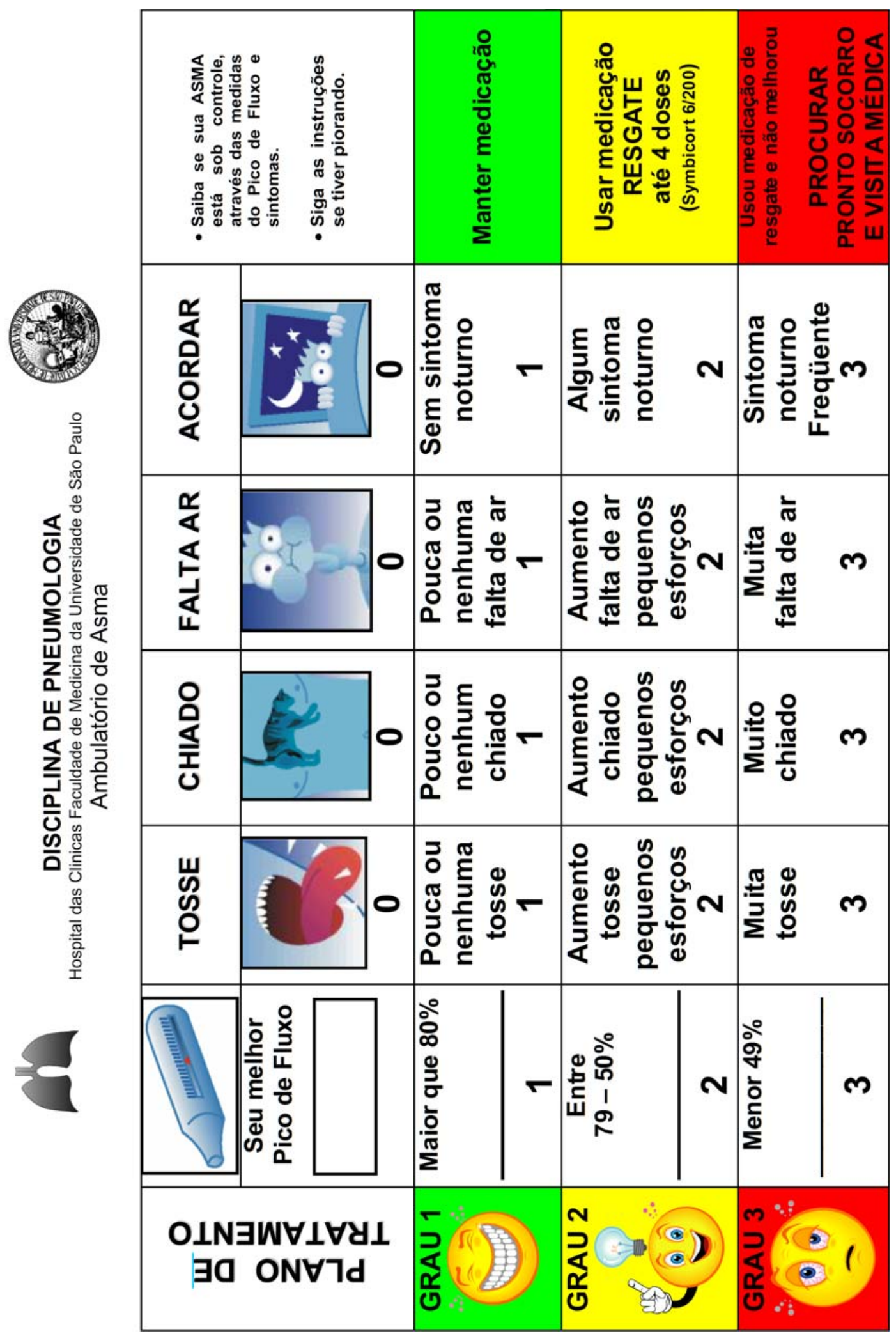


ANEXO J - Automanejo (complemento plano de ação)

\section{DISCIPLINA DE PNEUMOLOGIA}

Hospital Das Clinicas Faculdade de Medicina da Universidade de São Paulo Ambulatório de Asma

INSTRUÇÕES

\begin{tabular}{|l|c|c|}
\hline GRAU 1 & Se a soma for até 5 pontos & Manter medicação \\
\hline GRAU 2 & Se a soma for de 6 a 10 pontos & $\begin{array}{c}\text { Usar medicação RESGATE } \\
\text { até } 4 \text { doses } \\
\text { (Symbicort 6/200) }\end{array}$ \\
\hline GRAU 3 & Se a soma for acima 11 pontos & $\begin{array}{c}\text { E você já usou medicação de resgate } \\
\text { e não melhorou } \\
\text { PROCURAR PRONTO SOCORRO } \\
\text { E VISITA MÉDICA }\end{array}$ \\
\hline
\end{tabular}

\begin{tabular}{|c|c|c|c|c|c|c|}
\hline Data & $\begin{array}{c}\text { Pico de } \\
\text { Fluxo }\end{array}$ & Tosse & Chiado & Falta de ar & Acordar & Pontuação \\
\hline & & & & & & \\
\hline & & & & & & \\
\hline & & & & & & \\
\hline & & & & & & \\
\hline & & & & & & \\
\hline & & & & & & \\
\hline & & & & & & \\
\hline & & & & & & \\
\hline & & & & & & \\
\hline & & & & & & \\
\hline & & & & & & \\
\hline & & & & & & \\
\hline & & & & & & \\
\hline & & & & & & \\
\hline & & & & & & \\
\hline & & & & & & \\
\hline & & & & & & \\
\hline & & & & & & \\
\hline & & & & & & \\
\hline & & & & & & \\
\hline & & & & & & \\
\hline & & & & & & \\
\hline & & & & & & \\
\hline & & & & & & \\
\hline & & & & & & \\
\hline
\end{tabular}


ANEXO L - TCLE

HOSPITAL DAS CLÍNICAS

FACULDADE DE MEDICINA DA UNIVERSIDADE DE SÃO PAULO

TERMO DE CONSENTIMENTO LIVRE E ESCLARECIDO

(Instruções para preenchimento no verso)

\section{I - DADOS DE IDENTIFICAÇÃO DO SUJEITO DA PESQUISA OU RESPONSÁVEL LEGAL}

1. NOME DO PACIENTE.:

DOCUMENTO DE IDENTIDADE N ${ }^{\circ}$

SEXO : .M( ) F( )

DATA NASCIMENTO: ........................

ENDEREÇO

$\mathrm{N}^{\circ}$

APTO:

BAIRRO:

CIDADE

CEP:

TELEFONE: DDD

2. RESPONSÁVEL LEGAL

NATUREZA (grau de parentesco, tutor, curador etc.):

DOCUMENTO DE IDENTIDADE :

SEXO: $M() F(\quad)$

DATA NASCIMENTO.: .....................

ENDEREÇO:

$\mathrm{N}^{\circ}$

APTO:

BAIRRO:

CIDADE:

CEP: TELEFONE: DDD ( ..).

\section{II - DADOS SOBRE A PESQUISA CIENTÍFICA}

1. TÍTULO DO PROTOCOLO DE PESQUISA:

"AVALIAÇÃO DA EFICÁCIA DO AUTOMANEJO NO CONTROLE DA ASMA" PESQUISADOR: Rafael Stelmach

CARGO/FUnÇÃO: Médico Assistente

INSCRIÇÃO CONSELHO REGIONAL N 53505

UNIDADE DO HCFMUSP: Serviço de Pneumologia 
3. AVALIAÇÃO DO RISCO DA PESQUISA:

SEM RISCO

RISCO BAIXO
X RISCO MÍNIMO

RISCO MAIOR

(probabilidade de que o indivíduo sofra algum dano como conseqüência imediata ou tardia do estudo)

4.DURAÇÃO DA PESQUISA : 24 meses

\section{III - REGISTRO DAS EXPLICAÇÕES DO PESQUISADOR AO PACIENTE OU SEU REPRESENTANTE LEGAL SOBRE A PESQUISA, CONSIGNANDO:}

1. Justificativa e os objetivos da pesquisa;

Você vai participar de um programa de educação associado a um plano de tratamento em casa. Esse estudo envolve aulas e entrevistas para troca de informações e compreensão da doença, ajudando a reconhecer os sintomas, a intensidade da crise e o planejamento do esquema de tratamento. $O$ tratamento precoce através de sua colaboração é uma das melhores estratégias para evitar crises, ajudando a controlar melhor os sintomas e melhorar a qualidade de vida. A asma é uma doença crônica que não tem cura, mas tem controle se tratada adequadamente. $\mathrm{O}$ acompanhamento médico associado a uma participação ativa do paciente tende a melhorar o controle da asma e alcançar uma vida normal.

2. Procedimentos que serão utilizados e propósitos, incluindo a identificação dos procedimentos que são experimentais:

Se concordar em participar deste estudo, você será um entre 120 pacientes que estarão sendo avaliados. Este estudo tem duração de 12 meses e você deverá comparecer aproximadamente em 4 consultas como de rotina no ambulatório em conjunto com atendimento médico. A partir da sua concordância em participar do estudo, você participara:

1. Na primeira visita iremos preencher uma ficha com informações sobre sua saúde, seu histórico médico atual e anterior, informações sobre seus hábitos, ocupações profissionais, medicação utilizada para asma e para outras doenças. A partir desses dados a sua doença (a asma) será classificada quanto à gravidade em leve, moderada ou grave. Será então avaliado:

- Espirometria (exame de sopro) para avaliar a sua capacidade respiratória.

- Dosagem de monóxido de carbono: é uma substância que pode ser medida no ar que nós expiramos (eliminamos), e se encontra aumentada em pessoas que fumam, sendo a sua coleta realizada através da expiração do ar dos pulmões em um aparelho que faz a medida da substância. 
- Questionário de Controle da Asma (ACQ): são perguntas que você poderá responder para que possamos avaliar se a sua asma esta bem controlada ou não.

- Teste de alfabetização funcional para adultos na área de saúde (TOFHLA): são perguntas de entendimento sobre exames, medicações e consultas para avaliar funcionalmente a alfabetização em saúde.

- Questionário de qualidade de vida (ACQL): são perguntas sobre atividades que limitam suas atividades por ter asma, mas que são importantes para o seu dia a dia. Usado para avaliar sua qualidade de vida em relação à doença.

- Escala Hospitalar de ansiedade e depressão (HAD): são perguntas para avaliar seu estado emocional (ansiedade e depressão).

- Questionário de conhecimento: Antes e após estas aulas você terá que responder um questionário com perguntar sobre seus sintomas e conhecimento da asma.

2. Você participara de aulas com explicações sobre a sua doença (o que você tem nos pulmões), fatores que agravam a asma (para ajudar a controlar estes fatores e saber o que piora) e conhecer as medicações (para que servem e porque usar cada uma: as de crise e de controle).

3. Você vai levar para casa uma folha para anotar os sintomas todos os dias e reconhecer a intensidade da crise, monitorando através da medida do pico de fluxo e diário de sintomas durante os primeiros 15 dias e 1 mês antes do próximo retorno.

a. PICO DE FLUXO é um aparelho para medir o sopro (a velocidade de ar que sai dos pulmões).

b. DIÁRIO DE SINTOMAS é uma folha divida em colunas para você marcar com um " $X$ " como você esta se sentido (falta de ar, sensação de aperto no peito, acordar a noite, e se necessário usar bombinha de alívio).

4. Através dessa monitorização você vai receber um plano de tratamento (plano de ação): que consta de informações por escrito que vai ajudar você em casa: manter a medicação, mudar a medicação, qual medicação usar ou que fazer (procurar pronto socorro, procurar médico).

5. Por ser um estudo cientifico você poderá participar de um dos três grupos:

a. Os que continuarão em tratamento ambulatorial que já estão fazendo, sem nenhum tipo de intervenção extra;

b. Os que participarão da Educação, sem informações para modificarem a medicação;

c. Os que receberão o plano de tratamento com informações para auxiliar as crises em casa.

Em todos os casos você poderá utilizar broncodilatador para aliviar os sintomas; Você deverá trazer toda medicação em cada retorno. 
3. Desconfortos e riscos esperados;

Pico de Fluxo: Durante a manobra que mede a quantidade de ar dos pulmões pode desencadear uma crise de asma.

- Dosagem de Monóxido de Carbono: você poderá sentir alguma tontura pelo esforço de soprar o ar dos pulmões, mas que não apresenta risco.

4. Benefícios que poderão ser obtidos;

A asma é uma doença que leva desconforto para o paciente e acaba interferindo nas atividades diárias. Espera-se com estudo identificar os pacientes que não utilizam a medicação adequadamente, ou apresentem sintomas diários devido à exposição de fatores agravantes que pioram a asma e que não sabem sobre a doença e seu tratamento. A partir disso, melhorar qualidade de vida, diminuir internações, diminuir de idas ao pronto socorro, diminuir uso de corticóide oral e ajudar reconhecer melhor seus sintomas.

5. Procedimentos alternativos que possam ser vantajosos para o indivíduo;

Só uso da medicação não garante o controle total da intensidade das crises. Planos de ação que incluam educação do paciente, tratamento medicamentoso supervisionado e orientação por escrito trazem beneficio para um melhor controle da doença.

\section{IV - ESCLARECIMENTOS DADOS PELO PESQUISADOR SOBRE GARANTIAS DO SUJEITO DA PESQUISA:}

1. acesso, a qualquer tempo, às informações sobre procedimentos, riscos e benefícios relacionados à pesquisa, inclusive para dirimir eventuais dúvidas.

Sim, os pesquisadores estarão disponíveis para eventuais dúvidas todas as sextas-feiras no Ambulatório de pneumologia.

2. liberdade de retirar seu consentimento a qualquer momento e de deixar de participar do estudo, sem que isto traga prejuízo à continuidade da assistência.

Sim, obedecendo às normas legais o paciente pode interromper a participação no estudo a qualquer momento. Todos pacientes incluídos no protocolo são originados do Ambulatório de Pneumologia onde estão regularmente matriculados independentes da pesquisa.

3. salvaguarda da confidenciabilidade, sigilo e privacidade.

Sim, seguiremos as normas das "BOAS PRÁTICAS CLÍNICAS" para garantir confidenciabilidade.

4. disponibilidade de assistência no HCFMUSP, por eventuais danos à saúde, decorrentes da pesquisa.

Sim, o Serviço de Pneumologia atende todos os pacientes integralmente no 
complexo HC, 24 horas por dia/7 dias na semana.

5. viabilidade de indenização por eventuais danos à saúde decorrentes da pesquisa. Não haverá indenização. Eventuais casos de dano a saúde que tenham sido comprovadamente causado pela pesquisa (ainda que a mesma seja risco mínimo) os pesquisadores providenciaram atendimento médico necessário obedecendo as normas legais e os procedimentos estabelecidos pelo comitê de ética e pesquisa e administração - HCFMUSP.

\section{INFORMAÇÕES DE NOMES, ENDEREÇOS E TELEFONES DOS RESPONSÁVEIS PELO ACOMPANHAMENTO DA PESQUISA, PARA CONTATO EM CASO DE INTERCORRÊNCIAS CLÍNICAS E REAÇÕES ADVERSAS.}

Alberto Cukier CRM 24443 Av. Enéas de Carvalho Aguiar, 44 Serviço de Pneumologia F.: 3069-5695

Rafael Stelmach CRM 53505 Av. Enéas de Carvalho Aguiar, $2557^{\circ}$ andar - Pneumologia F.: 3069-7577

\section{OBSERVAÇÕES COMPLEMENTARES:}

\section{VII - CONSENTIMENTO PÓS-ESCLARECIDO}

Declaro que, após convenientemente esclarecido pelo pesquisador e ter entendido o que me foi explicado, consinto em participar do presente Protocolo de Pesquisa
São Paulo,
de
de 2008.

assinatura do sujeito da pesquisa ou

(Responsável legal) assinatura do pesquisador

(carimbo ou nome Legível) 
REFERÊNCIAS 


\section{REFERÊNCIAS}

1. Lemière $C$, Bai $T$, Balter $M$, Bayliff $C$, Becker $A$, Boulet LP et al. Adult asthma consensus guidelines update 2003. Can Respir J. 2004;11 (supplA):9A18A.

2. LópezViña A, del CastilloArévalo $E$. Influence of peak expiratory flow monitoring on an asthma self management education programme. Respir Med. 2000;94 (8):7606.

3. Becker A, Lemière $C$, Bérubé $D$, Boulet LP, Ducharme FM, FitzGerald $\mathrm{M}$ et al. Asthma Guidelines Working Group of the Canadian Network For Asthma Care Summary of recommendations from the Canadian Asthma Consensus Guidelines, 2003. CMAJ. 2005;173 (6): S311.

4. Global Iniciative for Asthma - GINA. Global Strategy for Asthma Management and Prevention (update 2007), 2006. [cited 2008 jun 22]. Available from: http://www.ginasthma.org.

5. Sociedade Brasileira de Pneumologia e Tisiologia. III Consenso Brasileiro no Manejo da Asma. J Pneumol. 2002; 28 (Supl 1).

6. Toelle BG, Ram FS. Written individualised management plans for asthma in children and adults. Cochrane Database Syst Rev. 2004;(2):CD002171.

7. De Oliveira MA, Faresin SM, Bruno VF, de Bittencourt AR, Fernandes AL. Evaluation of an educational programme for socially deprived asthma patients. Eur Respir J. 1999;14 (4):90814.

8. Sudre P, Jacquemet S, Uldry C, Perneger TV. Objectives, methods and content of patient education programmes for adults with asthma: systematic review of studies published between 1979 and 1998. Thorax.1999;54 (8):6817.

9. Gibson PG, Powell H. Written action plans for asthma: an evidencebased review of the key components. Thorax. 2004;59(2):94-9.

10. Put C, van den Bergh O, Lemaigre V, Demedts $M$, Verleden $G$. Evaluation of an individualised asthma programme directed at behavioural change. Eur Respir J. 2003;21(1):109-15 
11. De Oliveira MA, Muniz MT, Santos LA, Faresin SM, Fernandes AL. Custo-efetividade de programa de educação para adultos asmáticos atendidos em hospital-escola de instituição pública. J Pneumol. 2002;28(2):71-6.

12. Côté J, Cartier A, Robichaud P, Boutin H, Malo JL, Rouleau M et al. Influence of asthma education on asthma severety, quality of life and environmental control. Can Respir J. 2000 Sep-Oct;7 (5):395400.

13. Lemaigre $\mathrm{V}$, Van den Bergh $\mathrm{O}$, Van Hasselt K, De Peuter S, Victoir A, Verleden $\mathrm{G}$. Understanding participation in an asthma self-management program. Chest. 2005;128(5):3133-9.

14. Levy ML, Fletcher $M$, Price DB, Hausen T, Halbert RJ, Yawn BP. International Primary Care Respiratory Group (IPCRG) Guidelines: diagnosis of respiratory diseases in primary care. Prim Care Respir J. 2006;15(1):20-34.

15. Lozano P, Schaefer JK, Finkelstein JA, Stout J, Wagner EH, Weiss KB. Interventions to improve the management of asthma in primary care settings (Protocol for a Cochrane Review). In: The Cochrane Library, Issue 4, 2008.

16. The International Study of Asthma and Allergy in Childhood (ISSAC) Steering Committee. Worldwide variation in prevalence of asthma symptoms: The international Study of Asthma and Allergy in Childhood (ISSAC). Eur Respir J. 1998; 12:315-35.

17. National Institutes of Health/National Heart, Lung and Blood Institute, National Asthma Education and Prevention Program Expert Panel. Clinical practice guidelines: expert panel report 2-guidelines for the diagnosis and management of asthma, publication no. 97-4051. Bethesda (MD): National Institute of Health/National Heart, Lung, and Blood Institute; 1997.

18. Huang TT, Li YT, Wang CH. Individualized programme to promote selfcare among older adults with asthma: randomized controlled trial. J Adv Nurs. 2009 Feb;65(2):348-58. Epub 2008 Nov 27.

19. Haby MM, Waters E, Robertson CF, Gibson PG, Ducharme FM. Interventions for educating children who have attended the emergency room for asthma. Cochrane Database Syst Rev. 2001;(1):CD001290.

20. Nathan RA, Sorkness CA, Kosinski M, Schatz M, Li JT, Marcus P, et al. Development of the asthma control test: a survey for assessing asthma control. J Allergy Clin Immunol. 2004 Jan;113(1):59-65. 
21. Reddel H, Ware S, Marks G, Salome C, Jenkins C, Woolcock A. Differences between asthma exacerbations and poor asthma control. Lancet. 1999 Jan 30;353(9150):364-9.

22. Adams NP, Jones PW. The dose-response characteristics of inhaled corticosteroids when used to treat asthma: an overview of Cochrane systematic reviews. Respir Med 2006 Aug;100(8):1297-306.

23. Lipworth BJ. Systemic adverse effects of inhaled corticosteroid therapy: A systematic review and meta-analysis. Arch Intern Med 1999;159(9):941-55.

24. Hess DR. Metered-dose inhalers and dry powder inhalers in aerosol therapy. Respir Care. 2005 Oct;50(10):1376-83.

25. Allen SC, Ragab S. Ability to learn inhaler technique in relation to cognitive scores and tests of praxis in old age. Postgrad Med J. 2002 Jan;78(915):37-9.

26. Arshad SH. Primary prevention of asthma and allergy. J Allergy Clin Immunol. 2005 Jul;116(1):3-14; quiz 15.

27. Kilburn S, Lasserson TJ, McKean M. Pet Allergen control measures for allergic asthma in children and adults (Cochrane Review). In: The Cochrane Library, Issue 4, 2008.

28. Sheffer AL. Allergen avoidance to reduce asthma-related morbidity. $N$ Engl J Med. 2004 Sep 9;351(11):1134-6.

29. Upham JW, Holt PG. Environment and development of atopy. Curr Opin Allergy Clin Immunol. 2005 Apr;5(2):167-72.

30. Chalmers GW, Macleod KJ, Little SA, Thomson LJ, McSharry CP, Thomson NC. Influence of cigarette smoking on inhaled corticosteroid treatment in mild asthma. Thorax. 2002 Mar;57(3):226-30.

31. Lazarus SC, Chinchilli VM, Rollings NJ, Boushey HA, Cherniack R, Craig TJ, et al.; National Heart Lung and Blood Institute's Asthma Clinical Research Network. Smoking affects response to inhaled corticosteroids or leukotriene receptor antagonists in asthma. $\mathrm{Am} \mathrm{J}$ Respir Crit Care Med. 2007 Apr 15;175(8):783-90. Epub 2007 Jan 4.

32. Bateman ED, Boushey HA, Bousquet J, Busse WW, Clark TJ, Pauwels RA, Pedersen SE; GOAL Investigators Group. Can guideline-defined asthma control be achieved? The Gaining Optimal Asthma ControL study. Am J Respir Crit Care Med. 2004 Oct 15;170(8):836-44. Epub 2004 Jul 15. 
33. Szczeklik A, Nizankowska E, Bochenek G, Nagraba K, Mejza F, Swierczynska M. Safety of a specific COX-2 inhibitor in aspirin-induced asthma. Clin Exp Allergy. 2001 Feb;31(2):219-25.

34. Covar RA, Macomber BA, Szefler SJ. Medications as asthma triggers. Immunol Allergy Clin North Am. 2005 Feb;25(1):169-90.

35. Trebuchon F, Duracinsky M, Chassany O, Delaire C, Eydoux E, Longin $\mathrm{J}$, Demoly P. Validation of a questionnaire for assessment of asthma patient knowledge and behaviour. Allergy. 2009 Jan;64(1):62-71. Epub 2008 Nov 29.

36. Axelsson $M$, Emilsson $M$, Brink $E$, Lundgren $J$, Torén $K$, Lötvall J. Personality, adherence, asthma control and health-related quality of life in young adult asthmatics. Respir Med. 2009 Feb 12.

37. Janson SL, Earnest G, Wong KP, Blanc PD. Predictors of asthma medication nonadherence. Heart Lung. 2008 May-Jun;37(3):211-8.

38. Rubin BK. What does it mean when a patient says, "my asthma medication is not working?". Chest. 2004 Sep;126(3):972-81.

39. Yorke J, Fleming S, Shuldham C. Psychological interventions for children with asthma. Cochrane Database Syst Rev. 2005 Oct 19;(4):CD003272.

40. Loignon C, Bedos C, Sévigny R, Leduc N. Understanding the self-care strategies of patients with asthma. Patient Educ Couns. 2009 May;75(2):256-62. Epub 2008 Nov 28.

41. Gibson PG, Powell H, Coughlan J, Wilson AJ, Hensley MJ, Abramson M, Bauman A, Walters EH. Limited (information only) patient education programs for adults with asthma. Cochrane Database Syst Rev. 2002;(2):CD001005.

42. Jones MA. Asthma self-management patient education. Respir Care. 2008 Jun;53(6):778-84; discussion 784-6.

43. Angelini L, Robles-Ribeiro PG, Carvalho-Pinto RM, Ribeiro M, Cukier A, Stelmach R. Two-year evaluation of an educational program for adult outpatients with asthma. J Bras Pneumol. 2009 Jul; 35(7):618-27.

44. Elzen H, Slaets JP, Snijders TA, Steverink N. Evaluation of the chronic disease self-management program (CDSMP) among chronically ill older people in the Netherlands. Soc Sci Med. 2007 May;64(9):1832-41. Epub 2007 Mar 13.

45. Stelmach R, Cukier A. Uso de inaladores asma e DPOC, 2009. Disponível em: http://www.incor.usp.br. 
46. Newman SP. Inhaler treatment options in COPD. Eur Respir Rev 2005; 14(96):102-8.

47. Halterman JS, Fisher S, Conn KM, Fagnano M, Lynch K, Marky A, Szilagyi PG. Improved preventive care for asthma: a randomized trial of clinician prompting in pediatric offices. Arch Pediatr Adolesc Med. 2006 Oct;160(10):1018-25.

48. Gibson PG, Powell H, Coughlan J, Wilson AJ, Abramson M, Haywood P, Bauman A, Hensley MJ, Walters EH. Self-management education and regular practitioner review for adults with asthma. Cochrane Database Syst Rev. 2003;(1):CD001117.

49. Powell H, Gibson PG. Options for self-management education for adults with asthma. Cochrane Database Syst Rev. 2003;(1):CD004107.

50. Wolf FM, Grum CM, Clark NM. Educational interventions for asthma in adults (protocol for a Cochrane Review). Cochrane Database Syst Rev. 2008.

51. Tapp S, Lasserson TJ, Rowe B. Education interventions for adults who attend the emergency room for acute asthma. Cochrane Database Syst Rev. 2007 Jul 18;(3):CD003000.

52. Ring N, Malcolm C, Wyke S, Macgillivray S, Dixon D, Hoskins G, Pinnock $\mathrm{H}$, Sheikh A. Promoting the use of Personal Asthma Action Plans: a systematic review. Prim Care Respir J. 2007 Oct;16(5):271-83.

53. Schatz M, Mosen DM, Kosinski M, Vollmer WM, Magid DJ, O'Connor EO, Zeiger RS. Validity of the Asthma Control Test Completed at Home. Am J Manag Care 2007 Dec; 13(12): 661-7.

54. Juniper EF, Buist AS, Cox FM, Ferrie PJ, King DR. Validation of a standardized version of the Asthma Quality of Life Questionnaire. Chest. 1999 May;115(5):1265-70.

55. Botega NJ, Bio MR, Zomignani MA et al. Mood disorders among medical in-patients: a validation study of the Hospital Anxiety and Depresion scale (HAD). Rev Saude Publ. 1995; 29(5):355-63.

56. Carthery-Goulart MT, Anghinah R, Areza-Fegyveres R, Bahia VS, Brucki SM, Damin A, Formigoni AP, Frota N, Guariglia C, Jacinto AF, Kato EM, Lima EP, Mansur L, Moreira D, Nóbrega A, Porto CS, Senaha ML, Silva MN, Smid J, Souza-Talarico JN, Radanovic M, Nitrini R. Performance of a Brazilian population on the test of functional health literacy in adults. Rev Saude Publica. 2009 Aug;43(4):631-8. Epub 2009 May 29. 
57. Mehuys E, Van Bortel L, De Bolle L, Van Tongelen I, Annemans L, Remon JP, Brusselle G. Effectiveness of pharmacist intervention for asthma control improvement. Eur Respir J. 2008 Apr;31(4):790-9. Epub 2007 Dec 19.

58. Yilmaz A, Akkaya E. Evaluation of long-term efficacy of an asthma education programme in an out-patient clinic. Respir Med. 2002 Jul;96(7):519-24.

59. Dias-Júnior SA, Pinto RC, Angelini L, Fernandes FL, Cukier A, Stelmach $R$. Prevalence of active and passive smoking in a population of patients with asthma.J Bras Pneumol. 2009 Mar;35(3):261-5.

60. Santos UP, Gannam S, Abe JM, Esteves PB, Filho MF, Wakassa TB, Issa JS, Terra-Filho M, Stelmach R, Cukier A. Use of breath carbon monoxide as an indicator of smoking status. J Bras Pneumol. 2001 SetOut; 27(5):231-6.

61. Urek MC, Tudorić N, Plavec D, Urek R, Koprivc-Milenović T, Stojić M. Effect of educational programs on asthma control and quality of life in adult asthma patients. Patient Educ Couns. 2005;58(1):47-54.

62. Magar Y, Vervloet D, Steenhouwer F, Smaga S, Mechin H, Rocca Serra JP, et al. Assessment of a therapeutic education programme for asthma patients: "un souffle nouveau". Patient Educ Couns. 2005;58(1):41-6.

63. Bettencourt AR, Oliveira MA, Fernandes $A L$, Bogossian M. Educação de pacientes com asma: atuação do enfermeiro. J Pneumol. 2002;28(4):193-200.

64. Gallefoss F, Bakke PS, Rsgaard PK. Quality of life assessment after patient education in a randomized controlled study on asthma and chronic obstructive pulmonary disease. Am J Respir Crit Care Med. 1999;159(3):812-7.

65. Guevara JP, Wolf FM, Grum CM, Clark NM. Effects of educational interventions for self management of asthma in children and adolescents: systematic review and meta-analysis. BMJ. 2003;326(7402):1308-9.

66. Mühlhauser I, Richter B, Kraut D, Weske G, Worth $H$, Berger M. Evaluation of a structured treatment and teaching programme on asthma. J Intern Med. 1991;230(2):157-64. 
67. Klein JJ, Van Der Palen J, Uil SM, Zielhuis GA, Seydel ER, van Herwaarden CL. Benefit from the inclusion of self-treatment guidelines to a self-management programme for adults with asthma. Eur Respir J. 2001 Mar;17(3):386-94.

68. Clark LA, Watson D. Tripartite model of anxiety and depression: psychometric evidence and taxonomic implications. J Abnorm Psychol. 1991 Aug;100(3):316-36.

69. Kullowatz A, Kanniess F, Dahme B, Magnussen H, Ritz T. Association of depression and anxiety with health care use and quality of life in asthma patients. Respir Med. 2007 Mar;101(3):638-44. Epub 2006 Aug 7.

70. Carvalho NS, Robles-Ribeiro PG, Ribeiro M, Nunes MPT, Cukier A, Stelmach R. Comparing asthma and chronic obstructive pulmonary disease in terms of symptoms of anxiety and depression. J Bras Pneumol. 2007; 33(1):1-6.

71. Neffen H, Fritscher C, Schacht FC, Levy G, Chiarella P, Soriano JB, Mechali D; the AIRLA Survey Group. Asthma control in Latin America: The Asthma Insights and Reality in Latin America (AIRLA) survey. Rev Panam Salud Publica. 2005;17(3):191-7)

72. Canadian Lung Association. My Asthma Action Plan [Internet]. Canadá, CA. Disponível em: http://www.lung.ca/_resources/asthma_action_plan.pdf

73. Asthma Foundation of South Australia. My Asthma Action Plan [Internet]. Austrália, AU: Department of Health and Ageing; 2006. Disponível

em: http://www.asthmasa.org.au/sendfile.php/id/c12d9c0a255b990fa9fa318 8d1b778d6/name/Asthma\%20Action\%20Plan

74. National Jewish Health. My Asthma Action Plan [Internet]. Denver, CO. Disponível em: http://www.nationaljewish.org/pdf/asthma-action-plan.pdf

74. Williams MV, Baker DW, Honig EG, Lee TM, Nowlan A. Inadequate literacy is a barrier to asthma knowledge and self-care. Chest. 1998 Oct;114(4):1008-15.

75. Martinez FD, Wright AL, Taussig LM, Holberg CJ, Halonen M, Morgan WJ. Asthma and wheezing in the first six years of life. The Group Health Medical Associates. N Engl J Med. 1995 Jan 19;332(3):133-8.

76. Wolf MS, Gazmararian JA, Baker DW. Health literacy and functional health status among older adults. Arch Intern Med. 2005 Sep 26;165(17):1946-52. 
77. Williams MV, Baker DW, Parker RM, Nurss JR. Relationship of functional health literacy to patients' knowledge of their chronic disease. A study of patients with hypertension and diabetes. Arch Intern Med. 1998 Jan 26;158(2):166-72.

78. Baker DW, Williams MV, Parker RM, Gazmararian JA, Nurss J. Development of a brief test to measure functional health literacy. Patient Educ Couns. 1999 Sep;38(1):33-42.

79. Gazmararian JA, Williams MV, Peel J, Baker DW. Health literacy and knowledge of chronic disease. Patient Educ Couns. 2003 Nov;51(3):267-75.

80. Von Wagner C, Knight K, Steptoe A, Wardle J. Functional health literacy and health-promoting behaviour in a national sample of British adults. $J$ Epidemiol Community Health. 2007 Dec;61(12):1086-90. 
PUBLICAÇÃO 


\title{
Avaliação de dois anos de um programa educacional para pacientes ambulatoriais adultos com asma*
}

\author{
Two-year evaluation of an educational program \\ for adult outpatients with asthma
}

\author{
Luciene Angelini, Priscila Games Robles-Ribeiro, Regina Maria de Carvalho-Pinto, \\ Marcos Ribeiro, Alberto Cukier, Rafael Stelmach
}

\begin{abstract}
Resumo
Objetivo: Avaliar o conhecimento da doença e a melhora clínica de portadores de asma persistente moderada e grave antes e após a sua participação em um programa de educação realizado durante as visitas ambulatoriais de rotina. Métodos: Trata-se de um estudo piloto, prospectivo que envolveu 164 pacientes durante um período de dois anos. 0 programa de educação, oferecido para pequenos grupos nos dias de consulta, consistiu de aulas expositivas divididas em três módulos: fisiopatologia, controle ambiental e tratamento, incluindo o treinamento da técnica inalatória. Para a avaliação do programa, foram utilizados questionários padronizados sobre a melhora clínica e conhecimento da doença. Resultados: Em um ano, 120 pacientes completaram três visitas, e 51 pacientes foram reavaliados em dois anos. A média de idade dos pacientes foi de 44 anos, 70\% eram do sexo feminino, e 43\% tinham até oito anos de educação formal. A intervenção educacional aumentou o conhecimento da doença de forma significativa $(p<0,001)$ e possibilitou melhora clinica $(p<0,05)$ com a diminuição do uso de corticosteroide oral, redução de visitas ao serviço de emergência e menor número de faltas ao trabalho ou escola. Conclusões: 0 programa de educação expositivo oferecido durante a rotina de atendimento ambulatorial de adultos asmáticos de nosso serviço mostrou um crescente e progressivo aprendizado em longo prazo. Paralelamente, promoveu melhora clínica.
\end{abstract}

Descritores: Asma; Adulto; Educação de pacientes como assunto.

\begin{abstract}
Objective: To evaluate the understanding of asthma and the clinical improvement in patients with moderate or severe persistent asthma prior to and after their participation in an educational program presented during the routine outpatient visits. Methods: This was a prospective pilot study involving 164 patients over a two-year period. The educational program, presented to small groups on outpatient visit days, consisted of lectures divided into three parts: pathophysiology; environmental control; and treatment, including training in the inhalation technique. The program was evaluated using standardized questionnaires on clinical improvement and understanding of the disease. Results: By the end of the first year, 120 patients had completed three visits, and 51 of those patients were revaluated at the end of the second year. The mean age of the patients was 44 years, $70 \%$ were female, and $43 \%$ had up to eight years of schooling. The educational intervention significantly increased the understanding of the disease ( $p<0.001)$, and allowed greater clinical improvement $(p<0.05)$ with a decrease in the use of oral corticosteroids, fewer visits to the emergency room and fewer days missed from work or school. Conclusions: The educational program offered during the routine outpatient visits of adult patients with asthma at our clinic resulted in a progressive long-term increase in knowledge, as well as in clinical improvement.
\end{abstract}

Keywords: Asthma; Adult; Patient education as topic.

\footnotetext{
* Trabalho realizado no Instituto do Coração - INCOR - e no Grupo de Doenças Obstrutivas, Disciplina de Pneumologia, Faculdade de Medicina da Universidade de São Paulo - FMUSP - São Paulo (SP) Brasil.

Endereço para correspondência: Luciene Angelini. Rua Capepé, 58, CEP 03638-060, São Paulo, SP, Brasil.

Tel 5511 3069-7202.E-mail: lucieneangelini@usp.br

Apoio financeiro: Nenhum.

Recebido para publicação em 3/11/2008. Aprovado, após revisão, em 6/2/2009.
} 


\section{Introdução}

A educação em saúde é considerada essencial no controle da asma, ${ }^{(1)}$ por promover conhecimento, aumentar a habilidade na identificação de fatores agravantes e desencadeantes e melhorar a aderência a seu tratamento..$^{(2,3)}$

Embora as diretrizes para a terapêutica da asma incluam a implantação de programas de educação e manejo para melhorar a qualidade de assistência em asma, ${ }^{(4,5)} \mathrm{O}$ impacto no controle clínico de longo prazo de pacientes adultos não está claramente determinado. ${ }^{(6)}$ Metas para o controle nem sempre são atingidas, e a ausência de padronização sobre os requisitos mínimos para esses programas ocasiona desacordos entre autores na validação do melhor modelo de educação. ${ }^{(3)}$ Fatores associados à estruturação dos programas, às medidas de aderência, aos desfechos encontrados e às características dos pacientes são apontados como responsáveis por resultados díspares em diferentes estudos. ${ }^{(7,8)}$

Programas que incluam educação, automonitorização, avaliações regulares e manejo com planos de ação escritos são efetivos na redução de visitas ao serviço de emergência, do número de hospitalizações em até $2 / 3$, de consultas médicas não agendadas, da perda de dias de trabalho e de despertares noturnos. Até o momento, programas denominados estruturados resultam em desfechos melhores, maior repercussão clínica e parecem proporcionar maior benefício quando direcionados a pacientes com asma moderada ou grave, especialmente para aqueles com alto índice de comorbidades. ${ }^{(3,9)}$

Programas estruturados são realizados por longos períodos, para pequenos grupos, administrados por educadores treinados e utilizando formas verbais, escritas, visuais e/ou auditivas para transmitir conhecimento. ${ }^{(10)}$ Incluem, ainda, treinamento para o manejo baseado na automonitorização e no plano de ação por escrito, individualizado,associado à visita médica regular. ${ }^{(11,12)}$

A efetividade dos programas de educação depende de aspectos ambientais e sociais. Em geral, a administração de programas sequenciais de educação por longo período é limitada por falta de infraestrutura, principalmente de recursos humanos, e pela dificuldade de manter o seguimento do paciente. A participação em programas de educação em asma é baixa, o que dificulta sua implantação em larga escala e diminui sua eficiência. ${ }^{(8,13)} 0$ maior número de barreiras estruturais, como falta de tempo, de recursos financeiros, o fato de morar longe e a necessidade de retornos frequentes ao serviço de saúde diminui em quase 12 vezes a possibilidade de um paciente participar de um programa de educação. ${ }^{(13)}$

Por ser necessário adequar o programa de educação à realidade do serviço e disponibilizar o paciente para seu sucesso, este estudo baseia-se na hipótese de que implantar um trabalho de educação, realizado durante 0 atendimento médico ambulatorial de pacientes asmáticos, permite a melhora clínica de portadores de asma persistente moderada e grave.

0 objetivo principal foi avaliar o conhecimento de conceitos relativos à fisiopatologia, ao controle ambiental e ao tratamento de asma antes e após a aplicação de um programa de educação não-estruturado, acoplado ao atendimento médico ambulatorial. Adicionalmente, mediram-se os resultados desse programa com a melhora clinica dos pacientes.

\section{Métodos}

Trata-se de um estudo prospectivo realizado no ambulatório de asma de um hospital universitário terciário, previamente aprovado pela comissão de ética local. Este foi um estudo piloto para implantar o serviço de atendimento multidisciplinar ao paciente asmático. Os critérios de inclusão utilizados foram pacientes com diagnóstico de asma persistente moderada e grave, de acordo com os critérios do Global Initiative for Asthma de 2002, ${ }^{(14)} \mathrm{em}$ acompanhamento ambulatorial por, no mínimo, dois anos e tratamento medicamentoso regular (corticoide inalatório e broncodilatador de ação prolongada) por, no mínimo, 3 meses. Aqueles que aceitaram voluntariamente participar do estudo assinaram o termo de consentimento livre e esclarecido e foram submetidos ao programa de educação em visitas médicas subsequentes, agendadas de acordo com a rotina do ambulatório e/ou conforme a instabilidade clínica.

0 programa de educação consistiu de aulas expositivas (por meio de cartazes), ministradas a grupos de 7 a 10 pacientes. 0 programa foi realizado em módulos de uma hora, antes e após as consultas médicas, com duração total de duas horas. Na pré-consulta, foram ministrados os módulos de fisiopatologia e controle ambiental, 
focando informações conceituais sobre a doença e fatores desencadeantes, respectivamente. $\mathrm{Na}$ pós-consulta, foi ministrado o módulo tratamento, com informações sobre o tratamento medicamentoso e o treinamento da técnica inalatória.

Os pacientes foram avaliados a partir de um questionário padronizado, aplicado antes e após a participação no programa. Esse questionário era constituído de quatro questões qualitativas sobre fisiopatologia (sim/não); cinco questões sobre controle ambiental, sendo três questões qualitativas (sim/não), um checklist composto por 15 fatores desencadeantes/irritantes e uma escala analógica demarcada de 0 a 100 ; e cinco questões sobre tratamento, sendo quatro questões quantitativas (sim/não) e dois checklists da técnica inalatória, com e sem espaçador. Os questionários eram autoaplicáveis, exceto para pacientes não-alfabetizados. A melhora clínica referia-se ao mês anterior à consulta médica e considerada pelo número de dias em uso de corticoide oral, número de visitas à unidade de emergência e número de dias em que não foi possível realizar atividades de vida diária, trabalho e/ou lazer devido à asma. A estrutura do programa de educação, melhora clínica e o questionário de avaliação (Anexo 1) foram elaborados por uma equipe multidisciplinar formada por médicos pneumologistas, médicos alergistas,

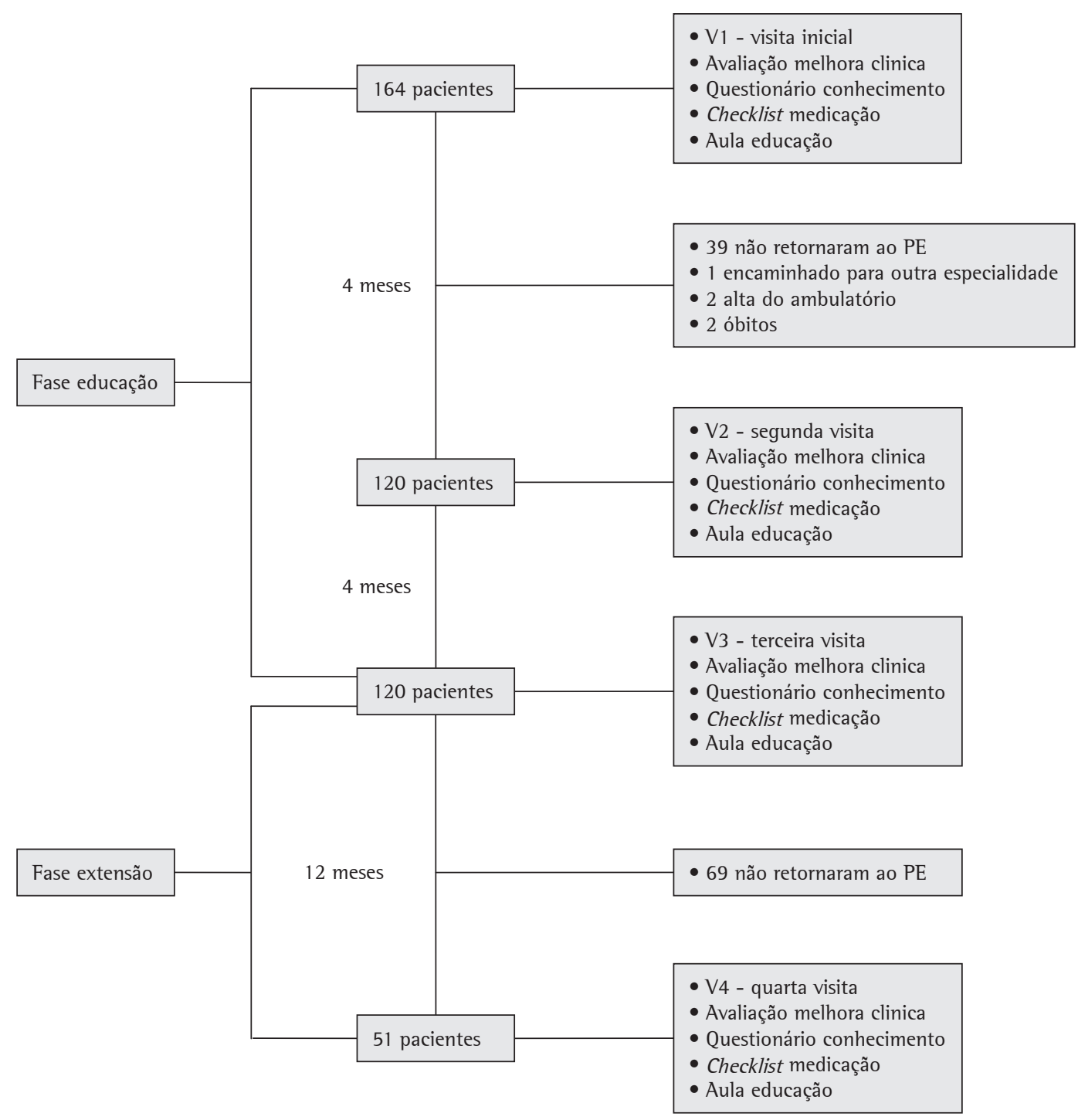

Figura 1 - Algoritmo. PE: Programa de educação. 
Tabela 1 - Dados demográficos dos pacientes que participaram do programa de educação, divididos por fase.

\begin{tabular}{lccc}
\hline \multicolumn{1}{c}{ Variáveis } & $\begin{array}{c}\text { Programa de } \\
\text { educação integral }\end{array}$ & $\begin{array}{c}\text { Fase de } \\
\text { educação }\end{array}$ & $\begin{array}{c}\text { Fase de } \\
\text { extensão }\end{array}$ \\
\cline { 2 - 4 } & $(\mathrm{n}=120)$ & $(\mathrm{n}=69)$ & $(\mathrm{n}=51)$ \\
\hline Sexo, F/M & $84 / 36$ & $48 / 21$ & $36 / 15$ \\
ldade, anos (média $\pm \mathrm{dp})$ & $44 \pm 16$ & $43 \pm 16$ & $46 \pm 16$ \\
Escolaridade, \% & & & \\
$\quad$ Não-alfabetizados & 1 & 1 & 0 \\
Até 4 anos & 29 & 19 & 3 \\
Até 8 anos & 43 & 48 & 40 \\
Até 11 anos & 22 & 20 & 1 \\
$>11$ anos & 6 & 8 & 2 \\
\hline
\end{tabular}

médicos clínicos gerais e fisioterapeutas respiratórios, sendo estes últimos os responsáveis por sua aplicação.

Após a visita inicial (V1), os pacientes retornaram para mais duas consultas médicas, sendo submetidos ao mesmo procedimento e avaliados pelo mesmo questionário de conhecimento. Esse período correspondia à primeira parte da pesquisa, chamada fase de educação.

$\mathrm{Na}$ terceira visita (V3), os pacientes receberam alta temporária do programa de educação e continuaram com o acompanhamento médico ambulatorial de rotina. Após um período de aproximadamente 12 meses, foram convocados para uma reavaliação (quarta visita; V4) e submetidos uma última vez ao programa de educação. Essa fase sequencial foi considerada fase de extensão.

Durante todo o período do estudo, incluindo a fase de extensão, os pacientes tiveram o tratamento medicamentoso ajustado pelo médico assistente de acordo com o grau de melhora clínica da asma.

Os resultados dos questionários de conhecimento preenchidos após as visitas $(\mathrm{V} 1, \mathrm{~V} 2, \mathrm{~V} 3 \mathrm{e}$ V4) foram submetidos à ANOVA para medidas repetidas, descritos em porcentagem média de acertos e apresentados graficamente na forma de probabilidade complementar. ${ }^{(15)}$ A avaliação da melhora clínica foi submetida à ANOVA de comparação múltipla e apresentada em média e desvio-padrão. ${ }^{(16)}$ Considerou-se significante um valor com $p<0,05$.

\section{Resultados}

Foram selecionados 164 pacientes, correspondendo aproximadamente a 15\% dos pacientes registrados no ambulatório de asma, durante um período de 24 meses (Figura 1). Destes, 39 pacientes (23\%) não retornaram ao programa de educação, 1 paciente foi encaminhado para atendimento em outra especialidade, 2 obtiveram alta do ambulatório e 2 evoluíram a óbito no início do estudo. Dessa forma, 120 pacientes (73\%) foram submetidos à fase de educação (três visitas), e 51 (31\%) retornaram para a reavaliação na fase de extensão, completando o total de quatro visitas do programa. A média de idade foi de 44 anos (variação, 14-82), sendo que 84 pacientes (70\%) eram do sexo feminino e 36 (30\%), do sexo masculino. Não houve diferenças em relação ao sexo, idade e escolaridade entre os pacientes que completaram o programa de educação (Tabela 1). A maioria dos pacientes (43\%) possuía até 8 anos de educação formal. Durante a fase de educação, o intervalo entre

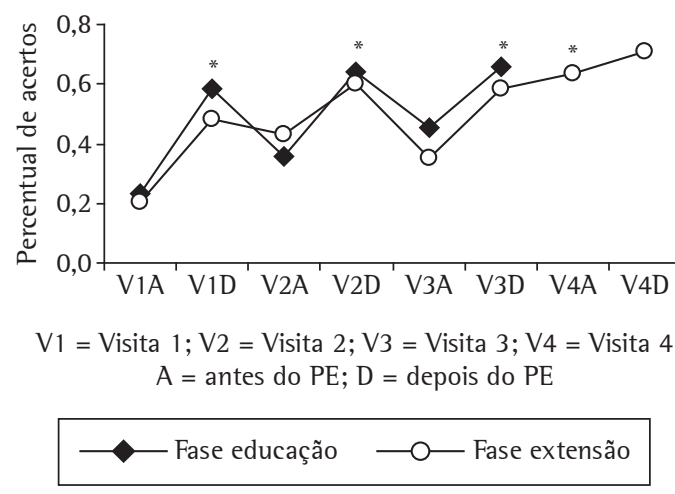

Figura 2 - Grau de conhecimento dos pacientes (\% de acertos) ao longo do estudo em dois momentos. Fase de educação $(n=120)$ em três visitas, e na fase de extensão $(n=51)$ após um período de 12 meses para reavaliação (quatro visitas). Probabilidade complementar. PE: programa de educação. 


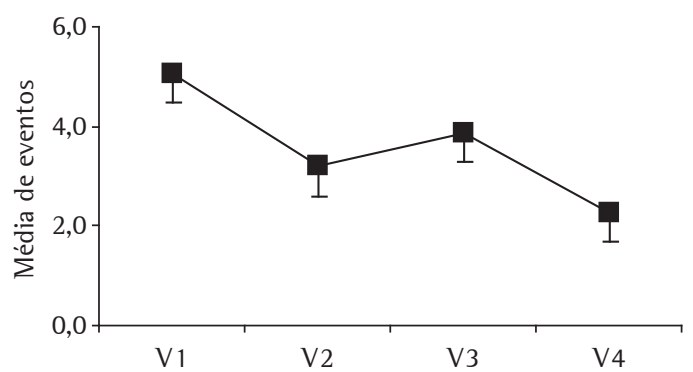

V1 = Visita 1 ; V2 = Visita 2; V3 = Visita 3; V4 = Visita 4

$$
\text { - } 51 \text { pacientes }
$$

Figura 3 - Melhora clínica dos pacientes ao longo do estudo ( $n=51)$. Média de dias em uso de corticoide oral + número de visitas à unidade de emergência + perda de atividade diária/trabalho/lazer devido à asma.

as visitas foi de 4 meses e, na fase de extensão, o intervalo (entre V3 e V4) foi de 12 meses, aproximadamente.

A Figura 2 mostra os resultados do questionário de conhecimento aplicado ao longo do tempo nas duas fases. Na fase de educação, 120 pacientes completaram três visitas, e os resultados demonstram que, mesmo em acompanhamento ambulatorial há alguns anos, os pacientes apresentaram grande carência de informações sobre a asma antes da aplicação do programa de educação (V1). Depois de ministrado o programa pela primeira vez, esses valores aumentaram significativamente de 0,23 para $0,58(p<0,001)$.

Após 4 meses (V2), observou-se uma queda não-significativa para 0,36 antes da aplicação do programa em relação aos valores atingidos pelos pacientes no final da V1. Entretanto, quando as informações do programa foram retransmitidas (V2), observou-se novamente um aumento dos valores para 0,64 . Passados mais 4 meses (V3), a porcentagem de respostas certas voltou a diminuir para 0,45 em relação aos valores atingidos ao final da V2, sem significância estatística. Todavia, ao ser submetido ao programa de educação na V3, a porcentagem de acertos voltou a atingir valores semelhantes $(0,66)$ aos obtidos no final da V1 e V2. Ao analisar a porcentagem de acertos após V1 e após V3, encontrou-se um aumento significante para todos os módulos: de 0,58 para $0,66(p<0,001)$. A porcentagem de acertos foi maior após aplicação do programa de educação em todas as visitas, e a queda nãosignificativa na porcentagem de acertos antes do programa na V2 e na V3 sugere uma fixação progressiva no processo de conhecimento.

A Figura 2 também mostra o resultado do questionário de conhecimento de 51 pacientes que foram reavaliados na fase extensão (V4). Os resultados mostram que a aquisição de conhecimento, em cada visita neste grupo, foi semelhante nos 120 pacientes, confirmando não haver diferença entre os grupos para as variáveis do estudo. Assim, ao analisar a porcentagem de acertos entre $\mathrm{V} 1 \mathrm{e} V 4$, encontrou-se um aumento significante de 0,48 para $0,63(p<0,001)$, indicando que os pacientes mantêm o conhecimento adquirido após um período de 12 meses, e que todo o grupo se comporta da mesma maneira a longo prazo.

$\mathrm{Na}$ Figura 3 são mostrados os resultados referentes à melhora clínica dos 51 pacientes. Analisando o mês anterior a cada visita, observou-se significativa diminuição de procura ao serviço de emergência, de uso de curso de corticoide oral e de faltas no trabalho e/ou escola de V1 para V2 $(5,06 \pm 0,44$ vs. $3,19 \pm 0,34$; $p<0,05$ ), estabilidade entre V2 e V3, além de nova redução significativa de V3 para V4 (de $3,86 \pm 0,39$ vs. $2,27 \pm 0,47 ; p<0,05)$.

\section{Discussão}

Este estudo demonstrou que um programa de educação expositivo, realizado no mesmo dia das consultas médicas agendadas em um hospital terciário, aumentou o conhecimento sobre a doença de forma significativa e possibilitou a melhora clínica de uma população de asmáticos moderados e graves. Realizado em pequenos grupos, com informações verbais, visuais e auditivas, e com aulas de reforço no período de quase 2 anos, proporcionou a fixação de conhecimento. 0 domínio individual para identificar sinais e sintomas de deterioração da asma e retomá-lo, advindo do programa de educação, beneficiou os pacientes, reduziu as visitas aos serviços de emergência e a utilização de corticoides orais e diminuiu a perda de dias de trabalho/escola e lazer em consequência da asma.

Programas de educação em saúde podem ser pontuais (curtos) ou longos. ${ }^{(17)}$ Programas de curto prazo têm como objetivo avaliar o conhe- 
cimento imediato, baseado nas orientações e na avaliação informal do processo de aprendizado, sem reforço e sem acompanhamento médico. ${ }^{(17)}$ Pudemos evidenciar que os pacientes do nosso estudo guardavam as informações adquiridas no dia da intervenção, mas não as fixavam para a consulta seguinte. Apresentavam aparente resistência em assimilar as informações em um curto espaço de tempo. A repetição das intervenções, mesmo em intervalos de meses, trouxe os resultados esperados, semelhantes aos encontrados em outro estudo no Brasil. ${ }^{(18)}$ Dois autores ${ }^{(19)}$ relataram que o programa de educação de longo prazo, realizado em ambulatório, tem impacto positivo sobre a morbidade da asma. Esse impacto pode ser ocasionado por uma variedade de fatores, como a aquisição de conhecimento, a compreensão da terapia medicamentosa e uma maior atenção da equipe médica aos pacientes. ${ }^{(7,20)} 0$ acoplamento do programa de educação à rotina de atendimento influenciou a tomada de decisão frente à doença, resultando em maior aderência ao tratamento e, consequentemente, em melhora clínica.

Cabe ressaltar que o programa realizado com nossos pacientes diferiu do que tradicionalmente se define como programa estruturado, por não termos utilizado a automonitorização e a automanejo da terapia medicamentosa. Segundo alguns autores, ${ }^{(21)}$ programas de educação estruturados encorajam o paciente a assumir uma maior responsabilidade no manejo da doença, resultando em aumento de aderência ao tratamento e em redução na morbidade da asma. A utilização da automonitorização, por meio de diários de sintomas ou PFE, e do automanejo do tratamento gera controvérsias. Uma revisão ${ }^{(22)}$ mostrou que a adequação do tratamento pelo médico assistente de forma sequencial foi igualmente eficaz. A ausência desses componentes na estrutura do programa aplicado, entretanto, não impediu que ocorresse um incremento no conhecimento e na melhora clínica da asma, semelhante aos resultados observados em estudos controlados e aleatorizados. Outros autores, ${ }^{(23)}$ estudando asmáticos moderados com três tipos de intervenção distintos (informações verbais individuais, informações por escrito e aulas sobre asma), encontraram um conhecimento melhor da doença no grupo que recebera as aulas e semelhante melhora de sintomas em todos os grupos. Por outro lado, em um programa estruturado aplicado a 127 pacientes asmáticos adultos, controlados em relação a 111 pacientes que não o receberam, mostrou uma melhora significativa no número de dias livres de sintomas e na redução do uso de corticoide oral no grupo sob intervenção. ${ }^{(24)}$

Nas duas maiores revisões sistemáticas sobre intervenções educacionais para o automanejo da asma, realizadas nos últimos anos, em crianças/ adolescentes e adultos, ${ }^{(25,26)}$ fica claro que quanto mais completo e individualizado for o programa de educação, maior será sua efetividade sobre as medidas de morbidade.

0 presente estudo possui limitações; entre elas, a ausência de um grupo controle. Não há dúvida que isso enfraquece o poder do trabalho; porém, como se tratou de um estudo piloto de longo prazo, como especificado anteriormente, envolvendo um alto número de pacientes, optou-se por adicionar voluntários, minimizando, assim, a perda progressiva de pacientes incluídos. A estratégia foi parcialmente bem sucedida uma vez que 73\% dos selecionados terminaram a primeira fase, e $42 \%$ dos incluídos terminaram a fase de extensão. Outra limitação refere-se às formas de avaliação da melhora clínica e à utilização de um questionário próprio para avaliar o conhecimento e a técnica adequada para usar a medicação. Também não foram utilizados instrumentos para avaliar a qualidade de vida relacionada à saúde, aspectos psicológicos e $\operatorname{cognitivos}^{(12,27,28)}$ e comportamento psicossocial. $^{(29)}$

Aparentemente, não há consenso sobre o melhor instrumento de avaliação dos programas de educação, uma vez que esses são delineados por princípios metodológicos específicos, e seus resultados não apresentam parâmetros pelos quais podemos afirmar que conseguiram atingir os objetivos conceituais. ${ }^{(8)}$ Diferentes modelos de intervenção são descritos pelos pesquisadores, baseados na população estudada e na sua caracterização, respeitando diferenças socioeconômicas e culturais. ${ }^{(3)}$ Neste estudo, o programa de educação, assim como o questionário utilizado para sua avaliação, foi elaborado após uma ampla discussão pela equipe multidisciplinar que atende os pacientes. As adequações no módulo de controle ambiental, por exemplo, procuraram especificar fatores desencadeantes e irritantes locais. Da mesma forma, a adequação da linguagem padrão utilizada na relação direta 
com o paciente é considerada fundamental para o sucesso da intervenção realizada. Como estabelecido na literatura, bons resultados são obtidos pela comunicação adequada entre educador, médico, paciente e seus familiares. ${ }^{(30)}$ Estudos de revisã $0^{(3)}$ apontaram, como medidas mais comumente utilizadas para avaliar 0 controle clínico, a dose da medicação de manutenção, da medicação de resgate e de corticoide oral; a necessidade de visitas em unidade de emergência; o número de hospitalizações; o absenteísmo escolar e no trabalho; e o diário de sintomas, entre outros. Apesar de não utilizar um diário de sintomas ou uma avaliação seriada do PFE, o programa de educação deste estudo correlacionou-se a um índice menor de limitação nas atividades diárias (absenteísmo do trabalho, escola ou lazer), a um menor número de dias de uso de corticoide oral e menos idas ao serviço de emergência. Alguns autores ${ }^{(10)}$ demonstraram que a procura ao serviço de emergência e o curso de corticoide oral não significam somente gastos adicionais com a medicação, mas estão relacionados ao aumento do número de hospitalizações e, consequentemente, da mortalidade. Mais do que o grau de escolaridade, fatores relacionados à compreensão das informações recebidas e dúvidas quanto ao benefício do programa de educação são mais importantes no comportamento do paciente. ${ }^{(13)}$

0 programa de educação é um componente essencial para o manejo da asma e deveria ser aplicado a todos os pacientes, mas parece ter maior benefício para aqueles com asma grave ou para portadores de comorbidades associadas à asma. ${ }^{(1)}$ Faz-se necessário simplificar e aperfeiçoar os tipos de programa e seus objetivos, assim como avaliar adequadamente seus desfechos. (7) 0 real impacto do programa de educação na evolução dos pacientes ainda não está definido, mas esse deve, além de incrementar o conhecimento, também modificar o comportamento frente à doença. A intervenção educacional expositiva na rotina de atendimento de adultos asmáticos de nosso serviço mostrou um crescente e progressivo aprendizado dos conceitos sobre a fisiopatologia da asma, o controle ambiental e seu tratamento em longo prazo. Paralelamente, o programa ampliou a melhora clínica da asma destes pacientes. Os resultados obtidos podem contribuir para o conhecimento do assunto devido à importância da adequação dos programas de educação de asmáticos às realidades locais.

\section{Referências}

1. Lemière C, Bai T, Balter M, Bayliff C, Becker A, Boulet LP, et al. Adult Asthma Consensus Guidelines Update 2003. Can Respir J. 2004;11(Suppl A):9A-18A.

2. López-Viña A, del Castillo-Arévalo E. Influence of peak expiratory flow monitoring on an asthma selfmanagement education programme. Respir Med. 2000;94(8):760-6.

3. Becker A, Lemière C, Bérubé D, Boulet LP, Ducharme FM, FitzGerald M, et al. Summary of recommendations from the Canadian Asthma Consensus guidelines, 2003. CMAJ. 2005;173(6 Suppl):S3-11.

4. Global Iniciative for Asthma. Global Strategy for Asthma Management and Prevention: update 2007. Bethesda: National Institutes of Health, National Heart, Lung, and Blood Institute; 2006.

5. Sociedade Brasileira de Pneumologia e Tisiologia. 111 Consenso Brasileiro no Manejo da Asma. J Bras Pneumol. 2002;28(Suppl 1):S8-S51.

6. Toelle BG, Ram FS. Written individualised management plans for asthma in children and adults. Cochrane Database Syst Rev. 2004;(2):CD002171.

7. de Oliveira MA, Faresin SM, Bruno VF, de Bittencourt AR, Fernandes AL. Evaluation of an educational programme for socially deprived asthma patients. Eur Respir J. 1999;14(4):908-14.

8. Sudre P, Jacquemet S, Uldry C, Perneger TV. Objectives, methods and content of patient education programmes for adults with asthma: systematic review of studies published between 1979 and 1998. Thorax. 1999;54(8):681-7.

9. Côté J, Cartier A, Robichaud P, Boutin H, Malo JL, Rouleau M, et al. Influence of asthma education on asthma severity, quality of life and environmental control. Can Respir J. 2000;7(5):395-400.

10 .De Oliveira MA, Muniz MT, Santos LA, Faresin SM, Fernandes AL. Custo-efetividade de programa de educação para adultos asmáticos atendidos em hospital-escola de instituição pública. J Pneumol. 2002;28(2):71-6.

11. Gibson PG, Powell H. Written action plans for asthma: an evidence-based review of the key components. Thorax. 2004;59(2):94-9.

12. Put C, van den Bergh O, Lemaigre V, Demedts M, Verleden G. Evaluation of an individualised asthma programme directed at behavioural change. Eur Respir J. 2003;21(1):109-15.

13. Lemaigre V, Van den Bergh 0, Van Hasselt K, De Peuter S, Victoir A, Verleden G. Understanding participation in an asthma self-management program. Chest. 2005;128(5):3133-9.

14. Global Iniciative for Asthma. Global Strategy for Asthma Management and Prevention. Bethesda: National Institutes of Health, National Heart, Lung, and Blood Institute; 2002.

15. Jaynes ET, Bretthorst GL, editors. Probability theory: the logic of science. Cambridge: Cambridge University Press; 2003.

16. Brunner E, Langer F. Nonparametric analysis of ordered categorical data in designs with longitudinal 
observations and small sample sizes. Biometrical J. 2000;42(6):663-76.

17. Melles AM, Zago MM. Análise da educação de clientes/ pacientes na literatura brasileira de enfermagem. Rev Lat Am Enfermagem. 1999;7(5):85-94.

18. Bettencourt AR, Oliveira MA, Fernandes AL, Bogossian M. Educação de pacientes com asma: atuação do enfermeiro. J Pneumol. 2002;28(4):193-200.

19. Yilmaz A, Akkaya E. Evaluation of long-term efficacy of an asthma education programme in an out-patient clinic. Respir Med. 2002;96(7):519-24.

20. Gallefoss F, Bakke PS, Rsgaard PK. Quality of life assessment after patient education in a randomized controlled study on asthma and chronic obstructive pulmonary disease. Am J Respir Crit Care Med. 1999;159(3):812-7.

21. Mühlhauser I, Richter B, Kraut D, Weske G, Worth $\mathrm{H}$, Berger M. Evaluation of a structured treatment and teaching programme on asthma. J Intern Med. 1991;230(2):157-64

22. Powell H, Gibson PG. Options for self-management education for adults with asthma. Cochrane Database Syst Rev. 2003;(1):CD004107.

23. Urek MC, Tudorić N, Plavec D, Urek R, Koprivc-Milenović T, Stojić M. Effect of educational programs on asthma control and quality of life in adult asthma patients. Patient Educ Couns. 2005;58(1):47-54.
24. Magar Y, Vervloet D, Steenhouwer F, Smaga S, Mechin $\mathrm{H}$, Rocca Serra JP, et al. Assessment of a therapeutic education programme for asthma patients: "un souffle nouveau". Patient Educ Couns. 2005;58(1):41-6.

25. Guevara JP, Wolf FM, Grum CM, Clark NM. Effects of educational interventions for self management of asthma in children and adolescents: systematic review and meta-analysis. BMJ. 2003;326(7402):1308-9.

26. Gibson PG, Powell H, Coughlan J, Wilson AJ, Abramson M, Haywood P, et al. Self-management education and regular practitioner review for adults with asthma. Cochrane Database Syst Rev. 2003;(1):CD001117.

27. Thoonen BP, Schermer TR, Van Den Boom G, Molema J, Folgering H, Akkermans RP, et al. Self-management of asthma in general practice, asthma control and quality of life: a randomised controlled trial. Thorax. 2003;58(1):30-6.

28. Mehuys E, Van Bortel L, De Bolle L, Van Tongelen I, Annemans L, Remon JP, et al. Effectiveness of pharmacist intervention for asthma control improvement. Eur Respir J. 2008;31(4):790-9.

29. Costa MR, Oliveira MA, Santoro IL, Juliano Y, Pinto JR, Fernandes AL. Educational camp for children with asthma. J Bras Pneumol. 2008;34(4):191-5.

30. Brown R, Bratton SL, Cabana MD, Kaciroti N, Clark NM. Physician asthma education program improves outcomes for children of low-income families. Chest. 2004;126(2):369-74.

\section{Sobre os autores}

\section{Luciene Angelini}

Pós Graduanda de Mestrado em Ciências da Saúde. Disciplina de Fisiopatologia Experimental, Faculdade de Medicina da Universidade de São Paulo - FMUSP - São Paulo (SP) Brasil.

\section{Priscila Games Robles-Ribeiro}

Mestre em Ciências da Saúde. Disciplina de Fisiopatologia Experimental, Faculdade de Medicina da Universidade de São Paulo FMUSP - São Paulo (SP) Brasil.

\section{Regina Maria de Carvalho-Pinto}

Médica Assistente. Instituto do Coração - INCOR - Faculdade de Medicina da Universidade de São Paulo - FMUSP - São Paulo (SP) Brasil.

\section{Marcos Ribeiro}

Médico Pneumologista. Instituto do Coração - INCOR - Faculdade de Medicina da Universidade de São Paulo - FMUSP - São Paulo (SP) Brasil.

\section{Alberto Cukier}

Professor Colaborador. Instituto do Coração - INCOR - Faculdade de Medicina da Universidade de São Paulo - FMUSP - São Paulo (SP) Brasil.

\section{Rafael Stelmach}

Professor Colaborador. Instituto do Coração - INCOR - Faculdade de Medicina da Universidade de São Paulo - FMUSP - São Paulo (SP) Brasil. 
Anexo 1 - Questionário de melhora clínica e avaliação do grau de conhecimento.

Avaliação da melhora clínica

Quantas vezes precisou ir ao Pronto Socorro no último mês por causa da asma?

0 ( ) 1 ( ) 2 ( ) 3 ( ) 4 ( ) mais que 4 vezes ( )

Quantos dias precisou tomar corticoide em comprimido no último mês, por exemplo, Meticorten/Prednisona?

0 ( ) 1 ( ) 2 ( ) 3 ( ) 4 ( ) mais que 4 vezes ( )

Quantas vezes não conseguiu ir ao trabalho, ou à escola ou fazer as atividades de casa no último mês por causa da asma?

0 ( ) 1 ( ) 2 ( ) 3 ( ) 4 ( ) mais que 4 vezes ( )

Questionário de conhecimento pré-consulta

Fisiopatologia e controle ambiental

0 que você acha que tem no pulmão?

Asma ( ) Bronquite ( ) Os dois ( )

0 que é asma para você?

( ) não sei

( ) é uma doença contagiosa

( ) é uma doença que pode pegar em contato com o gato

( ) é uma inflamação dos brônquios

( ) é uma infecção nos brônquios

0 que é broncoespasmo, quando você está chiando ou sente aperto no peito?

( ) não sei

( ) fechamento do caminho do ar nos brônquios

( ) entupimento do pulmão

( ) sujeira nos pulmões

( ) infecção nos pulmões

Você acha que alguém pode morrer por causa da asma?

Sim ( ) Não ( )

Marque o que poderia levar qualquer pessoa a ter uma crise de asma:

fumaça de cigarro ( ) produto de limpeza ( ) pelos de animais ( )

perfume/cheiro forte ( ) poeira e/ou poluição ( ) mudança no tempo ( )

mofo/bolor ( ) alimentos ( ) gravidez ( )

emoção/raiva/tristeza ( ) menstruação ( ) risada ( )

gripe/resfriado ( ) esforço físico ( ) remédio ( )

Marque em cima da linha o quanto é importante o cuidado com o local em que você vive para não ter mais crise de asma. (Como se fosse dar uma nota de 0 a 10, assinalando um risco na linha).

0 10

Tratamento e técnica inalatória

Questionário de conhecimento pós-consulta

Para que servem os broncodilatadores na asma?

( ) não sei

( ) é uma medicação para abrir os brônquios

( ) é uma medicação para melhorar a inflamação

( ) é uma medicação que acelera o coração

Para que servem os corticoides na asma?

( ) não sei

( ) é uma medicação para fazer a crise passar

( ) é uma medicação para tratar a inflamação

( ) é uma medicação que deixa a pessoa inchada

Você acha que o corticoide

( ) pode torná-lo dependente

( ) pode fazer mal ao coração

( ) deve ser usado quando começa a crise de asma

( ) deve ser usado para prevenir as crises de asma 
Anexo 1 - Continuação...

Você sabe usar a sua medicação em spraye/ou pó?

Sim ( ) Não ( )

CHECAR O USO DA MEDICAÇÃO (o paciente é solicitado a demonstrar como normalmente usa duas doses da medicação com dispositivos placebos; o educador confere e assinala o que ele realizou, seguindo a lista abaixo).

Com espaçador ( )

Tira a tampa da bombinha ( )

Encaixa o espaçador ( )

Agita a bombinha ( )

Solta todo ar antes de colocar a bombinha na boca ( )

Dispara um jato da bombinha ( )

Puxa o remédio lentamente com a boca aberta ( )

Segura a respiração após puxar o remédio ( )

Conta até 10 e depois solta o ar ( )

Espera um minuto para disparar outro jato ( )

Sem espaçador ( )

Tira a tampa da bombinha ( )

Agita a bombinha ( )

Deixa espaço entre a bombinha e a boca ( )

Solta todo ar antes de colocar a bombinha na boca ( )

Dispara um jato da bombinha ( )

Puxa o remédio lentamente com a boca aberta ( )

Segura a respiração após puxar o remédio ( )

Conta até 10 e depois solta o ar ( )

Espera um minuto para disparar outro jato ( ) 